\title{
Emotional support for chronically ill elderly persons : feasibility, effectiveness and cost-effectiveness of a minimal psychological intervention
}

Citation for published version (APA):

Jonkers, C. C. M. (2009). Emotional support for chronically ill elderly persons : feasibility, effectiveness and cost-effectiveness of a minimal psychological intervention. [Doctoral Thesis, Maastricht University]. Datawyse / Universitaire Pers Maastricht. https://doi.org/10.26481/dis.20090205cj

Document status and date:

Published: 01/01/2009

DOI:

10.26481/dis.20090205cj

Document Version:

Publisher's PDF, also known as Version of record

Please check the document version of this publication:

- A submitted manuscript is the version of the article upon submission and before peer-review. There can be important differences between the submitted version and the official published version of record.

People interested in the research are advised to contact the author for the final version of the publication, or visit the DOI to the publisher's website.

- The final author version and the galley proof are versions of the publication after peer review.

- The final published version features the final layout of the paper including the volume, issue and page numbers.

Link to publication

\footnotetext{
General rights rights.

- You may freely distribute the URL identifying the publication in the public portal. please follow below link for the End User Agreement:

www.umlib.nl/taverne-license

Take down policy

If you believe that this document breaches copyright please contact us at:

repository@maastrichtuniversity.nl

providing details and we will investigate your claim.
}

Copyright and moral rights for the publications made accessible in the public portal are retained by the authors and/or other copyright owners and it is a condition of accessing publications that users recognise and abide by the legal requirements associated with these

- Users may download and print one copy of any publication from the public portal for the purpose of private study or research.

- You may not further distribute the material or use it for any profit-making activity or commercial gain

If the publication is distributed under the terms of Article 25fa of the Dutch Copyright Act, indicated by the "Taverne" license above, 


\section{Emotional support for chronically ill elderly persons}

Feasibility, effectiveness and cost-effectiveness of a minimal psychological intervention 
The studies presented in this thesis were performed at the School for Public Health and Primary Care (Caphri) of the Maastricht University. Caphri participates in the Netherlands School of Primary Care Research (CaRe), which has been acknowledged since 1995 by the Royal Netherlands Academy of Arts and Sciences (KNAW).

The Netherlands Organisation for Health Research and Development (ZonMw; grant number 945-03-047) is gratefully acknowledged for funding the studies in this thesis.

ISBN: 9789052787985

Cover design: Esther van de Beek

Printed by Datawyse / Universitaire Pers Maastricht

(C) 2009 C.C.M. Jonkers, Maastricht

All rights reserved. No parts of this thesis may be reproduced, stored in a retrieval system, or transmitted in any form or by any means, electronic, mechanical, photocopying, recording, or otherwise, without written permission from the author or from the publisher holding the copyright of the published articles. 


\title{
Emotional support for chronically ill elderly persons
}

Feasibility, effectiveness and cost-effectiveness of a minimal psychological intervention

\author{
Proefschrift \\ ter verkrijging van de graad van doctor \\ aan de Universiteit Maastricht, \\ op gezag van de Rector Magnificus, Prof. mr. G.P.M.F. Mols, \\ volgens het besluit van het College van Decanen, \\ in het openbaar te verdedigingen \\ op donderdag 5 februari 2009 om 14.00 uur
}

door

Catharina Cornelia Maria Jonkers

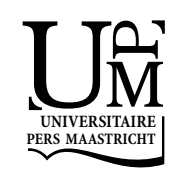




\section{Promotores}

Prof. dr. J.Th.M. van Eijk

Prof. dr. J.F.M. Metsemakers

\section{Copromotores}

Dr. H. Bosma

Dr. S.M.A.A. Evers

\section{Beoordelingscommissie}

Prof. dr. J.L. Severens (voorzitter)

Prof. dr. P.A. Aréan (University of California, San Francisco)

Prof. dr. K. van der Meer (Universitair Medisch Centrum Groningen)

Prof. dr. F.R.J. Verhey

Dr. T. van der Weijden 


\section{Contents}

$\begin{array}{lll}\text { Chapter } 1 \quad \text { General introduction } & 7\end{array}$

Chapter 2 Effectiveness and cost-effectiveness of a minimal psychological intervention to reduce non-severe depression in chronically ill elderly patients: the design of a randomised controlled trial [ISRCTN92331982]

Chapter 3 Process evaluation of a minimal psychological intervention to reduce depression in chronically ill elderly persons

Chapter 4 The effectiveness of a minimal psychological intervention in 45 chronically ill elderly patients with depression: a randomised trial (the DELTA-study)

Chapter 5 A minimal psychological intervention to treat depression in the chronically ill elderly: does it improve self-management beliefs and behaviors?

Chapter 6 Personality characteristics as predictors of differential treatment outcome of a minimal psychological intervention in chronically ill elderly patients with depression

Chapter 7 Economic evaluation of a minimal psychological intervention in chronically ill elderly patients with depression: a randomised trial (the DELTA-study)

Chapter 8 Cost-utility estimates in depression: does the valuation method matter?

Chapter 9 General discussion

Chapter 10 Summary

Samenvatting

Co-authors and affiliations

Dankwoord

About the author 



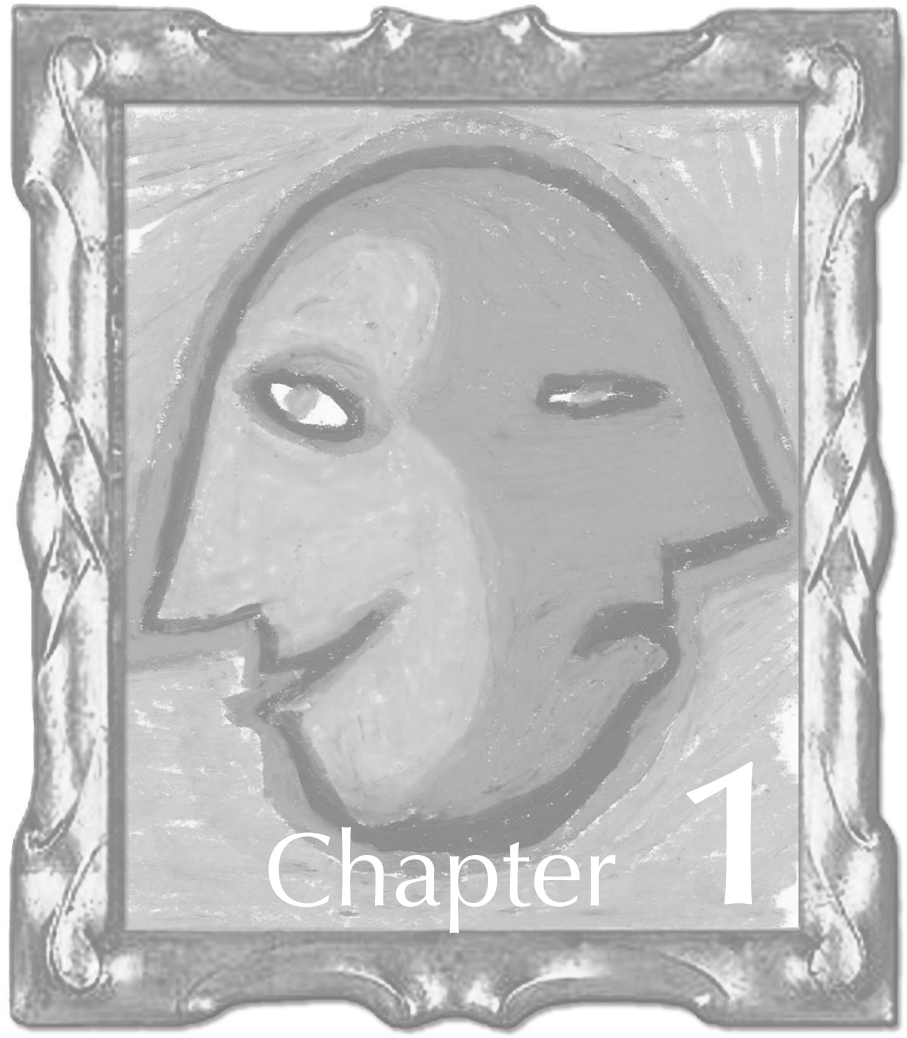

Introduction 
In the Netherlands, the care for a majority of patients with chronic diseases is nested within primary care. The Dutch College of General Practitioners has developed practice guidelines according to which most patients receive care. ${ }^{1-3}$ Furthermore, for a number of chronic conditions, such as type 2 diabetes mellitus (DM) and chronic obstructive pulmonary disease (COPD), disease management programs have been developed and applied in regular care. These disease management programs provide coordinated, comprehensive care along the continuum of the disease. ${ }^{4}$ The disease management programs and the practice guidelines are primarily aimed at the medical management of the chronic disease, including disease control and adherence to guidelines. However, less attention is being paid to the emotional consequences of having a chronic disease. This is remarkable, because emotional problems and disorders, for example depression and anxiety, often co-occur with chronic diseases and adversely affect the lives of chronically ill persons. Especially in elderly persons, the co-occurrence is high, which makes it important to intervene. For this reason, the main subject of this thesis was to evaluate the impact of a minimal psychological intervention (MPI) specifically aimed at chronically ill elderly persons with cooccurring depression.

This chapter starts with a further elaboration on the personal and economic consequences of chronic disease, also in relation to depression. Next, the current management of chronic disease in primary care is described as well as the management of depression. Finally, the aims of the present study and the outline of the thesis is provided.

\section{PERSONAL CONSEQUENCES OF CHRONIC DISEASE AND DEPRESSION}

Many persons with a chronic disease face limitations that cause a disruption of their normal life. The chronically ill patients are confronted with various changes in lifestyle, physical functioning, and future perspectives. ${ }^{5}$ The physical problems, such as reduced mobility, pain, and shortness of breath, can limit patients in their daily functioning. The experienced limitations can easily provoke negative thoughts about the patients' possibilities of (social) participation which in turn negatively influence their daily functioning. Not surprisingly, many patients with chronic diseases develop mood problems, such as depression and anxiety, which might reflect a less desirable reaction to their taxing circumstances. ${ }^{6-8}$

In chronically ill elderly, depression is associated with a reduced quality of life, ${ }^{9}$ increased morbidity, ${ }^{10}$ increased physical disability, ${ }^{8}$ and increased health care utilization and higher medical costs. ${ }^{11} 12$ Patients with depression run the risk of sliding into a downward spiral, since depression and disability are mutually reinforcing. ${ }^{8}$ The prevalence rates for depression in chronically ill persons are high. For instance, in chronic obstructive pulmonary disease (COPD), prevalence rates for depression range from 6 to $42 \%$ and, in diabetic patients, prevalence rates for depression of $17 \%$ have been reported. ${ }^{13-15}$ 


\section{ECONOMIC CONSEQUENCES OF CHRONIC DISEASE AND DEPRESSION}

The aging of the population is expected to be among the most prominent global demographic trends of the $21^{\text {st }}$ century. ${ }^{16}$ In the Netherlands, the number of persons aged 65 and over is estimated to have risen from $14 \%$ in 2005 to $21 \%$ in $2025 .{ }^{17}$ This aging of the population not only reflects longer life expectancy, but also an increase in persons with a chronic disease. For example, the number of Dutch elderly persons with type 2 diabetes mellitus (DM) is estimated to rise to 867,700 persons between 2005 and 2025; a rise of $58 \% .{ }^{17}$ The socio-economic impact of chronic diseases as a result of an aging population is considerable. In the Netherlands, the costs for diabetes care were 735 million euro in 2003, of which 54\% was spent in persons of 65 years and older. ${ }^{18}$ For COPD, the costs in 2003 were 739 million, of which also $54 \%$ was spent in persons of 65 years and older. ${ }^{18}$ The costs of depression care were somewhat less in this age group: the total costs of depression care amounted to 660 million euro in 2003, of which $28 \%$ was spent in persons of 65 years and older. However, the World Health Organization has projected that depression becomes the second most disabling disease in the world in $2020 .{ }^{19}$ Therefore, the costs of treatment are likely to increase over the years. The costs of chronic diseases and depression for society are even higher if, in addition to the cost of treatment, also patient and family costs are taken into account, such as the cost of informal care. ${ }^{20}$

Until now, most health care is organized around a model of acute care which does not meet the needs of many chronically ill older patients. In order to address the global burden of chronic diseases and depression, health care systems have to be prepared to address the consequences of the aging population. This requires investment in the development of more effective community based primary health care to optimize future care for persons with chronic diseases. ${ }^{21}$

\section{MANAGEMENT OF THE CHRONIC DISEASE IN PRIMARY CARE}

In recent years, the monitoring of chronically ill patients often has shifted from the general practitioner (GP) to a primary care nurse. Through the development and implementation of disease management programs, the regular care for these patients has improved. ${ }^{4}$ Support of self-management is increasingly considered a core component of the management of chronic diseases. ${ }^{22}$ In self-management approaches, patients themselves take the responsibility for the day-to-day management of the chronic disease.

Three types of self-management tasks for patients can be distinguished. ${ }^{22} 23$ The first type of tasks involves the medical management of the disease, for example taking medication or adhering to a special diet. The second type of tasks, role management, includes maintaining, changing, and creating new meaningful behaviors or life roles. Patients might need to adapt their usual behavior, such as changing from biking to swimming for patients with knee problems. The last type of self-management tasks involves the emotional management of having a chronic condition. Emotions such as 
anger, fear, frustration, and depression are common in chronically ill patients and patients have to learn how to deal with those emotions.

The willingness of patients to take the responsibility for the day-to-day management of the chronic disease themselves increases, as they recognize the advantages of being in control of their own health. ${ }^{24}$ It empowers patients and let them make autonomous decisions about their own health. ${ }^{25}$ However, effective self-management requires several skills including problem-solving, decision making, action planning, and self-tailoring. ${ }^{26}$ Many patients need support developing those skills and gain confidence in their ability to apply those skills and to undertake behaviors that may lead to improved health. ${ }^{27}$ The focus of self-management support for chronically ill persons is primarily aimed at the medical management of the disease, including disease control and adherence to guidelines. ${ }^{28}$ Support for role management and emotional management, the two other management tasks that patients are faced with, receive less attention, neither in disease management programs nor in the practice guidelines for chronic diseases. ${ }^{1-328}$ However, the support for emotional management is important, because emotional wellbeing is a precondition for effective medical management; patients with emotional problems tend to adhere worse to medical regimens. ${ }^{7}$

\section{MANAGEMENT OF DEPRESSION IN PRIMARY CARE}

Despite the high prevalence of depression in elderly persons, depression often remains unrecognized and undertreated in primary care. ${ }^{29}$ This is partly due to the focus on the medical management of the chronic disease instead of the emotional management. ${ }^{30}$ Depression is often not viewed as a legitimate illness to be taken to the GP by elderly patients. ${ }^{31}$ Both GPs and patients sometimes feel that depression is a natural consequence of aging and illness and therefore does not require treatment. ${ }^{31}$ 32 In addition, somatic symptoms of depression, for example weight loss and loss of energy, may overlap with symptoms of the chronic somatic disease, making it more difficult to recognize the depression (Table 1).

Table 1. Symptoms and diagnosis of depression (DSM-IV $)^{33}$

\begin{tabular}{|c|c|c|}
\hline \multicolumn{2}{|c|}{ Symptoms } & \multirow{2}{*}{ Diagnostic criteria } \\
\hline 1 & Depressive mood & \\
\hline 2 & Loss of interest/ pleasure & \multirow{4}{*}{$\begin{array}{l}\text { Major depression: At least five symptoms of depression } \\
\text { during the same two-week period with at least one of } \\
\text { the symptoms being depressed mood or loss of } \\
\text { interest/pleasure }\end{array}$} \\
\hline 3 & Significant weight loss/gain & \\
\hline 4 & Insomnia/ hypersomnia & \\
\hline 5 & Fatigue/ loss of energy & \\
\hline 6 & Feeling of worthlessness & \multirow{4}{*}{$\begin{array}{l}\text { Minor depression: Two to four symptoms of depression } \\
\text { during the same two-week period with at least one of } \\
\text { the symptoms being depressed mood or loss of } \\
\text { interest/pleasure }\end{array}$} \\
\hline 7 & Psychomotor agitation/ retardation & \\
\hline 8 & Problems concentration/indecisiveness & \\
\hline 9 & Recurrent thoughts of death & \\
\hline
\end{tabular}


Notwithstanding the under recognition of depression by patients and health care providers, effective treatments are available. The Dutch practice guidelines for depression recommend antidepressants or psychological treatments, depending on the severity of the depression, the perceived burden in daily life and the patient's preference for treatment. ${ }^{34}$ Antidepressants appear effective in elderly, ${ }^{35}{ }^{36}$ although problems with non-adherence and polypharmacy have been reported. ${ }^{37} 38$ Therefore, psychological treatments might be a good alternative, especially because of the enduring effect that these treatments might have. ${ }^{25} 39$

Cognitive behavioral therapy (CBT) is one of the psychological treatments that have proven effectiveness in elderly. ${ }^{40}{ }^{41}$ It refers to therapies that aim to reduce dysfunctional emotions or behaviors by changing cognitions and/or behaviors. ${ }^{42}$ In CBT, links between dysfunctional cognitions and behaviors are identified and challenged. Through the use of new skills, such as problem solving, the patient explores alternatives for these cognitions and tries out new, desirable behavior. Patients are stimulated to think about desirable behaviors and to describe their experiences when this behavior is carried out. In that way, the accuracy of their cognitions and of alternatives is tested. Repeated application of these newly acquired skills will lead to changes in behaviors and subsequently to changes in cognitions (reattribution). This reattribution of cognitions and consequent behavior also forms the theoretical background of self-management support. Both approaches apply similar techniques, for example problem-solving, and focus on the personal confidence or self-efficacy of patients to organize and execute certain behaviors. Nonetheless, CBT and other psychological treatments are often not available in primary care practices, most likely due to the time burden involved with the administration of psychological treatments by GPs.

\section{MERGING MANAGEMENT FOR CHRONIC DISEASE AND DEPRESSION: THE DELTA STUDY}

Nurses have found to be capable of administering psychological interventions. ${ }^{434}$ As Dutch primary care nurses are already involved in the support of medical selfmanagement of chronic diseases, it might be feasible to train them in providing support for co-occurring emotional problems as well. In that way, they can support patients in all three different self-management tasks and also relieve the GPs' burden of providing psychological treatment.

This thesis describes the results of the Depression in Elderly with Long-Term Afflictions (DELTA) study. In this study, a nurse-led minimal psychological intervention $(\mathrm{MPI})$ is tested that is specifically aimed at support regarding role management and emotional management for patients with chronic diseases. The MPI is based on CBT and self-management approaches and is tailored to the patients' needs. By applying these approaches we aim at behavioral change and increased self-confidence through changing beliefs about self-efficacy. In that way, we hope to shape an active selfmanager who independently and autonomously can explore solutions for current and 
$12 \mid$ CHAPTER 1

future problems in daily life. In the DELTA study the effectiveness of the MPI is reviewed in elderly primary care patients with DM and/or COPD and co-occurring depression. Primary care nurses have been trained to administer the intervention.

A special focus of the study was the integration of such care for emotional problems in regular care. Whether an intervention is suitable for further dissemination and implementation in regular care does not only depend on the effectiveness of an intervention. For example, an intervention can be very effective, but might cause resistance in health care providers, be a burden to patients, or provide other barriers that might limit possibilities to implement such an intervention. Furthermore, in a context of scarcity of resources, the cost-effectiveness of an intervention is important and should be considered before implementation in regular care. As a result, all these elements were object of study in the DELTA trial.

\section{AIM AND RESEARCH QUESTIONS}

The research in this thesis is aimed at studying the impact of a nurse-led MPI in elderly diabetic and COPD patients with a co-occurring minor to moderate depression. The main research questions are:

- What is the feasibility of the MPI for patients and nurses?

- What is the effectiveness of the MPI compared to usual care in reducing depression, increasing quality of life, and improving self-management beliefs and behaviors?

- Which patients benefit most from treatment with the MPI?

- What is the cost-effectiveness of the MPI compared to usual care from a societal perspective?

- What is the best valuation method to estimate cost-utility in depression research?

\section{OUTLINE OF THIS THESIS}

Chapter 2 of this thesis describes the study design and rationale of the DELTA study. Chapter 3 addresses the process evaluation in which we assess whether the MPI was implemented and received as planned, which barriers were encountered and whether nurses and patients were satisfied with the intervention. In Chapter 4, the results on the effectiveness of the MPI on depressive symptoms and quality of life are presented and in chapter 5 the effectiveness is examined in relation to selfmanagement beliefs and behaviors. Both chapters pay attention to whether or not the intervention is generic across DM and COPD patients. In chapter 6, it is examined whether patients who differ in personality characteristics also differently benefit from treatment. Chapter 7 reports on the cost-effectiveness of the intervention from a societal perspective. Program costs, health care costs, patient and family costs, and production losses were included as well as effects in terms of quality adjusted life years (QALY) and depression-free days (DFD). Chapter 8 further elaborates on the 
method to measure effects in cost-effectiveness studies on depression. Finally, in chapter 9 the methods and findings of the DELTA-study are discussed. In addition, implications and recommendations for health care practice and future research are presented. 


\section{REFERENCES}

1. Geijer RMM, Thiadens HA, Smeele IJM, Sachs APE, Bottema BJAM, van Hensbergen W, et al. NHGStandaard COPD en Astma bij Volwassenen: Diagnostiek [NHG Practice Guideline COPD: Diagnosis]. Huisarts Wet 2001;44(3):107-117.

2. Rutten GEHM, De Grauw WJC, Nijpels G, Goudswaard AN, Uitewaal PJM, Van der Does FEE, et al. NHGStandaard Diabetes mellitus type 2 [NHG Practice Guideline Diabetes mellitus type 2]. Huisarts Wet 2006;49(3):137-152.

3. Geijer RMM, van Schayk CP, van Weel C, Sachs APE, van der Zwan ACC, Bottema BJAM, et al. NHGStandaard COPD en Astma bij Volwassenen: Behandeling [NHG Practice Guideline COPD: Treatment]. Huisarts Wet 1997;40:430-442.

4. Ellrodt G, Cook DJ, Lee J, Cho M, Hunt D, Weingarten S. Evidence-based disease management. Jama 1997;278(20):1687-92.

5. Marks R, Allegrante JP, Lorig K. A review and synthesis of research evidence for self-efficacy-enhancing interventions for reducing chronic disability: implications for health education practice (part I). Health Promot Pract 2005;6(1):37-43.

6. Ciechanowski PS, Katon WJ, Russo JE. Depression and diabetes: impact of depressive symptoms on adherence, function, and costs. Arch Intern Med 2000;160(21):3278-85.

7. DiMatteo MR, Lepper HS, Croghan TW. Depression is a risk factor for noncompliance with medical treatment: meta-analysis of the effects of anxiety and depression on patient adherence. Arch Intern Med 2000;160(14):2101-7.

8. Penninx BW, Guralnik JM, Ferrucci L, Simonsick EM, Deeg DJ, Wallace RB. Depressive symptoms and physical decline in community-dwelling older persons. JAMA 1998;279(21):1720-6.

9. Spitzer RL, Kroenke K, Linzer M, Hahn SR, Williams JB, deGruy FV, 3rd, et al. Health-related quality of life in primary care patients with mental disorders. Results from the PRIME-MD 1000 Study. JAMA 1995;274(19):1511-7.

10. Penninx BW, Geerlings SW, Deeg DJ, van Eijk JT, van Tilburg W, Beekman AT. Minor and major depression and the risk of death in older persons. Arch Gen Psychiatry 1999;56(10):889-95.

11. Katon WJ, Lin E, Russo J, Unutzer J. Increased medical costs of a population-based sample of depressed elderly patients. Arch Gen Psychiatry 2003;60(9):897-903.

12. Katz IR. On the inseparability of mental and physical health in aged persons: Lessons from depression and medical comorbidity. Am J Geriatr Psychiatry 1996;4(1):1-16.

13. Kunik ME, Roundy K, Veazey C, Souchek J, Richardson P, Wray NP, et al. Surprisingly high prevalence of anxiety and depression in chronic breathing disorders. Chest 2005;127(4):1205-11.

14. Mikkelsen RL, Middelboe T, Pisinger C, Stage KB. Anxiety and depression in patients with chronic obstructive pulmonary disease (COPD). A review. Nord J Psychiatry 2004;58(1):65-70.

15. Ali S, Stone MA, Peters JL, Davies MJ, Khunti K. The prevalence of co-morbid depression in adults with Type 2 diabetes: a systematic review and meta-analysis. Diabet Med 2006;23(11):1165-73.

16. World Health Organization. Active Ageing: A Policy Framework. Geneva: World Health Organization, 2002.

17. Blokstra A, Baan CA, Boshuizen HC, Feenstra TL, Hoogenveen RT, Picavet HSJ, et al. Vergrijzing en toekomstige ziektelast; Prognose chronische ziekteprevalentie 2005-2025 [Impact of the ageing population on burden of disease. Projections of chronic disease prevalence for 2005-2025]. In: Blokstra A, Verschuren WMM, editors. Bilthoven: RIVM, 2007.

18. Slobbe LCJ, Kommer GJ, Smit JM, Groen J, Meerding WJ, Polder JJ. Costs of illness in the Netherlands 2003 In: RIVM, editor. Bilthoven: RIVM, 2003.

19. Murray CJL, Lopez AD. Alternative visions of the future: projecting mortality and disability, 1990-2020. In: Murray CJL, Lopez AD, editors. The global burden of disease: a comprehensive assessment of mortality and disability from diseases, injuries, and risk factors in 1990 and projected to 2020. Cambridge, M.A.: Harvard University Press, 1996:325-395.

20. Donohue JM, Pincus HA. Reducing the societal burden of depression: a review of economic costs, quality of care and effects of treatment. Pharmacoeconomics 2007;25(1):7-24.

21. World Health Organization. Towards Age-friendly Primary Health Care. In: Organization WH, editor. Geneva, 2004.

22. Wagner EH, Austin BT, Von Korff M. Organizing care for patients with chronic illness. Milbank $Q$ 1996;74(4):511-44. 
23. Corbin JM, Strauss AL. Unending Work and Care: Managing Chronic IIIness at Home. San Francisco: Jossey-Bass, 1988.

24. Lewis R, Dixon J. Rethinking management of chronic diseases. BMJ 2004;328(7433):220-2.

25. Biegler P. Autonomy, stress, and treatment of depression. Bmj 2008;336(7652):1046-8.

26. Lorig KR, Holman H. Self-management education: history, definition, outcomes, and mechanisms. Ann Behav Med 2003;26(1):1-7.

27. Marks R, Allegrante JP, Lorig K. A review and synthesis of research evidence for self-efficacy-enhancing interventions for reducing chronic disability: implications for health education practice (part II). Health Promot Pract 2005;6(2):148-56.

28. Weingarten SR, Henning JM, Badamgarav E, Knight K, Hasselblad V, Gano A, Jr., et al. Interventions used in disease management programmes for patients with chronic illness-which ones work? Meta-analysis of published reports. BMJ 2002;325(7370):925.

29. Djernes JK. Prevalence and predictors of depression in populations of elderly: a review. Acta Psychiatr Scand 2006;113(5):372-87.

30. Schwenk TL. Diagnosis of late life depression: the view from primary care. Biol Psychiatry 2002;52(3): 157-63.

31. Burroughs H, Lovell K, Morley M, Baldwin R, Burns A, Chew-Graham C. 'Justifiable depression': how primary care professionals and patients view late-life depression? A qualitative study. Fam Pract 2006;23(3):369-77.

32. Unutzer J. Diagnosis and treatment of older adults with depression in primary care. Biol Psychiatry 2002;52(3):285-92.

33. American Psychiatric Association. DSM-IV-TR: Diagnostic and statistical manual of mental disorders. fourth edition, text revision ed. Washington DC: American Psychiatric Association, 2000.

34. van Marwijk HWJ, Grundmeijer HGLM, Bijl D, van Gelderen MG, de Haan M, van Weel-Baumgarten EM, et al. NHG-standaard Depressieve stoornis (depressie) (eerste herziening). Huisarts Wet 2003;46(11): 614-23.

35. Wilson K, Mottram P, Sivanranthan A, Nightingale A. Antidepressant versus placebo for depressed elderly. Cochrane Database Syst Rev 2001(2):CD000561.

36. Mottram P, Wilson K, Strobl J. Antidepressants for depressed elderly. Cochrane Database Syst Rev 2006(1):CD003491.

37. Spina E, Scordo MG. Clinically significant drug interactions with antidepressants in the elderly. Drugs Aging 2002;19(4):299-320.

38. Montgomery SA. Late-life depression: rationalizing pharmacological treatment options. Gerontology 2002;48(6):392-400.

39. Hollon SD, DeRubeis RJ, Shelton RC, Amsterdam JD, Salomon RM, O'Reardon JP, et al. Prevention of relapse following cognitive therapy vs medications in moderate to severe depression. Arch Gen Psychiatry 2005;62(4):417-22.

40. Cuijpers P, van Straten A, Smit F. Psychological treatment of late-life depression: a meta-analysis of randomized controlled trials. Int. J. Geriatr. Psychiatry 2006;21(12):1139-49.

41. Pinquart M, Duberstein PR, Lyness JM. Treatments for later-life depressive conditions: a meta-analytic comparison of pharmacotherapy and psychotherapy. Am. J. Psychiatry 2006;163(9):1493-501.

42. Brewin CR. Theoretical foundations of cognitive-behavior therapy for anxiety and depression. Annu Rev Psychol1996;47:33-57.

43. Mynors-Wallis LM, Gath DH, Day A, Baker F. Randomised controlled trial of problem solving treatment, antidepressant medication, and combined treatment for major depression in primary care. BMJ 2000;320(7226):26-30.

44. Richards A, Barkham M, Cahill J, Richards D, Williams C, Heywood P. PHASE: a randomised, controlled trial of supervised self-help cognitive behavioural therapy in primary care. Br J Gen Pract 2003;53(495): 764-70. 



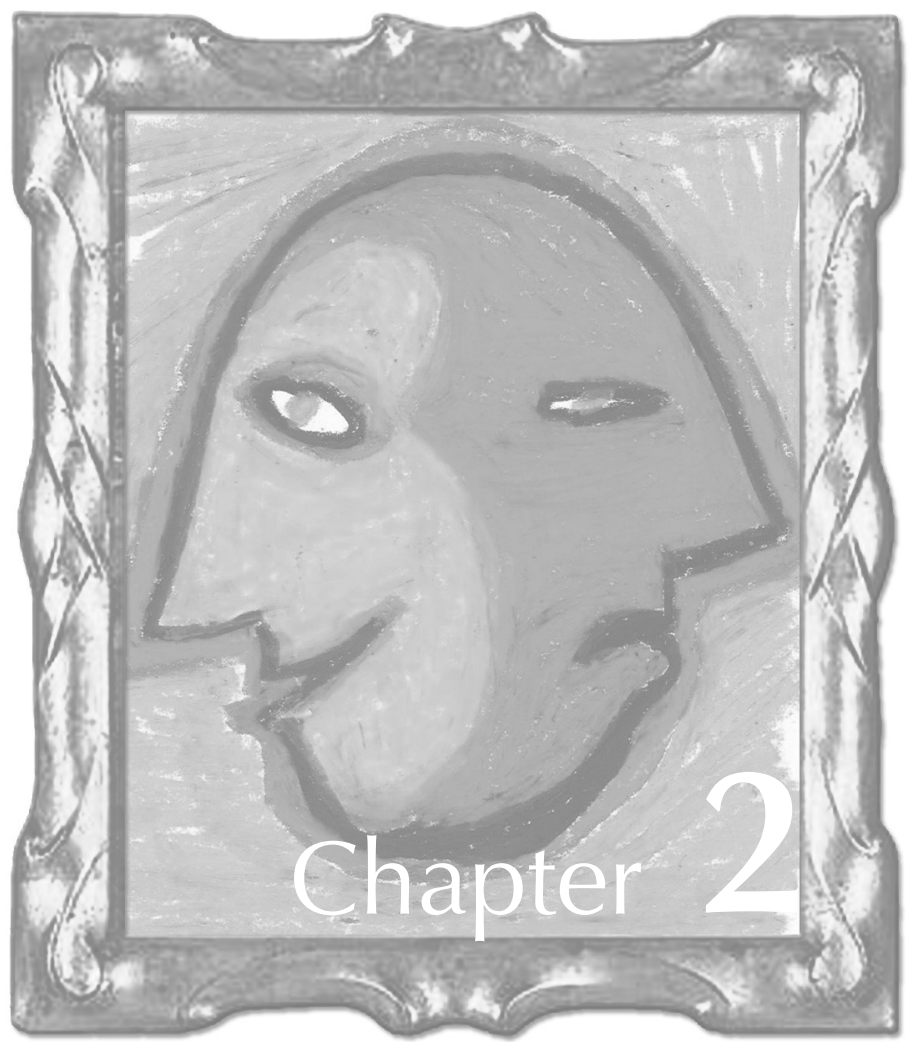

Effectiveness and cost-effectiveness of a minimal psychological intervention to reduce non-severe depression in chronically ill elderly patients: the design of a randomised controlled trial [ISRCTN92331982] 


\section{ABSTRACT}

Objective Depression is a prevalent disorder in chronically ill elderly persons. It may decrease quality of life, and increase functional disability, medical costs, and health care utilisation. Because patients may slip into a downward spiral, early recognition and treatment of depression is important. Depression can be treated with antidepressants or psychological interventions; the latter can also be applied by trained paraprofessionals. In this paper, we describe the design of the DELTA study (Depression in Elderly with Long-Term Afflictions). The first objective of the DELTA study is to evaluate the effectiveness and cost-effectiveness of a minimal psychological intervention (MPI) to reduce depression in chronically ill elderly patients. The second objective is to evaluate whether a potential effect of the MPI may differ between types of chronic illnesses. The tailor-made intervention is administered by nurses, who are trained in the principles of cognitive behavioral therapy and self-management.

Methods DELTA is a two-armed randomised controlled trial, comparing MPI to usual care. A total number of 180 patients with diabetes mellitus type II (DM) and 180 patients with chronic obstructive pulmonary disease (COPD), who in addition suffer from non-severe depression, will be included in the study. In our study, non-severe depression is defined as having minor depression, mild major depression or moderate major depression. The primary outcome measure is depression using the Beck Depression Inventory. Secondary outcome measures include quality of life, daily functioning, self-efficacy, autonomy, and participation. In the economic evaluation, cost-effectiveness and cost-utility ratios will be calculated. Furthermore, a process evaluation will be carried out. Analyses will include both univariate and multivariate techniques and according to the intention to treat principle. The economic evaluation will be done from a societal perspective and data of the process evaluation will be analysed using descriptive techniques. 


\section{INTRODUCTION}

Depression is a prevalent and disabling disorder, especially in patients with chronic illnesses, such as diabetes mellitus type II (DM) and chronic obstructive pulmonary disease (COPD). In older patients with DM, prevalence rates of clinical relevant depression range from 14 to $17 \% .^{12}$ In older patients with COPD, prevalence rates of $25 \%$ for minor depression have been reported. ${ }^{3}$ Prevalence rates of major depression in older COPD patients range from 6 to $42 \%{ }^{4}$

Persons suffering from minor or major depression have increased mortality risks and a decreased quality of life compared with non-depressed persons. ${ }^{5-7}$ Furthermore, depression has been shown to increase health care utilisation, ${ }^{89}$ medical costs, ${ }^{10}$ and disability. ${ }^{8} 911$ Since disability predicts the onset of depression and depression itself may further heighten risks of a progressing disability, this process of mutual reinforcement may lead to a downward spiral. ${ }^{11-14}$ In addition, depression impairs one's ability to adhere to disease management regimens (diet, exercise, quitting smoking, taking medication regularly), potentially worsening the course of the chronic illness. ${ }^{15}$ ${ }^{16}$ Hence, an early detection of depressive symptoms and treatment of depression is important in chronically ill elderly persons, thereby preventing or breaking a downward spiral. In primary care however, depression often remains undetected. ${ }^{17}$ General practitioners have limited time and furthermore, current Dutch guidelines for DM and COPD don't take into account the psychological consequences of the chronic illness.

Available treatment options are antidepressants or psychological interventions. The effectiveness of antidepressants has been extensively studied and proven in major depression. ${ }^{18}$ Since there is no clear evidence of the effectiveness of antidepressants in minor depression, ${ }^{19}{ }^{20}$ clinical guidelines advise against using antidepressants in minor depression. ${ }^{212}$ Cognitive therapy (CT) seems to be as effective as antidepressants in severe depression, ${ }^{23}$ and also in patients with mild and moderate depression. ${ }^{24}$ Furthermore, CT seems to have an enduring effect. ${ }^{25}$ It is also increasingly recognised that chronically ill elderly suffering from depression might benefit from psychosocial support and improving coping skills, such as self-management techniques. ${ }^{2126}$ In a study with DM type II patients, cognitive behavioral therapy (CBT) in combination with supportive diabetes education proved to be an effective treatment for major depression. ${ }^{27}$ Similarly, self-management strategies in COPD patients have been reported to improve the patients' health status and to reduce hospital admissions. $^{28}$

Accumulating evidence shows that primary care staff can be trained in psychological interventions for depression. ${ }^{29}$ Several studies reported that practice nurses can successfully administer interventions to reduce depression in primary care settings. ${ }^{3031}$

We developed a minimal psychological intervention (MPI), based on principles of self-management and CBT. The intervention is administered by nurses and aims to reduce non-severe depression in chronically ill elderly persons. Findings of a prior smaller pilot study showed that the intervention was feasible and acceptable to 
patients. Furthermore, the training programme, developed to teach nurses to administer the intervention, appeared to be feasible, attractive and successful among nurses. ${ }^{32}$

In this contribution, we present the design of the DELTA study (Depression in Elderly with Long-Term Afflictions). The first objective of this randomised controlled trial (RCT) is to evaluate the effectiveness and cost-effectiveness of an MPI that is administered by a nurse and aims to reduce non-severe depression in chronically ill elderly patients. The effects of the MPI are compared with usual care. The second objective is to evaluate whether a potential effect of the MPI is different between types of chronic illnesses.

\section{DESIGN AND METHODS}

\section{Design}

The DELTA study is a two-armed randomised controlled trial, in which an effect evaluation, an economic evaluation and a process evaluation will be carried out. A total number of 360 patients will be included, 180 of which are patients with DM and 180 are patients suffering from COPD. We chose DM and COPD because first, they are highly prevalent in primary care. Second, they have a different course and prognosis. DM can be seen as a gradual progressive illness, whereas COPD as a gradual relapsing condition. ${ }^{33}$ This difference enables us to test whether the intervention is potentially generic. Approval for conducting this study was granted by the Medical Ethics Committee of the Maastricht University/ Academic Hospital Maastricht.

\section{Setting and recruitment}

In general practices in the southern part of Limburg, a province in the south of the Netherlands, all patients of 60 years and over with DM and or COPD were selected by the general practitioner, the general practitioner's assistant, or the research assistant. Selection was made using ICPC codes (T90, R91.01, R95, R99.06) if possible and otherwise by medication prescriptions (those drugs which are most often prescribed by the general practitioner for these chronic illnesses). In the last phase of patient selection, the general practitioner applied the inclusion and exclusion criteria using a pre-coded form with checkboxes for each criterion (Table 1).

All selected patients received a letter from their general practitioner with a request to complete a short screening questionnaire. This questionnaire, the Patient Health Questionnaire-9 (PHQ-9), consists of nine questions regarding the prevalence of symptoms of depression over the last two weeks. The response options are: "Not at all", "Several days", "More than half the days" and "Nearly every day". Its brevity and the fact that it is a self-administered questionnaire make it a useful tool in screening for depression in primary care. The PHQ-9 has been validated for both diagnosing 
depression and measuring severity. ${ }^{34-36}$ Five questions on demographic variables were included in the questionnaire. Patients received a reminder by telephone two weeks after the questionnaire had been sent. All patients who scored at least 2 depressive symptoms at least at "more than half the days" and at least one of these symptoms was depressed mood or anhedonia, were invited to participate in an interview to confirm or reject the diagnosis of depression. The Mini International Neuropsychiatric Interview (MINI) was used to confirm the diagnosis from the PHQ-9. The interview took place at the patient's home and was administered by a trained nurse. The MINI is a validated and reliable diagnostic structured interview, covering 17 disorders based on DSM-IV criteria. ${ }^{3738}$ An extra diagnosis box for minor depression was added to the MINI, based on the research criteria for minor depression as described in the DSMIV. ${ }^{39}$ Furthermore, the Hamilton Depression Rating Scale (HDRS) was used to determine the severity of the depression. ${ }^{404}$ Patients were excluded if they met one of the following criteria: if the MINI indicated a major depression in combination with a score above 18 (indicating a severe depression) on the HDRS, if the MINI indicated suicidal risk, or if the MINI indicated no depression at all (Table 1). Patients with a major depression and/or suicidal risk were referred back to their general practitioner. All remaining eligible patients (patients with a minor depression, non-severe major depression, or dysthymia) were invited to participate in the study and to give their informed consent.

Table 1. Inclusion and exclusion criteria as applied by the general practitioner ${ }^{*}$ or research nurse ${ }^{t}$

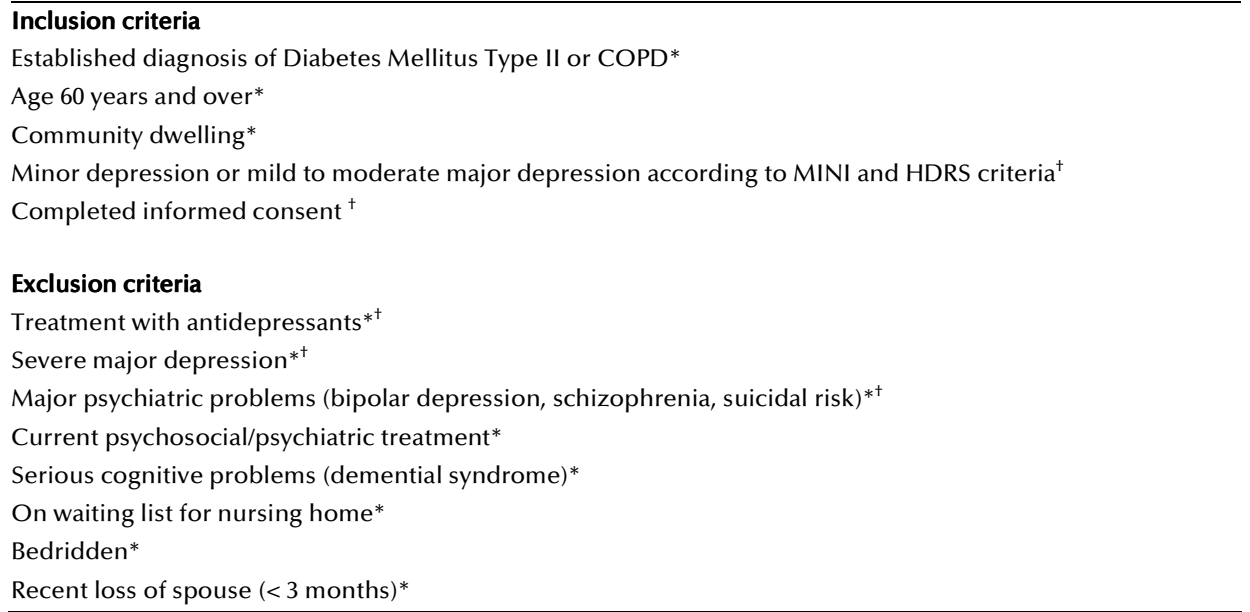

\section{Randomisation}

After having signed the informed consent form, patients enrolled in the study and filled in the baseline questionnaire. After having completed the baseline questionnaire, patients were assigned to either the intervention or control group. Randomisation was performed by an external agency using a computerized random number 
$22 \mid$ CHAPTER 2

generator. In order to avoid an imbalance of chronic illness and general practice (care level) over the two groups, stratification for general practice and chronic illness (DM or COPD) was performed. Furthermore, to obtain equal numbers in both arms, a blocked design with a block size of two was applied. The intervention group received a minimal psychological intervention, while the control group received usual care as given by their general practitioner, according to the guidelines for the specific chronic illness.

\section{Minimal psychological intervention}

The intervention was given by a trained nurse, at the patient's own home. During a period of at most three months, patients received a maximum of 10 visits from the nurse. The number of visits depended on the patient's progress.

The minimal psychological intervention contains elements from the Chronic Disease Self-Management Program (CDSMP) by Lorig and Gonzales, ${ }^{42}$ the Reattribution model from Goldberg ${ }^{43}$ and from the work of the project group of the Interventie Studie Eerste Lijn (INSTEL), ${ }^{44}$ as previously described. ${ }^{32}$ The intervention aims at teaching patients to take responsibility for day-to-day management of their illness and its consequences. In short, it consists of five phases:

PHASE 1: The nurse explores the patient's cognitions on the origin of symptoms and complaints, and their relation to limitations and behavior.

PHASE 2: The patient keeps a diary, where he or she records symptoms, complaints, thoughts, worries, related feelings, and behavior.

PHASE 3: Using information from the diary, the nurse challenges the patient to link his or her mood and consequent behavior to the course of the chronic illness. A distinction will be made between complaints related to the illness itself, and those related to the emotional and behavioral consequences of the illness.

PHASE 4: Introduction of the self-management approach by the nurse. The patient explores his or her possibilities to alter his or her behavior. He or she then makes a plan on how to solve perceived problems and sets specific goals to be reached before the next visit from the nurse.

PHASE 5: Evaluation of the progress in achieving the goals.

After a patient has completed these five phases successfully, he or she is supposed to be able to apply the self-management approach to any situation or problem he or she may encounter in the future. In consultation with the patient, the nurse can then decide to conclude the series of intervention visits.

\section{The training program for nurses}

\section{Administering the MINI}

In an $8 \mathrm{~h}$ session, the nurses were trained how to confirm a diagnosis of depression by using the MINI and HDRS by a psychiatrist. 


\section{Applying the minimal psychological intervention}

During three 8h sessions, with 2-week intervals, four nurses were trained by two experienced trainers (a psychologist/cognitive behavior therapist, and a general practitioner) on how to apply the intervention. In between training days, nurses practised their newly learned skills on a pilot patient. As mentioned earlier, the training program has been shown to be feasible, attractive and successful among nurses. ${ }^{32}$ Booster sessions were being held regularly during the study, and both a psychiatrist and a psychologist could be contacted by telephone to discuss cases at any time.

\section{DATA COLLECTION}

Data was collected at five points in time: at baseline (T0), one week after the intervention period (T1), and at three, six and nine months after the intervention period (T2, T3, T4) (Fig. 1). The intervention period for patients allocated to the intervention group varies from one week to three months. The intervention period of the control group is fixed at six weeks, which is estimated to be the mean duration of the intervention period in the intervention group. Data were collected using self-administered questionnaires and cost diaries in combination with interviews by telephone.

\section{Effect evaluation}

Table 2 provides an overview of the measures of the effect and economic evaluation, and time of assessment.

\section{Primary outcome measures}

The primary outcome measure in this study was level of depression, measured with the Beck Depression Inventory (BDI). ${ }^{45}{ }^{46}$ The BDI consists of 21 items measuring symptoms of depression and has proven to be a valid and reliable too. ${ }^{47}$

\section{Secondary outcome measures}

Secondary outcome measures in the study were: Quality of life measured with the Short Form-36 (SF-36), ${ }^{48}$ disease-specific quality of life assessed with the Problem Areas in Diabetes questionnaire (PAID-1) for diabetes patients, ${ }^{49}$ and the St. George's Respiratory Questionnaire (SGRQ) for patients with pulmonary disease. ${ }^{5051}$ Furthermore, daily functioning was assessed with the Activities of Daily Life scale (ADL) from the Groningen Activity Restriction Scale (GARS) ${ }^{52}$ self-efficacy assessed using the 12item Self-efficacy scale ${ }^{5354}$ and autonomy and participation using the questions from the domain Autonomy outdoors from the Impact on Participation and Autonomy questionnaire (IPA). ${ }^{55} 56$ 


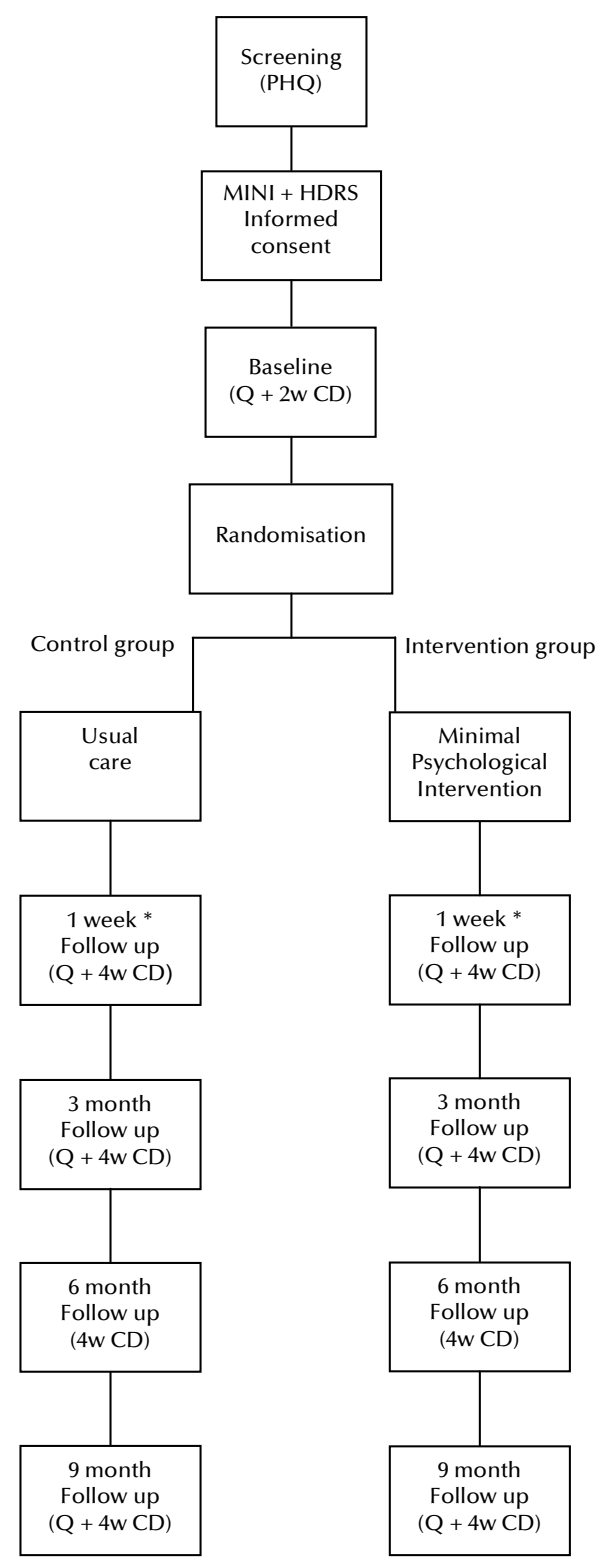

Figure 1. DELTA flowchart

Q questionnaire, 2w CD two week cost diary, $4 \mathrm{w}$ CD four week cost diary

* First follow up takes place one week after the intervention period. In the intervention group, this may vary from one week to three months. In the control group, the intervention period is fixed at six weeks, which is estimated to be the mean duration of the intervention in the intervention group 


\section{Covariates}

Additionally, information on possible confounding factors and effect modifiers was collected. Information on demographic factors (age, gender, marital status, religion, education, occupation) was collected in the screening phase. Other factors measured are: coping using the active coping, avoidant coping and passive coping scales from the Utrecht Coping List (UCL), ${ }^{57}$ mastery using the Personal Mastery Scale developed by Pearlin and Schooler, ${ }^{58}$ anxiety assessed using the anxiety subscale from the Symptom Checklist (SCL-90) ${ }^{59}$ social support using the short version of the Social Support List- Interactions questionnaire (SSL-I), ${ }^{60}$ co-morbidity using the Chronic conditions list from Statistics Netherlands (CBS - Centraal Bureau voor de Statistiek), life events using a list of 16 life events where patients report which life events they have experienced in the past year, and how they value these events (positive, negative, or neutral). Personality was measured using scales for neuroticism and extraversion from the Eysenck Personality Questionnaire (EPQ), ${ }^{62}$ severity of the chronic illness was assessed using the St. George's Respiratory Questionnaire (SGRQ) for COPD patients, ${ }^{50} 51$ and the Diabetes Symptom Checklist - Revised (DSC-R) for diabetes patients. ${ }^{63}$ If possible, severity of the chronic illness will also be assessed by retrieving lung function (FEV1) and/or blood glucose levels (Hba1c) from hospital records or the general practitioner's records at the end of the study Finally, smoking and body mass index (BMI) were assessed, and in order to check for contamination in the control group, two questions to check whether or not the patients in the control group had heard or benefited from the intervention were added to the questionnaire. Contamination of the control group may lead to a smaller difference in effect between intervention and control group.

\section{Economic evaluation}

A combined cost-effectiveness/ cost-utility analyses will be performed from a societal perspective. The BDI is used as primary outcome measure in the cost-effectiveness analyses. The primary outcomes measure for the cost-utility measure will be utilities based on the social tariff of the EuroQol. ${ }^{64}$ Health care costs, patient and family costs, as well as productivity losses will be recorded using cost diaries. ${ }^{65}$ Patients prospectively kept the diary for two weeks at baseline and for four weeks at each follow up measurement. Afterwards, a telephonist contacted them to retrieve the information from the diary. Data were immediately entered in a computer file to ensure efficiency and reliability. The costs of the intervention were separately calculated. For the valuation of health care costs and patient and family costs, the updated Dutch Guideline for costing in economic evaluations will be used. ${ }^{66}$ If no guideline costs existed, cost prizes were estimated using real costs and tariffs. For future costs and effectiveness data, a discount rate of $4 \%$ will be used. 
Table 2. Outcome measures and time of assessment in the DELTA study

\begin{tabular}{|c|c|c|c|c|c|c|c|}
\hline Name questionnaire/variable & Screening & Baseline & FU1 & FU2 & FU3 & FU4 & Other \\
\hline Marital status/living situation & $x$ & - & - & - & - & - & - \\
\hline Occupation/work situation & $\mathrm{x}$ & - & - & - & - & - & - \\
\hline Education & $x$ & - & - & - & - & - & - \\
\hline Gender & $x$ & - & - & - & - & - & - \\
\hline Age & $x$ & - & - & - & - & - & - \\
\hline Religion & $\mathrm{x}$ & - & - & - & - & - & - \\
\hline$\overline{\mathrm{BDI}}$ & - & $x$ & $x$ & $x$ & - & $x$ & - \\
\hline Euroqol (QALY's) & - & $x$ & $x$ & $x$ & - & $x$ & - \\
\hline SF36 & - & $x$ & $x$ & $x$ & - & $x$ & - \\
\hline SGRQ & - & $x$ & $x$ & $x$ & - & $x$ & - \\
\hline PAID-1 & - & $x$ & $x$ & $x$ & - & $x$ & - \\
\hline ADL-scale from GARS & - & $x$ & $x$ & $x$ & - & $x$ & - \\
\hline UCL & - & $x$ & $x$ & $x$ & - & $x$ & - \\
\hline Personal mastery scale & - & $x$ & $x$ & $x$ & - & $x$ & - \\
\hline Self-efficacy-scale & - & $\mathrm{x}$ & $\mathrm{x}$ & $\mathrm{x}$ & - & $\mathrm{x}$ & - \\
\hline IPA & - & $x$ & $x$ & $x$ & - & $x$ & - \\
\hline SCL-90 subscale anxiety & - & $x$ & $x$ & $x$ & - & $x$ & - \\
\hline SSL-I 12 & - & $x$ & - & - & - & $x$ & - \\
\hline CBS List Chronic conditions & - & $\mathrm{x}$ & - & - & - & $x$ & - \\
\hline Diabetes Symptom Checklist-Revised & - & $x$ & $x$ & $x$ & - & $x$ & - \\
\hline Life-events & - & - & - & - & - & $x$ & - \\
\hline EPQ & - & - & $x$ & - & - & - & - \\
\hline Year of diagnosis DM/COPD & - & $x$ & - & - & - & - & - \\
\hline Smoking & - & - & - & - & - & $x$ & - \\
\hline BMI & - & - & - & - & - & $x$ & - \\
\hline Contamination in control group & - & - & - & - & - & $x$ & - \\
\hline Direct costs within health care system & - & $\mathrm{x}$ & $\mathrm{x}$ & $\mathrm{x}$ & $\mathrm{x}$ & $\mathrm{x}$ & - \\
\hline Direct costs outside health care system & - & $x$ & $x$ & $\mathrm{x}$ & $x$ & $x$ & - \\
\hline Indirect costs outside health care system & - & $\mathrm{x}$ & $x$ & $\mathrm{x}$ & $x$ & $x$ & - \\
\hline Lung function - if available & - & - & - & - & - & - & * \\
\hline Hba1c - if available & - & - & - & - & - & - & * \\
\hline Process evaluation & - & - & - & - & - & - & + \\
\hline Compliance (in process-evaluation) & - & - & - & - & - & - & $\ddagger$ \\
\hline
\end{tabular}

FU follow up

* After intervention

† During nurses training and intervention

‡ During intervention

\section{Process evaluation}

A process evaluation was carried out to assess the following outcomes. The reach of the intervention, defined as the proportion of the intended target population that actually participated in the intervention. The dose delivered was defined as the completeness of the intervention and number and duration of the intervention visit. Dose received, described in two concepts, namely exposure and satisfaction. Exposure is the extent to which patients actively engage with and are receptive to the intervention, and satisfaction is defined as patient's satisfaction with the intervention. ${ }^{67}$ Barriers were described as the extent in which problems were encountered during the intervention.

Data were collected using questionnaires filled out by nurses after every intervention visit, by means of checklists that were kept by the nurse for every patient to report 
which steps of the intervention had been taken, and by questionnaires filled out by patients after finishing the intervention.

\section{ANALYSIS}

Data will be analysed according to the intention to treat principle. In addition, on treatment analyses will be performed. Changes in primary and secondary outcome measures between intervention and control group will be analysed using both univariate and multivariate techniques. Models will be adjusted for age, gender and socio-economic status (SES), and baseline differences. Potential additional confounding factors and effect modifiers will be checked and, if necessary, included in the model. Since dependency between observations of subjects from the same general practice may exist as well as between repeated observations within persons, multilevel analyses will also be carried out. All analyses will be performed for intervention and control group in total, as well as for DM and COPD separately.

In the economic evaluation the cost and effects of care as usual and MPI by a practice nurse will be calculated and compared. The cost-effectiveness ratio will be stated in terms of costs per improvement on the BDI, the cost-utility ratio will focus on the net cost per QALY gained. Ratios will be determined for the total patient population as well as for COPD or DM patients separately. Bootstrapping will be used to estimate confidence intervals for calculated ratios.

Descriptive statistics, Chi-square and t-tests will be used to analyse data from the process evaluation.

\section{POWER CALCULATION}

Assuming an $\alpha$ of 0.05 , a $1-\beta$ (power) of 0.90 , a decrease of 18 percent of non-severe depression in the intervention group versus zero percent in the control group, 192 persons were needed, ${ }^{68} 48$ COPD and 48 DM patients in the intervention group and $48 \mathrm{COPD}$ and $48 \mathrm{DM}$ patients in the control group. We decided to recruit four groups of 90 patients (in total: 360), as we not only anticipated the potential need for subgroup specific analyses, but also anticipated attrition varying between 20 and 30 percent (e.g. due to refusals during the follow-up).

\section{DISCUSSION}

\section{Progress of the study}

Based on experiences in the pilot study, we anticipated having to screen 3600 patients in order to include 360 patients. However, we had to increase the number of patients to be screened to reach this number. This was done because the percentage of patients eligible for the MINI interview was lower than in the pilot study. Further- 
more, the percentage of patients refusing the MINI interview was higher than expected. To arrive at a gross number of 360 patients we had to screen a total number of 8326 patients. The response rate to the screening questionnaire was $67 \%$. Eventually, 361 non-severely depressed patients were recruited in the study (DM: $N=184$; COPD: $\mathrm{N}=177$ ). All interventions have been administered; currently follow-up data are being collected. Data collection will be complete in September 2006.

\section{Process evaluation}

First results of the process evaluation indicate that patients' satisfaction with the intervention is high, and $96.5 \%$ of the patients who received the intervention reported to have benefited from the intervention.

\section{Future implementation}

If this intervention proves to be effective in reducing depression and improving quality of life and proves to be cost-effective, implementation of the intervention in the health care system is considered and anticipated. An implementation and dissemination plan has been developed and is being updated regularly to the latest insights.

\section{Acknowledgements}

We would like to thank Dr. Silvia Evers for her input in the sections about the economic evaluation. This study was funded by the Netherlands Organisation for Health Research and Development (ZonMw), grant number 945-03-047. 


\section{REFERENCES}

1. Pouwer F, Beekman AT, Nijpels G, Dekker JM, Snoek FJ, Kostense PJ, et al. Rates and risks for co-morbid depression in patients with Type 2 diabetes mellitus: results from a community-based study. Diabetologia 2003;46(7):892-8.

2. Bruce DG, Casey GP, Grange V, Clarnette RC, Almeida OP, Foster JK, et al. Cognitive impairment, physical disability and depressive symptoms in older diabetic patients: the Fremantle Cognition in Diabetes Study. Diabetes Res Clin Pract 2003;61(1):59-67.

3. Yohannes AM, Baldwin RC, Connolly MJ. Prevalence of sub-threshold depression in elderly patients with chronic obstructive pulmonary disease. Int. J. Geriatr. Psychiatry 2003;18(5):412-6.

4. Van Ede L, Yzermans CJ, Brouwer HJ. Prevalence of depression in patients with chronic obstructive pulmonary disease: a systematic review. Thorax 1999;54(8):688-92.

5. Spitzer RL, Kroenke K, Linzer M, Hahn SR, Williams JB, deGruy FV, 3rd, et al. Health-related quality of life in primary care patients with mental disorders. Results from the PRIME-MD 1000 Study. JAMA 1995;274(19):1511-7.

6. Goldney RD, Phillips PJ, Fisher LJ, Wilson DH. Diabetes, depression, and quality of life: a population study. Diabetes Care 2004;27(5):1066-70.

7. Penninx BW, Leveille S, Ferrucci L, van Eijk JT, Guralnik JM. Exploring the effect of depression on physical disability: longitudinal evidence from the established populations for epidemiologic studies of the elderly. Am J Public Health 1999;89(9):1346-52.

8. Katz IR. On the inseparability of mental and physical health in aged persons: Lessons from depression and medical comorbidity. Am J Geriatr Psychiatry 1996;4(1):1-16.

9. Broadhead WE, Blazer DG, George LK, Tse CK. Depression, disability days, and days lost from work in a prospective epidemiologic survey. JAMA1990;264(19):2524-8.

10. Katon WJ, Lin E, Russo J, Unutzer J. Increased medical costs of a population-based sample of depressed elderly patients. Arch Gen Psychiatry 2003;60(9):897-903.

11. Penninx BW, Guralnik JM, Ferrucci L, Simonsick EM, Deeg DJ, Wallace RB. Depressive symptoms and physical decline in community-dwelling older persons. JAMA 1998;279(21):1720-6.

12. Geerlings SW, Beekman AT, Deeg DJ, Van Tilburg W. Physical health and the onset and persistence of depression in older adults: an eight-wave prospective community-based study. Psychol Med 2000;30(2):369-80.

13. Bruce ML, Hoff RA. Social and physical health risk factors for first-onset major depressive disorder in a community sample. Soc Psychiatry Psychiatr Epidemio/1994;29(4):165-71.

14. Bruce ML, Seeman TE, Merrill SS, Blazer DG. The impact of depressive symptomatology on physical disability: MacArthur Studies of Successful Aging. Am J Public Health 1994;84(11):1796-9.

15. Ciechanowski PS, Katon WJ, Russo JE. Depression and diabetes: impact of depressive symptoms on adherence, function, and costs. Arch Intern Med 2000;160(21):3278-85.

16. DiMatteo MR, Lepper HS, Croghan TW. Depression is a risk factor for noncompliance with medical treatment: meta-analysis of the effects of anxiety and depression on patient adherence. Arch Intern Med 2000;160(14):2101-7.

17. Ormel J, Koeter MW, van den Brink W, van de Willige G. Recognition, management, and course of anxiety and depression in general practice. Arch Gen Psychiatry 1991;48(8):700-6.

18. Wilson K, Mottram P, Sivanranthan A, Nightingale A. Antidepressant versus placebo for depressed elderly. Cochrane Database Syst Rev 2001(2):CD000561.

19. Ackermann RT, Williams JW, Jr. Rational treatment choices for non-major depressions in primary care: an evidence-based review. J Gen Intern Med 2002;17(4):293-301.

20. Oxman TE, Sengupta A. Treatment of minor depression. Am / Geriatr Psychiatry 2002;10(3):256-64.

21. National Institute for Clinical Excellence. Depression. Management of depression in primary and secondary care. London: NHS, NICE, 2004.

22. van Marwijk HWJ, Grundmeijer HGLM, Bijl D, van Gelderen MG, de Haan M, van Weel-Baumgarten EM, et al. NHG-standaard Depressieve stoornis (depressie) (eerste herziening). Huisarts Wet 2003;46(11): 614-23.

23. DeRubeis RJ, Hollon SD, Amsterdam JD, Shelton RC, Young PR, Salomon RM, et al. Cognitive therapy vs medications in the treatment of moderate to severe depression. Arch Gen Psychiatry 2005;62(4):409-16. 
24. Gloaguen V, Cottraux J, Cucherat M, Blackburn IM. A meta-analysis of the effects of cognitive therapy in depressed patients. J Affect Disord 1998;49(1):59-72.

25. Hollon SD, DeRubeis RJ, Shelton RC, Amsterdam JD, Salomon RM, O'Reardon JP, et al. Prevention of relapse following cognitive therapy vs medications in moderate to severe depression. Arch Gen Psychiatry 2005;62(4):417-22.

26. NIH consensus conference. Diagnosis and treatment of depression in late life. JAMA 1992;268(8):1018-24.

27. Lustman PJ, Griffith LS, Freedland KE, Kissel SS, Clouse RE. Cognitive behavior therapy for depression in type 2 diabetes mellitus. A randomized, controlled trial. Ann Intern Med1998;129(8):613-21.

28. Bourbeau J, Nault D, Dang-Tan T. Self-management and behaviour modification in COPD. Patient Educ Couns 2004;52(3):271-7.

29. Moore RG. Improving the treatment of depression in primary care: problems and prospects. $\mathrm{Br} / \mathrm{Gen}$ Pract 1997;47(422):587-90.

30. Mynors-Wallis LM, Gath DH, Day A, Baker F. Randomised controlled trial of problem solving treatment, antidepressant medication, and combined treatment for major depression in primary care. BMJ 2000;320(7226):26-30.

31. Hunkeler EM, Meresman JF, Hargreaves WA, Fireman B, Berman WH, Kirsch AJ, et al. Efficacy of nurse telehealth care and peer support in augmenting treatment of depression in primary care. Arch Fam Med 2000;9(8):700-8.

32. Van Eijk JT, Diederiks JP, Kempen GI, Honig A, van der Meer K, Brenninkmeijer WJ. Development and feasibility of a nurse administered strategy on depression in community-dwelling patients with a chronic physical disease. Patient Educ. Couns. 2004;54(1):87-94.

33. Rolland JS. Chronic illness and the life cycle: a conceptual framework. Fam Process 1987;26(2):203-21.

34. Spitzer RL, Kroenke K, Williams JB. Validation and utility of a self-report version of PRIME-MD: the PHQ primary care study. Primary Care Evaluation of Mental Disorders. Patient Health Questionnaire. JAMA 1999;282(18):1737-44.

35. Lowe B, Spitzer RL, Grafe K, Kroenke K, Quenter A, Zipfel S, et al. Comparative validity of three screening questionnaires for DSM-IV depressive disorders and physicians' diagnoses. J Affect Disord 2004;78(2):13140.

36. Kroenke K, Spitzer RL, Williams JB. The PHQ-9: validity of a brief depression severity measure. J Gen Intern Med 2001;16(9):606-13.

37. Sheehan DV, Lecrubier Y, Sheehan KH, Janavs J, Weiller E, Keskiner A, et al. The validity of the Mini International Neuropsychiatric Interview (MINI) according to the SCID-P and its reliability. Eur Psychiatry 1997;12(5):232-241.

38. Lecrubier Y, Sheehan DV, Weiller E, Amorim P, Bonora I, Sheehan KH, et al. The Mini International Neuropsychiatric Interview (MINI): A short diagnostic structured interview: Reliability and validity according to the CIDI. European Psychiatry 1997;12(5):224-231.

39. American Psychiatric Association. DSM-IV-TR: Diagnostic and statistical manual of mental disorders. fourth edition, text revision ed. Washington DC: American Psychiatric Association, 2000.

40. Hamilton M. A rating scale for depression. J Neuro/ Neurosurg Psychiatry 1960;23:56-62.

41. Hamilton M. Development of a rating scale for primary depressive illness. British journal of social and clinical psychology 1967;6(4):278-96.

42. Lorig K, Gonzalez V. The integration of theory with practice: a 12-year case study. Health Educ $Q$ 1992;19(3):355-68.

43. Goldberg D, Gask L, O'Dowd T. The treatment of somatization: teaching techniques of reattribution. J Psychosom Res 1989;33(6):689-95.

44. Van Os TW, Ormel J, van den Brink RH, Jenner JA, Van der Meer K, Tiemens BG, et al. Training primary care physicians improves the management of depression. Gen Hosp Psychiatry 1999;21(3):168-76.

45. Beck AT, Ward CH, Mendelson M, Mock J, Erbaugh J. An inventory for measuring depression. Archives of General Psychiatry1961;4:561-571.

46. Lustman PJ, Clouse RE, Griffith LS, Carney RM, Freedland KE. Screening for depression in diabetes using the Beck Depression Inventory. Psychosom Med1997;59(1):24-31.

47. Beck AT, Steer RA, Garbin MG. Psychometric properties of the Beck Depression Inventory: Twenty-five years of evaluation. Clinical Psychology Review 1988;8(1):77-100.

48. Aaronson NK, Muller M, Cohen PD, Essink-Bot ML, Fekkes M, Sanderman R, et al. Translation, validation, and norming of the Dutch language version of the SF-36 Health Survey in community and chronic disease populations. J Clin Epidemio/1998;51(11):1055-68. 
49. Snoek FJ, Pouwer F, Welch GW, Polonsky WH. Diabetes-related emotional distress in Dutch and U.S. diabetic patients: cross-cultural validity of the problem areas in diabetes scale. Diabetes Care 2000;23(9):1305-9.

50. Jones PW, Quirk FH, Baveystock CM. The St George's Respiratory Questionnaire. Respir Med 1991;85 Suppl B:25-31; discussion 33-7.

51. Jones PW, Quirk FH, Baveystock CM, Littlejohns P. A self-complete measure of health status for chronic airflow limitation. The St. George's Respiratory Questionnaire. Am Rev Respir Dis 1992;145(6):1321-7.

52. Kempen Gl, Sullivan M, van Sonderen E, Ormel J. Performance-based and self-reported physical functioning in low-functioning older persons: congruence of change and the impact of depressive symptoms. J Gerontol B Psychol Sci Soc Sci1999;54(6):P380-6.

53. Bosscher RJ, Smit JH. Confirmatory factor analysis of the General Self-Efficacy Scale. Behav Res Ther 1998;36(3):339-43.

54. Sherer M, et al. The Self-efficacy Scale: Construction and validation. Psychological Reports 1982;51(2): 663-671.

55. Cardol M, de Haan RJ, van den Bos GA, de Jong BA, de Groot IJ. The development of a handicap assessment questionnaire: the Impact on Participation and Autonomy (IPA). Clin Rehabil1999;13(5):411-9.

56. Cardol M, de Haan RJ, de Jong BA, van den Bos GA, de Groot IJ. Psychometric properties of the Impact on Participation and Autonomy Questionnaire. Arch Phys Med Rehabil 2001;82(2):210-6.

57. Schreurs PJG, Willige van de G, Brosschot JF, Tellegen B, Graus GMH. De Utrechtse Coping Lijs: UCL; Omgaan met problemen en gebeurtenissen. Lisse: Swets en Zeitlinger B.V., 1993.

58. Pearlin LI, Schooler C. The structure of coping. J Health Soc Behav1978;19(1):2-21.

59. Arrindel WA, Ettema JHM. SCL-90: Handleiding bij een multidimensionele psychopathalogie-indicator. Lisse: Swets en Zeitlinger B.V., 1986.

60. Sonderen van E. Het meten van sociale steun met de Sociale Steun Lijst-Interacties (SSL-I) en Sociale Steum Lijst-Discrepanties (SSL-D); een handleiding. Groningen: Noordelijk Centrum voor Gezondheidsvraagstukken (NCG), 1993.

61. Kempen GIJM, Van Eijk LM. The psychometric properties of he SSL12-I, a short scale for measuring social support in the elderly. Social Indicators Research 1995;35(3):303-312.

62. Sanderman R, Arrindell WA, Ranchor AV, Eysenck HJ, Eysenck SBG. Het meten van persoonlijkheidskenmerken met de Eysenck Personality Questionnaire (EPQ): een handleiding. Groningen: Noordelijk centrum voor Gezondheidsvraagstukken, Rijksuniversiteit Groningen, 1995.

63. Grootenhuis PA, Snoek FJ, Heine RJ, Bouter LM. Development of a type 2 diabetes symptom checklist: a measure of symptom severity. Diabet Med1994;11(3):253-61.

64. Dolan P. Modeling valuations for EuroQol health states. Med Care 1997;35(11):1095-108.

65. Goossens ME, Rutten-van Molken MP, Vlaeyen JW, van der Linden SM. The cost diary: a method to measure direct and indirect costs in cost-effectiveness research. J Clin Epidemio/2000;53(7):688-95.

66. Oostenbrink JB, Bouwmans CAM, Koopmanschap MA, Rutten FFH. Handleiding voor kostenonderzoek, methoden en standaard kostprijzen voor economische evaluaties in de gezondheidszorg. Diemen: College voor zorgverzekeringen, Geactualiseerde versie 2004.

67. Linnan L, Steckler A. Process Evaluation for Public Health Interventions and Research: An Overview. In: Steckler A, Linnan L, editors. Process Evaluation for Public Health Interventions and Research. San Francisco: Jossey-Bass, 2002:1-23.

68. Potock S. Clinical trials: A Practical Approach. Chichester: John Wiley and Sons, 1983. 



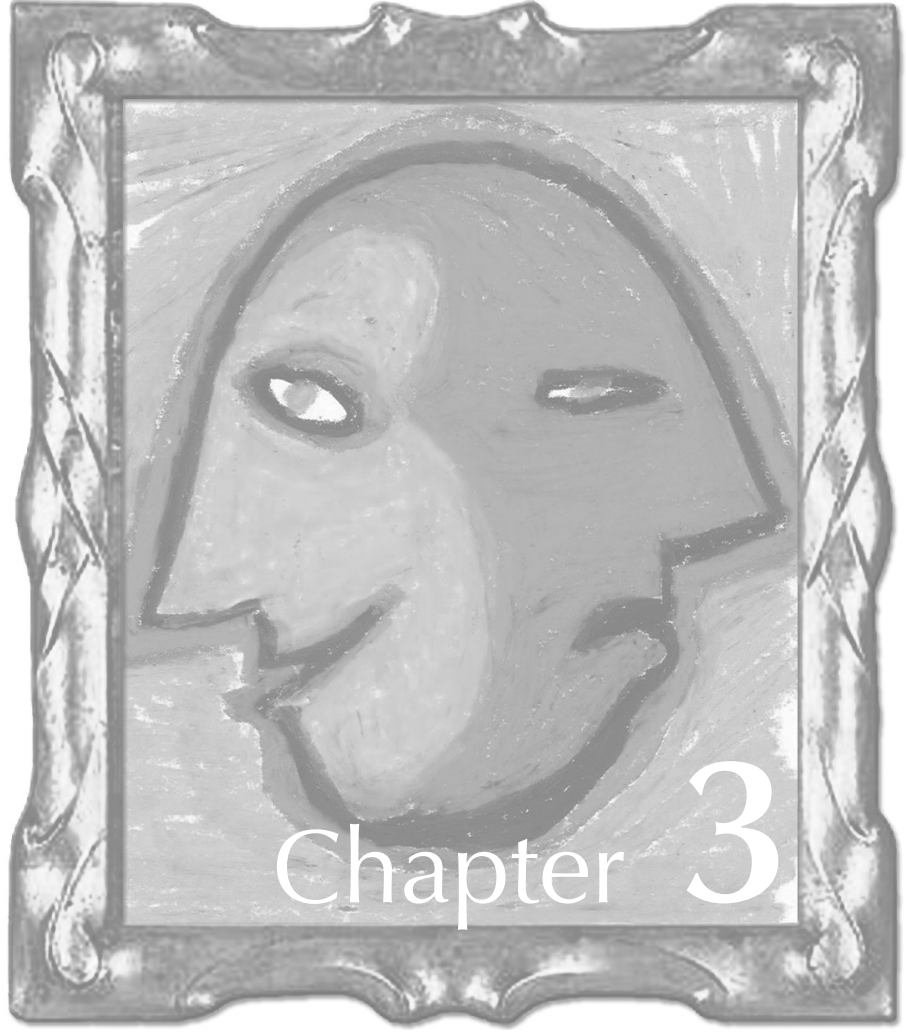

Process evaluation of a minimal psychological intervention to reduce depression in chronically ill elderly persons

CCM Jonkers, F Lamers, H Bosma, JFM Metsemakers, GIJM Kempen, JThM Van Eijk

Patient Education and Counselling, 2007; 68: 252-7 


\section{ABSTRACT}

Objective This article describes the process evaluation of the DELTA (Depression in Elderly with Long-Term Afflictions) intervention, a nurse-led minimal psychological intervention to reduce depression in chronically ill elderly persons. The aim was to assess whether the DELTA intervention was implemented and received as planned, which barriers were encountered and whether nurses and patients were satisfied with the intervention.

Methods Quantitative and qualitative data were gathered from all 183 patients who participated in the intervention and from four nurses who administered the intervention. Data were assessed by means of self-administered questionnaires, checklists, and a group interview with the nurses.

Results Although several barriers were encountered, the intervention was well performed by nurses and well received by patients. However, a small proportion of the patients found the intervention not useful and thought they would not benefit.

Conclusion The implementation of the minimal psychological intervention aimed at reducing depression in chronically ill elderly persons was successful and therefore feasible. By making the intervention part of regular care for patients with a chronic condition, patients can be monitored and, if necessary, support can be provided to implement the intervention in their daily life. 


\section{INTRODUCTION}

Depression is a common problem, especially in older persons with chronic diseases like type II diabetes mellitus (DM) and chronic obstructive pulmonary disease (COPD) ${ }^{1-3}$ Depression impairs one's ability to adhere to disease management regimens, potentially worsening the course of the chronic illness. ${ }^{4}{ }^{5}$ In addition, depression reduces quality of life, ${ }^{6}$ and increases morbidity, ${ }^{7}$ physical disability, ${ }^{8}$ medical costs, ${ }^{9}$ and health care utilization. ${ }^{10}$

Treatments aimed at improvement of depressive symptoms, should take the multifaceted nature of depression combined with a chronic illness into account. Therefore, complex interventions are needed that allow for the multifaceted nature and the dependence on social context. ${ }^{11}$ The pragmatic randomised controlled trial (RCT) that studies the effectiveness of a treatment under usual circumstances rather than clinical settings, has been introduced for complex interventions. ${ }^{12} 13$

By incorporating a process evaluation in a pragmatic trial, the context, implementation and receipt of the intervention can be examined in depth. A process evaluation provides an understanding of how and why an intervention has achieved, or failed to achieve, its objectives and among which patients it failed or succeeded. ${ }^{14}$ In recent years, several advances have been made to develop a more systematic approach for the development of process evaluations. ${ }^{15-17}$ These approaches involve the key elements reach, fidelity, dose received, and barriers.

Based on these key elements, the process evaluation of the Depression in Elderly with Long-Term Afflictions (DELTA) study was conducted. This pragmatic RCT evaluates a minimal psychological intervention $(\mathrm{MPI})$ designed to treat minor depression and mild to moderate major depression in chronically ill elderly persons. The MPI, based on principles of self-management and cognitive behavioral therapy (CBT), is carried out by primary care nurses. This paper will present the results of the process evaluation.

\section{METHODS}

\section{Population and intervention}

Between October 2003 and May 2005, participants were recruited in 89 primary care practices in the south of the Netherlands. Approval for conducting this study was granted by the Medical Ethics Committee of the Maastricht University/Academic Hospital Maastricht.

Participants of 60 years and over, known to the general practitioner with either DM or COPD, were identified by systematic depression screening. Eligible patients $(n=361)$ were randomly allocated to the intervention group receiving the MPI $(n=183)$ or the control group receiving usual care $(n=178)$. This process evaluation will focus on the intervention group, since patients in the control group only received usual care and could not form an opinion about the intervention. 
Four nurses, trained in principles of CBT and self-management, visited patients at home during a period of at most three months. The mean number of visits was 4.5, the exact amount of visits was dependent on the progress of the patient with a maximum of ten visits. The average duration of a visit was 61 minutes, excluding travel time.

The DELTA intervention consists of five phases. In phase one, the nurse explores feelings, cognitions, and behaviors of the patient. During phase two, the patient keeps a diary, in which symptoms, complaints, thoughts, worries, related feelings, and behavior are recorded. In phase three, the patient is challenged to link his mood to the consequent behavior, using information from the diary. The self-management approach is introduced in phase four where the patient explores possibilities to alter his behavior and where an action plan with commitments is made. Phase five consists of an evaluation of the progress in achieving these commitments. The design and intervention have been described in more depth elsewhere. ${ }^{1819}$
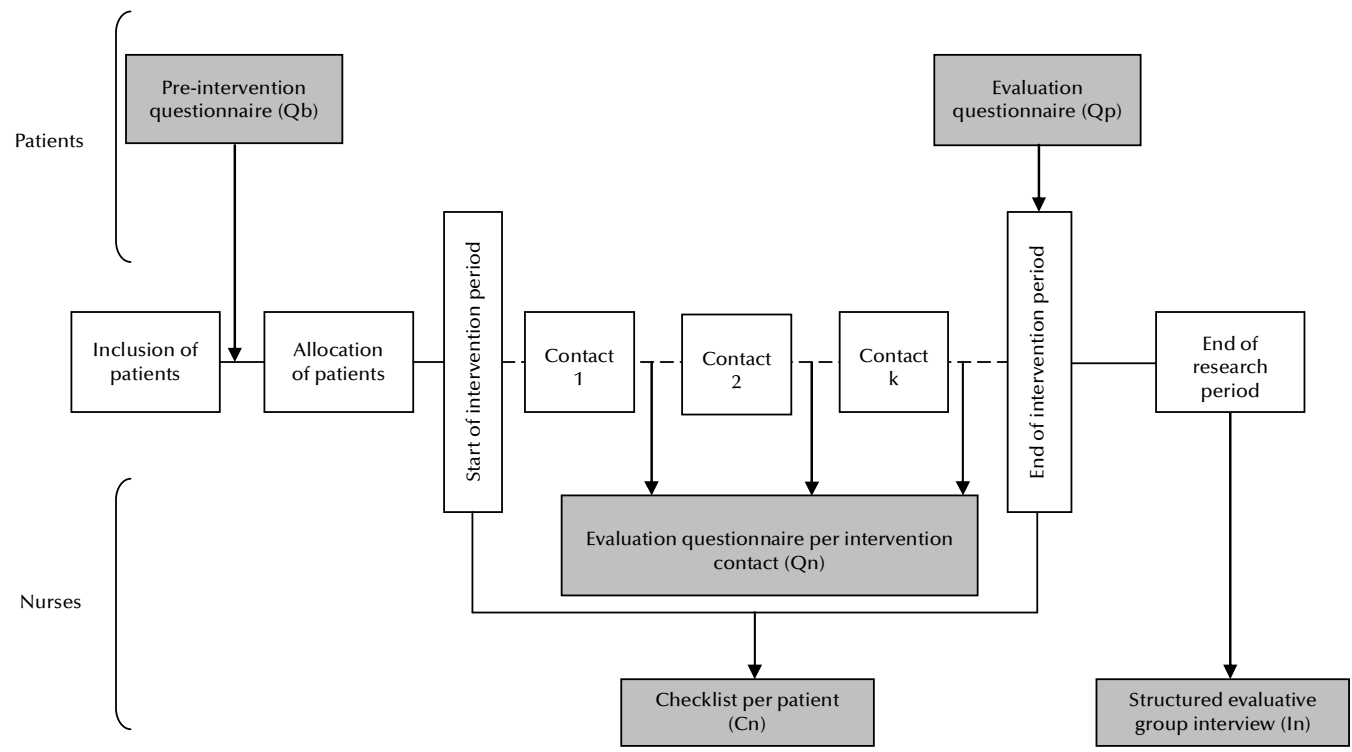

Figure 1. Data collection

Qb pre-intervention questionnaire filled in by patient, $\mathrm{Cn}$ checklist filled in by nurse per patient, Qn questionnaire filled in by nurses per patient per intervention contact, Qp post-intervention questionnaire filled in by patient, In group interview with nurses 


\section{Design and data collection of the process evaluation}

Both quantitative and qualitative information was collected among nurses and patients. Figure 1 shows the collection of data for the process evaluation throughout the whole research period. Patient characteristics (i.e. demographics, level of depression and self-efficacy) were collected prior to randomisation by means of selfadministered questionnaires $(\mathrm{Qb})$. Patients evaluated the intervention by means of a self-administered questionnaire $(\mathrm{Qp})$, directly after their last intervention contact (response rate $76 \%, \mathrm{n}=139$ ). The researchers collected reasons for refusal and dropout throughout the research period (Dr). After each intervention contact, nurses completed a checklist $(\mathrm{Cn})$ to record the progress of the intervention, and selfadministered questionnaires (Qn) to evaluate each contact. In addition, a qualitative structured group interview (In) was held with the nurses after the research period to evaluate their experiences with the intervention.

\section{Measures}

The researchers developed the questionnaires $(\mathrm{Qp}, \mathrm{Cn}, \mathrm{Qn})$ by translating theoretical key elements of process evaluations as described by Baranowski \& Stables ${ }^{17}$ and Linnan \& Steckler, ${ }^{15}$ into structured questions. Table 1 shows how the adapted elements reach, fidelity, dose received (exposure and satisfaction), and barriers, were defined and measured in this study.

Dose delivered, which describes the 'amount' of delivered intervention, is often considered a key element as well, but, since our intervention is tailor-made, it is not reported separately as a process outcome. We did compose a completeness measure to establish the fidelity. The intervention was considered completely implemented, if nurses addressed phase three, four, and five of the intervention, as indicated in the checklist (Cn).

Dose received in terms of exposure is measured through the adherence of patients. During every intervention contact the nurse reviewed with the patient the adherence to previously made commitments $(\mathrm{Qn})$. The opinion of the nurses about the ability of the patients to understand and implement the intervention was assessed by means of five-point Likert scales (Qn). This was done because the nurses knew the essence of the intervention and could, therefore, judge whether patients understood the scope of the intervention. In addition, patients were asked if they intended to implement the intervention into their daily lives $(\mathrm{Qp})$.

Satisfaction of patients was measured by asking patients about the benefits, burden, and usefulness of the intervention using four- and five-point Likert scales. The usefulness was considered for six different aspects of the intervention, namely keeping a diary of mood and behavior, discussing the diary, discussing emotions, discussing social contacts, discussing physical problems, and learning to implement the intervention in daily life. The opinion of patients was further assessed through an open ended question and an overall grade (Qp). The satisfaction of nurses was 
assessed by a qualitative structured group interview (In). The interview was recorded on audiotape and minutes were taken.

Barriers were assessed by means of an open question to nurses asking for encountered barriers and how they dealt with them $(\mathrm{Qn})$.

Table 1. Elements of process evaluation and ways of measurement

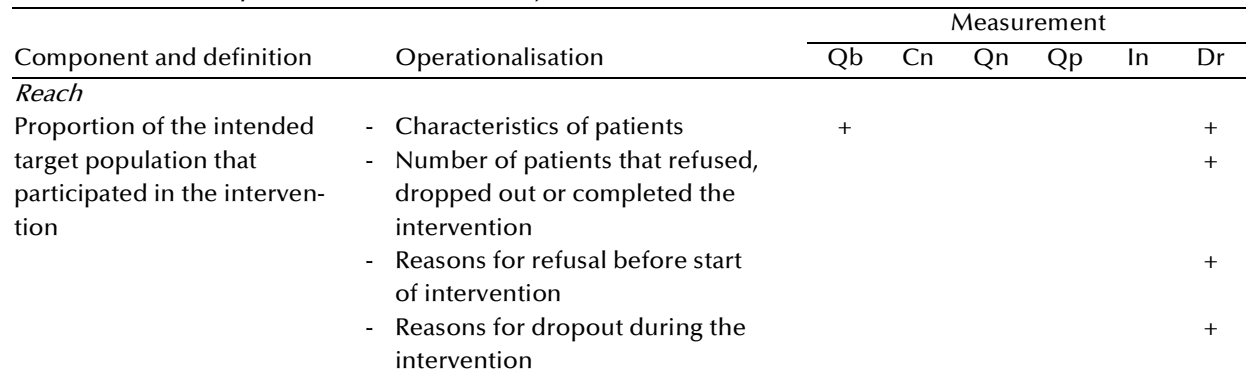

Fidelity

Extent to which the intervention was implemented as planned

- Completeness of intervention

- Intended manner and spirit

Dose received (exposure) Extent of active engagement in and receptiveness to the intervention of patients

- Opinion on patient's ability to understand and implement principles of intervention

- Adherence to commitments made by patient

- Intention of patient to implement intervention

Dose received (satisfaction) Satisfaction of patients and nurses with the intervention

- Overall opinion of patient of intervention (grade and open question)

- Benefits experienced by patient

- Burden experienced by patient

- Usefulness experienced by patient

- Recommendation to others by patient

- Overall opinion of nurses of intervention

\section{Barriers}

The extent to which problems were encountered while applying the interven-

- Barriers in applying the intervention

- Deviations from protocol

tion

$\overline{\mathrm{Qb}}$ pre-intervention questionnaire filled in by patient, $\mathrm{Cn}$ checklist filled in by nurse per $\overline{\text { patient, } \overline{\mathrm{Qn}}}$ questionnaire filled in by nurses per patient per intervention contact, Qp post-intervention questionnaire filled in by patient, In group interview with nurses, Dr data recorded by researchers during intervention period 


\section{Data analysis}

Data were analyzed by means of descriptive statistics, Chi-square tests, t-tests, and ANOVA. Two researchers independently categorized answers to open questions in order to identify relevant themes. Agreement between the two researchers was more than $85 \%$ and in case of a difference, mutual consensus was reached.

\section{RESULTS}

Reach

Of the patients assigned to the intervention group, $7.7 \%$ did not start the intervention $(n=14)$. The main reason was lack of perceived usefulness $(n=9)$. The dropout rate of patients who started the intervention was $19.5 \% \quad(n=33)$. Main reasons were lack of perceived usefulness $(n=10)$, perceived burden $(n=9)$, personal or family circumstances $(n=4)$, and two patients deceased during the intervention period. At the end, $74.3 \%$ of the patients in the intervention group finished the intervention $(n=136)$.

Characteristics of the intervention group are described in Table 2. Patients who finished the intervention appeared to be significantly younger than patients who refused or dropped out of the intervention $(p=.002)$. The self-efficacy expectancy at baseline of patients who refused the intervention was significantly higher than of patients who started the intervention $(p=.011)$, even after adjustment for age. Level of depression at baseline, measured with the Beck Depression Inventory (BDI), did not differ significantly between groups.

\section{Fidelity}

The completeness measure showed that the core elements of the intervention were delivered to $66.3 \%$ of the 169 patients who started the intervention and to $81.6 \%$ of the 136 patients who finished the whole intervention. One of the nurses reported significantly less complete interventions $(p<.000)$ than the other three nurses. From the qualitative structured group interview (In) followed that all nurses picked up the principles of the intervention and tried to carry it out in the manner in which it was intended.

\section{Dose received-exposure}

Patients followed $83.5 \%$ of the commitments made with the nurses during the intervention period. According to the nurses, $65.2 \%$ of the patients certainly understood the link between mood and behavior and $39.8 \%$ were certainly able to implement the principles of the intervention. Another $33.1 \%$ were probably able to implement the principles. Of the patients, $94.7 \%$ felt they were likely to implement the intervention in their lives. 
Table 2. Patient characteristics of patients who finished the intervention, patients who dropped out of the intervention and patients who did not start the intervention

\begin{tabular}{|c|c|c|c|c|}
\hline & $\begin{array}{c}\text { Intervention } \\
\text { finished } \\
(n=136)\end{array}$ & $\begin{array}{l}\text { Intervention } \\
\text { dropout } \\
(\mathrm{n}=33)\end{array}$ & $\begin{array}{l}\text { Intervention } \\
\text { not started } \\
(\mathrm{n}=14)\end{array}$ & Pvalue \\
\hline \multicolumn{5}{|l|}{ Chronic disease } \\
\hline COPD (\%) & 41.2 & 36.4 & 64.3 & .399 \\
\hline $\mathrm{DM}(\%)$ & 47.8 & 51.5 & 35.7 & \\
\hline Both diseases (\%) & 11.0 & 12.1 & 0.0 & \\
\hline Age (mean \pm S.D. years) & $69.9 \pm 6.11$ & $74.1 \pm 6.69$ & $72.4 \pm 7.57$ & .002 \\
\hline Male (\%) & 56.6 & 39.4 & 57.1 & .197 \\
\hline Single $(\%)$ & 41.2 & 28.1 & 64.3 & .069 \\
\hline \multicolumn{5}{|l|}{ Level of education * } \\
\hline Low (\%) & 36.8 & 38.7 & 30.8 & .132 \\
\hline Medium (\%) & 31.6 & 48.4 & 23.1 & \\
\hline High (\%) & 31.6 & 12.9 & 46.2 & \\
\hline Self-efficacy (mean \pm S.D.) + & $48.5 \pm 0.55$ & $48.6 \pm 0.45$ & $55.4 \pm 6.34$ & .011 \\
\hline BDI $($ mean \pm S.D. $) \neq$ & $17.03 \pm 0.10$ & $17.30 \pm 0.17$ & $17.74 \pm 0.61$ & .934 \\
\hline
\end{tabular}

* Low refers to primary school only, medium refers to lower vocational training or lower general education, high refers to higher vocational training, secondary school, college and university training

+ Scores range from 29 (representing low self-efficacy expectancy) to 73 (representing high self-efficacy expectancy)

‡ BDI (Beck Depression Inventory) measures level of depression. Scores range from 0 (representing low levels of depression) to 63 (representing high levels of depression)

\section{Dose received - satisfaction}

Patient satisfaction with the intervention was high. Most opinions derived from the open ended questions were positive, but some patients $(n=6)$ indicated that the intervention was too short. A mean score of 8.4, ranging 0 (minimum) to 10 (maximum), was given as an overall score for the intervention. In addition, $68.7 \%$ of the patients reported to have benefited a lot from the intervention. The perceived burden was low; $94.0 \%$ of the patients felt the intervention was not burdensome. Patients found discussing their emotions $(83.3 \%)$, physical wellbeing $(84.7 \%)$, social contacts $(82.9 \%)$, and learning to implement the intervention in life $(81.8 \%)$ useful. However, fewer patients thought keeping a diary $(60.9 \%)$ or discussing the diary $(71.1 \%)$ was useful. A majority of the patients $(93.9 \%)$ would recommend the intervention to other chronically ill persons.

The nurses who applied the intervention were enthusiastic about the intervention. The techniques of the intervention (CBT, self-management) were considered very useful and a valuable asset for all nurses working with patients. The nurses believed that most patients benefited from the intervention. However, they felt that a booster session would help patients to better integrate the intervention into their daily lives. In addition, they suggested that the intervention should be implemented in regular care for all depressed patients with a chronic illness, regardless of age or type of chronic illness. 


\section{Barriers}

Nurses experienced one or more barriers (range 1-4, modus 1) in 79 of the 169 patients who started the intervention. These barriers could be divided in four categories, which are shown in Table 3.

In 42 patients one or more barriers concerning resistance against the intervention were reported by nurses. For example, problems with keeping the diary caused resistance in 11 patients. During the evaluative interview, the nurses indicated that the diary was an important tool, but needed simplification in order to be more manageable for patients.

The second category consists of barriers due to personality, for example patients who get easily frustrated were reported to have difficulties with adapting to the intervention. The third and fourth category consists of health-related barriers (e.g. severe physical problems) and barriers due to the social environment of the patient (e.g. family problems). Barriers in these two categories could easily lead to a delay in progress of the intervention according to the nurses, because patients wanted to address the health-related problems or problems in the social environment before continuation of the intervention.

Most barriers could be addressed and handled during the intervention contacts. However, some barriers led to a deviation from the protocol $(n=17)$. Main reasons were problems with the diary $(n=11)$, inability of patients to understand the link between mood and behavior $(n=3)$, and resistance from the patient to undertake action $(n=3)$.

Table 3. Number of patients in which nurses reported a barrier and \% of patients that started the intervention $(n=169)$

\begin{tabular}{lc}
\hline Barriers & $\mathrm{n}(\%)$ \\
\hline Resistance against intervention & $42(24.9)$ \\
Personality & $29(17.2)$ \\
Health-related & $29(17.2)$ \\
Social environment & $13(7.7)$ \\
\hline
\end{tabular}

\section{DISCUSSION}

The overall satisfaction of patients with the intervention was high and the perceived burden was low. Nurses were very positive about the theoretical principles of the intervention and the perceived benefits for patients. Despite experienced barriers, the nurses rarely reported problems with the administration of the intervention. This can be supported by the fact that most interventions were completely implemented. However, a difference was found in percentage of complete interventions between nurses. This could indicate that the deliverance of the intervention was affected by characteristics of the nurse.

The main reason for refusal at the start and dropout during the intervention was lack of perceived usefulness. Late-life depression is often taken for granted by patients and seen as a consequence of their physical illness and age. Therefore, the relevance of addressing depression might not have been clear to patients. The lack of attention 
$42 \mid$

from caregivers for depressive feelings can make it even less appealing for patients to address depressive feelings ${ }^{20}$. Another explanation for lack of perceived usefulness is that patients who refused to participate had high self-efficacy expectancy levels. This could have influenced the perceived usefulness and presumed capability to address their own depression.

Lack of motivation is commonly reported in people with depressive feelings. Although nurses were trained in dealing with lack of motivation, it might have influenced dropout rates. Barriers due to resistance against the intervention might be explained by lack of motivation from patients as well.

A limitation of this study is that fidelity and dose received were only measured subjectively through the opinion of nurses and patients. No measurements were available to test these elements more objectively, for example through independent observations. A second limitation is that patient satisfaction was measured directly after the last intervention visit. Therefore, patients might not have had enough time to form a mature opinion about the usefulness of the intervention. A follow-up measurement would have been appropriate and useful to assess whether patients had actually implemented the intervention in daily life. A last limitation is that this study only evaluates patients who had signed informed consent and agreed to participate in the intervention. Therefore, we assessed a group of patients who were likely to be rather positive about the intervention.

\section{Conclusion}

The DELTA study was well performed by nurses and well received by patients and therefore feasible. Results indicate that the implementation of the DELTA study in our research population was successful and is likely to be feasible in regular care for patients with a chronic disease. However, a small proportion of the patients found the intervention not useful and thought they would not benefit.

\section{Practice implications}

The first practice implication that follows from this process evaluation is that the usefulness and relevance of the DELTA intervention should be made clearer to patients and caregivers by improving the introduction of the intervention. More information about depression and treatment options would also help to reduce the stigma around depressive feelings in older persons. Second, the diary that is used by patients to record feelings and behaviors needs simplification in order to be easier to use for elderly persons.

Finally, more attention should be paid to the integration of the intervention into the patient's life because it remains unclear whether patients actually succeed to integrate the principles in their lives. By making the intervention part of regular care for patients with a chronic condition, patients can be monitored and, if necessary, support can be provided to further implement the intervention. If the intervention 
proves to be (cost)effective, further dissemination of the DELTA intervention in regular care appears to be appropriate.

Acknowledgement

We would like to thank Kitty Daemen, Henny Geelen, Francine Hendriks and Mieke Witte for administering the intervention with dedication and enthusiasm, Wendy Engering for the recruitment of patients, Dorien Mintjes for her contribution to the data entry and MEMIC (Centre for Data and Information Management) for providing us with a data management system. This study was funded by the Netherlands Organisation for Health Research and development (ZonMw), programme of Health Care Efficiency Research, grant number 945-03-047. 


\section{REFERENCES}

1. Penninx BW, Beekman AT, Ormel J, Kriegsman DM, Boeke AJ, van Eijk JT, et al. Psychological status among elderly people with chronic diseases: does type of disease play a part? J. Psychosom. Res. 1996;40(5):521-34.

2. Anderson RJ, Freedland KE, Clouse RE, Lustman PJ. The prevalence of comorbid depression in adults with diabetes: a meta-analysis. Diabetes Care 2001;24(6):1069-78.

3. Yohannes AM, Baldwin RC, Connolly MJ. Prevalence of sub-threshold depression in elderly patients with chronic obstructive pulmonary disease. Int. J. Geriatr. Psychiatry 2003;18(5):412-6.

4. Ciechanowski PS, Katon WJ, Russo JE. Depression and diabetes: impact of depressive symptoms on adherence, function, and costs. Arch Intern Med 2000;160(21):3278-85.

5. DiMatteo MR, Lepper HS, Croghan TW. Depression is a risk factor for noncompliance with medical treatment: meta-analysis of the effects of anxiety and depression on patient adherence. Arch Intern Med 2000;160(14):2101-7.

6. Spitzer RL, Kroenke K, Linzer M, Hahn SR, Williams JB, deGruy FV, 3rd, et al. Health-related quality of life in primary care patients with mental disorders. Results from the PRIME-MD 1000 Study. JAMA 1995;274(19):1511-7.

7. Penninx BW, Geerlings SW, Deeg DJ, van Eijk JT, van Tilburg W, Beekman AT. Minor and major depression and the risk of death in older persons. Arch Gen Psychiatry 1999;56(10):889-95.

8. Penninx BW, Guralnik JM, Ferrucci L, Simonsick EM, Deeg DJ, Wallace RB. Depressive symptoms and physical decline in community-dwelling older persons. JAMA 1998;279(21):1720-6.

9. Katon WJ, Lin E, Russo J, Unutzer J. Increased medical costs of a population-based sample of depressed elderly patients. Arch Gen Psychiatry 2003;60(9):897-903.

10. Katz IR. On the inseparability of mental and physical health in aged persons: Lessons from depression and medical comorbidity. Am J Geriatr Psychiatry 1996;4(1):1-16.

11. Oakley A, Strange V, Bonell C, Allen E, Stephenson J. Process evaluation in randomised controlled trials of complex interventions. Brit Med /2006;332(7538):413-6.

12. Hotopf M. The pragmatic randomised controlled trial. Adv Psychiatr Treat 2002;8(5):326-333.

13. Roland M, Torgerson DJ. What are pragmatic trials? BMJ1998;316(7127):285.

14. Platt S, Gnich W, Rankin D, Ritchie D, Truman J, Backett-Milburn K. Applying process evaluation: Learning from two research projects. In: Thorogood M, Coombes $\mathrm{Y}$, editors. Evaluating health promotion: Practice and methods. 2nd ed. New York: Oxford University Press, 2004:73-89.

15. Linnan L, Steckler A. Process Evaluation for Public Health Interventions and Research: An Overview. In: Steckler A, Linnan L, editors. Process Evaluation for Public Health Interventions and Research. San Francisco: Jossey-Bass, 2002:1-23.

16. Saunders RP, Evans MH, Joshi P. Developing a process-evaluation plan for assessing health promotion program implementation: a how-to guide. Health Promot Pract 2005;6(2):134-47.

17. Baranowski T, Stables G. Process evaluations of the 5-a-day projects. Health Educ Behav 2000;27(2):157-66.

18. Van Eijk JT, Diederiks JP, Kempen GI, Honig A, van der Meer K, Brenninkmeijer WJ. Development and feasibility of a nurse administered strategy on depression in community-dwelling patients with a chronic physical disease. Patient Educ. Couns. 2004;54(1):87-94.

19. Lamers F, Jonkers CC, Bosma H, Diederiks JP, van Eijk JT. Effectiveness and cost-effectiveness of a minimal psychological intervention to reduce non-severe depression in chronically ill elderly patients: the design of a randomised controlled trial [ISRCTN92331982]. BMC Public Health 2006;6(1):161.

20. Graham N, Lindesay J, Katona C, Bertolote JM, Camus V, Copeland JR, et al. Reducing stigma and discrimination against older people with mental disorders: a technical consensus statement. Int J Geriatr Psychiatry 2003;18(8):670-8.

21. Burroughs H, Lovell K, Morley M, Baldwin R, Burns A, Chew-Graham C. 'Justifiable depression': how primary care professionals and patients view late-life depression? A qualitative study. Fam Pract 2006;23(3):369-77. 


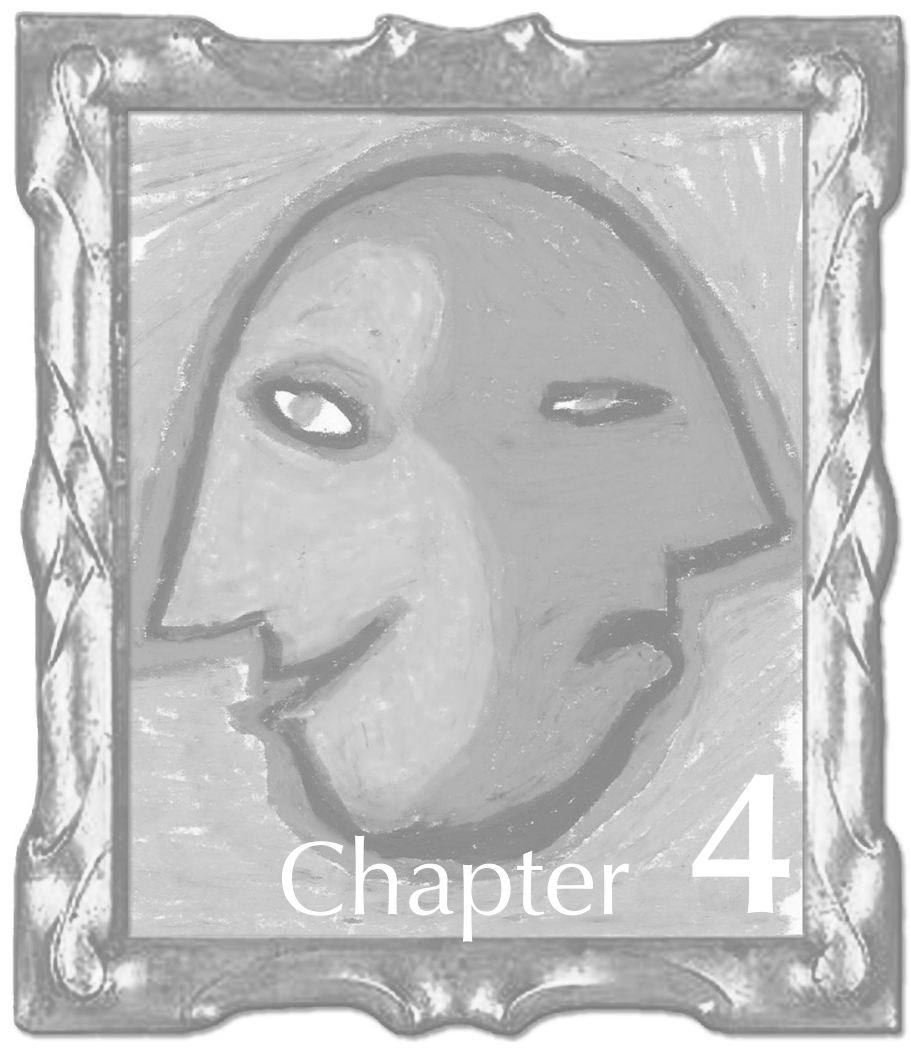

The effectiveness of a minimal psychological intervention in chronically ill elderly patients with depression: a randomised trial (the DELTA-study) 


\section{ABSTRACT}

Objective Among older persons with chronic somatic diseases, depression often remains unrecognized and untreated in primary care. The aim of this study is to evaluate the effectiveness of a nurse-led minimal psychological intervention (MPI) in chronically ill elderly persons with depression.

Methods A randomised controlled trial, comparing the MPI with usual care in 361 primary care patients. Patients were 60 years and older and had a minor depression or mild to moderate major depression and either had type II diabetes or chronic obstructive pulmonary disease.

Results Nine months after the treatment, patients receiving the MPI had fewer depressive symptoms $(\mathrm{p}=0.03)$ and higher odds of a substantial depression reduction $(\geq 50 \%)$ relative to baseline values (OR 3.22; $95 \% \mathrm{Cl} 1.31-7.89)$ than controls. A positive effect was also found on quality of life in diabetic patients.

Conclusion The nurse-led MPI appears both a feasible and effective treatment for minor to moderate depression in chronically ill elderly persons. 


\section{INTRODUCTION}

Elderly patients with chronic somatic illnesses often have a co-occurring minor or major depression, but such depression often remains unrecognised or untreated in primary care. ${ }^{1}$ As depression may further worsen the patients' prognosis, its treatment in chronically ill elderly patients is important. Several meta-analyses showed that psychological treatments, including cognitive behavioral therapy (CBT), are effective in the treatment of depression in older adults. ${ }^{2-4}$ Two studies on collaborative care further suggest that somatic comorbidity does not adversely affect the positive response $^{5}{ }^{6}$ and studies on psychological interventions (including CBT) or selfmanagement in chronically ill elderly patients found beneficial effects on various outcomes. $^{7-12}$ Recent studies show that paraprofessionals, like nurses, can successfully be trained to administer forms of CBT and self-management strategies and thus may complement the general practitioner's (GP) regular work. ${ }^{13}{ }^{14}$ The aim of the DELTA study (Depression in Elderly with Long-Term Afflictions) was to evaluate the effectiveness of a nurse-administered minimal psychological intervention (MPI) in reducing depressive symptoms in elderly primary care patients with type II diabetes mellitus (DM) or chronic obstructive pulmonary disease (COPD) and a co-occurring non-severe depression.

\section{METHODS}

\section{Design}

The DELTA study (Depression In Elderly with Long-Term Afflictions) was a two-armed, pragmatic, randomised controlled trial with a baseline measurement (before randomisation) and three follow-up measurements at one week and at three and nine months after the intervention period (trial registration: ISRCTN92331982). In contrast to an explanatory trial in which a treatment is compared to a placebo under ideal circumstances, we conducted a pragmatic trial, measuring effectiveness of the MPI in a setting that realistically reflects routine clinical practice. To achieve this realistic setting, we included a heterogenic population, consisting of both DM and COPD patients with depression severities that - if detected and treated - most commonly would be treated in primary care. The intervention group received the MPI, while the control group received care as usual. Time between baseline and the first-follow-up measurement depended upon the time it took to complete the tailor-made intervention. In the control group, the first follow-up measurement was set at six weeks after baseline, which beforehand was estimated the mean duration of the intervention (in the intervention group).

A block randomisation scheme was used with stratification for chronic illness and general practice. The block size was two, because we expected to include a small number of patients per general practice and wanted to have them equally distributed 
over groups. The researchers entered patients in a computer connected to an external agency, which performed the randomisation using a computerised random number generator. All data were collected through self-administered questionnaires. Data entry was performed by researchers blinded for the allocation. Approval for the study protocol was obtained from the Medical Ethics Committee of Maastricht University / University Hospital Maastricht. A detailed description of the study protocol has been published elsewhere. ${ }^{15}$

We hypothesized that the MPI, based on the principles of CBT and self-management, would be more effective in reducing symptoms of depression and increasing quality of life than care as usual. We also examined whether the type of chronic illness (DM or COPD) modified the effects of the MPI. Since patients with different chronic illnesses probably face similar problems in coping with their disease (or its consequences) in daily life, ${ }^{1617}$ we expected that the effect of the intervention would be generic across diseases.

\section{Participants and setting}

Between October 2003 and May 2005, participants with DM or COPD were recruited in 89 primary care practices in the south of the Netherlands. The decision to include DM and COPD patients was based on the fact that these prevalent diseases are mainly treated in primary care in the Netherlands. Patients who had been diagnosed by their GP with type II diabetes mellitus or COPD, who were aged 60 years or over, who were community-dwelling and who did not meet exclusion criteria (treatment with antidepressants for depression, major psychiatric problems (bipolar depression, schizophrenia, alcohol or substance abuse), current psychosocial/psychiatric treatment, serious cognitive problems, on waiting list for nursing home, bedridden, loss of spouse within last three months, and not being fluent in Dutch) were sent the Patient Health Questionnaire (PHQ-9). ${ }^{18}$ Patients who reported having at least two symptoms present for more than half of the days, one of them being loss of interest or depressed mood, were invited to a structured diagnostic interview for DSM-IV axis I disorders, the Mini International Neuropsychiatric Interview (MINI). ${ }^{19}$ The MINI was administered at the patients' home by nurses who had been trained by a psychiatrist and a GP, and had regular booster sessions with the psychiatrist. Patients with minor depression, mild to moderate major depression or dysthymia, according to the MINI, were invited to participate in the trial. Patients with suicidal risk and patients with severe major depression, according to the Hamilton Depression Rating Scale (HDRS $>18),{ }^{20}$ were excluded and referred to their GP. Somatic symptoms on the Hamilton scale were assessed using an 'etiologic' approach; symptoms that could be accounted for by the chronic somatic illness would not be counted towards the depression. This is a recommended approach for the assessment of depression in persons with a physical illness. ${ }^{21}$ After signing an informed consent form and completing a baseline questionnaire, patients were randomly allocated to the MPI or to care as usual. In all, 361 patients (185 DM; 176 COPD) were randomised. Multimorbidities are common in elderly persons, as was indeed the case in our study: 11 
patients stratified for DM also had COPD, and 23 patients stratified for COPD also had DM.

\section{Interventions}

Patients allocated to the intervention group received the MPI additionally to usual care. Table 1 lists the phases of the intervention; more details can be found elsewhere. $^{1522}$ The intervention aims to educate patients to take responsibility for day-today management of their own illness and its consequences. The intervention was delivered at the patient's home by trained nurses. The nurse delivering the intervention was a different nurse than the one administering the MINI. The intervention is a combination of CBT and self-management; reattribution of negative cognitions and problem solving were core elements of the intervention. The intervention is tailormade; during the study, patients received two to ten visits over a period of at most three months. The number of visits depended on their progress through the steps of the intervention; on average patients received four intervention visits, each lasting approximately one hour. On average, patients in the intervention group completed the intervention in ten weeks (mean 10.3 (SD 5.6)). To ensure that the nurses adhered to the protocol during the study, they were asked to keep checklists, covering all essential intervention steps, for each patient. Examination of these lists showed that nurses had adhered closely to the guidelines in the protocol. ${ }^{23}$ Patients allocated to the control group received care as usual for their somatic illness, according to the clinical guidelines of the Dutch College of General Practitioners. These guidelines encompass regular check-up of medical symptoms, but do not explicitly involve detection and treatment of depressive symptoms. ${ }^{24-26}$ Depression treatment next to the MPI during follow-up was uncommon and non-differential between the intervention and control group. At the last follow-up phase, seven and one person in the control group received antidepressants or consulted a psychiatrist or psychologist, respectively, compared with four and six persons in the intervention group. Only after the follow-up, GPs were informed about which patients had participated in the trial.

Table 1. Phases of the minimal psychological intervention

\begin{tabular}{ll}
\hline Phase & Description \\
\hline 1 & The nurse explores the patient's feelings, cognitions and behaviors \\
2 & The patient keeps a diary, where he or she records symptoms, complaints, thoughts, worries, \\
& related feelings, and behavior \\
3 & $\begin{array}{l}\text { The patient is challenged to link his or her mood to the consequent behavior, using information } \\
\text { from the diary }\end{array}$ \\
4 & $\begin{array}{l}\text { The self-management approach is introduced. The patient explores possibilities to alter his or her } \\
\text { behavior and draws up an action plan }\end{array}$ \\
& Evaluation of progress in achieving the goals of the action plan \\
\hline
\end{tabular}


$50 \mid$

\section{Main outcome measures}

The primary outcome measure was depression, using the Beck Depression Inventory (BDI). ${ }^{27} 28$ In addition to the continuous BDI score, a dichotomous BDI score to represent clinically relevant improvement was calculated. Improvement of depression was defined as an $\geq 50 \%$ reduction relative to the baseline BDI score. ${ }^{29}$ The secondary outcome measure was quality of life, using the Physical Component Score (PCS) and Mental Component Score (MCS) of the Short-Form 36 (SF-36). ${ }^{30}$ Missing items on the SF-36 and on the BDI were imputed using the individual mean score of items that were not missing in patients for whom at least $50 \%$ of items were available. The number of patients in whom imputation was not possible across measurements (T0T1-T2-T4) was two-zero-two-two for the BDI and 47-22-16-21 for the PCS and MCS; this was equally distributed over groups. Data on age, sex, and education, as covariates, were collected during the PHQ-9 screening.

\section{Statistical analysis}

Assuming an $\alpha$ of 0.05 , a $1-\beta$ (power) of 0.90 , including $2 \times 96=192$ patients (48 COPD and $48 \mathrm{DM}$ patients in the intervention group and 48 COPD and $48 \mathrm{DM}$ patients in the control group) would allow a minimum difference between groups of $18 \%$ in improvement $\left(\geq 50 \%\right.$ reduction relative to the baseline BDI score) to be detected. ${ }^{31}$ These numbers would further allow the detection of a difference in BDI score of at least 3.57 points at the $5 \%$ significance level to be detected (power 0.9). Anticipating an attrition rate of approximately $30 \%$ and the potential need for sub-group analyses, we decided to recruit a gross number of 360 patients.

All analyses were carried out according to a pre-established analysis plan on an intention-to-treat basis. Chi-square and t-tests were used to test the comparability of groups at baseline in terms of all outcomes and demographic variables. We used a mixed-model, repeated-measures ANCOVA to test for differences between groups at different points in time. We included seven fixed effects in our model (age, sex, education level, baseline value, treatment group, time, and the interaction term between treatment group and time). There was no support for general practice being an additional level. Several random effects and covariance matrices were then tested, using -2 log likelihood tests to decide which model had the best fit. Lastly, two-way and three-way interaction terms for group, time, and illness (DM or COPD) were used to test for effect modification by disease $(p<0.10)$. A check for outliers was conducted, but no serious outlier influence was established. Percentages of improvement of depression score were calculated for both groups and between-group differences were tested using Chi-square tests. Logistic regression was used to calculate odds ratios (ORs) for improvement, correcting for age, sex, level of education, time, and BDI baseline score. Additional per-protocol analyses were performed with intervention patients who - according to an analysis of process data ${ }^{23}$ - had received the complete intervention $(n=136)$ and excluding nine control patients who responded positively to a check for contamination during the data collection. 


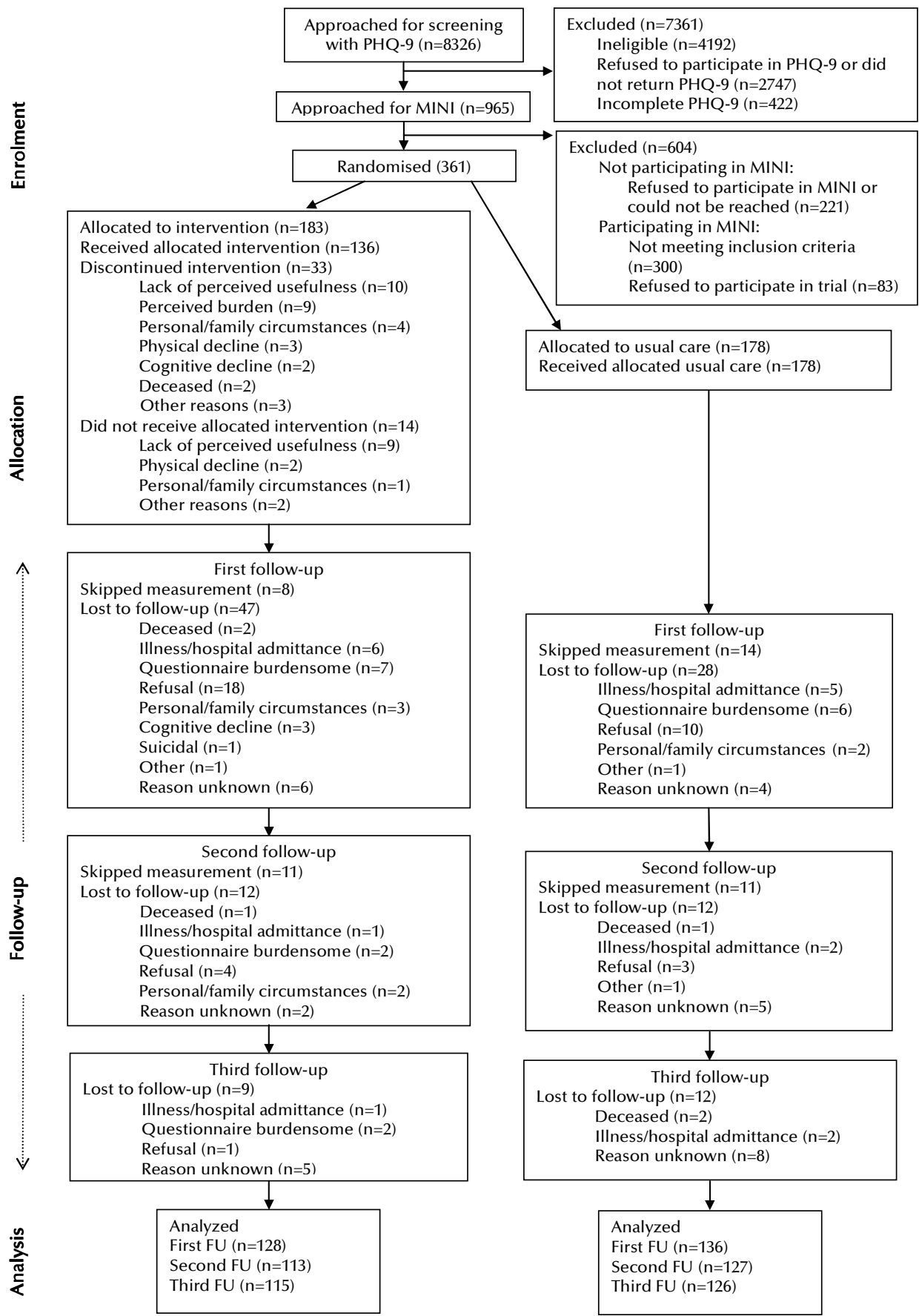

Figure 1. Patient flow and follow-up in the DELTA study

First follow-up at one week after the intervention, second follow-up at three months after the intervention and third follow-up at nine months after the intervention 
Finally, sensitivity analyses using the last value carried forward-method were done. These analyses gave similar results.

\section{RESULTS}

Figure 1 describes the patient flow and follow-up. In total, 8,326 patients with DM or COPD received the screening questionnaire, $67 \%$ of whom returned the questionnaire. Nine hundred and sixty-five patients were eligible for the diagnostic interview $(17.3 \%)$. Of these patients, $221(23 \%)$ refused to participate in the MINI or could not be reached. A comparison of participants $(n=744)$ and non-participants $(n=221)$ revealed no differences between these groups regarding gender, age, educational level, or PHQ-9 sum score. The 83 patients that were eligible, but who refused to participate in the trial, were more often female, older and were significantly lower educated. In total, 361 patients were randomised; 183 to the intervention and 178 to usual care.

During the follow-up period, we had a dropout rate of $33 \%$, as anticipated. The dropout rate was somewhat higher, but not significantly, in the intervention group than in the control group $(37.7 \%$ vs. $29.8 \%$, p value 0.11$)$. Overall, dropouts were on average 2.8 years older than non-dropouts ( $p$ value $<0.00$ ), but they did not differ in baseline BDI depression scores ( $p$ value 0.11 ). As shown in Table 2, the intervention and control groups were comparable in terms of baseline characteristics.

Table 2. Comparability of intervention and control groups in terms of socio-demographic variables and baseline values of outcomes

\begin{tabular}{|c|c|c|c|}
\hline & $\begin{array}{c}\text { Usual Care } \\
\mathrm{n}=178\end{array}$ & $\begin{array}{c}\mathrm{MPI} \\
\mathrm{n}=183\end{array}$ & Pvalue \\
\hline Age, yrs (SD) & $70.6(6.8)$ & $70.8(6.5)$ & .73 \\
\hline \multicolumn{4}{|l|}{ Sex, No. $(\%)$} \\
\hline Male & $95(53.4)$ & $98(53.6)$ & \multirow[t]{2}{*}{.97} \\
\hline Female & $83(46.6)$ & $85(46.4)$ & \\
\hline \multicolumn{4}{|c|}{ Chronic illness, No. (\%) } \\
\hline Diabetes & $94(52.8)$ & $91(49.7)$ & \multirow[t]{2}{*}{.56} \\
\hline COPD & $84(47.2)$ & $92(50.3)$ & \\
\hline \multicolumn{4}{|c|}{ Education level*十, No. (\%) } \\
\hline Low & $60(33.9)$ & $64(35.4)$ & \multirow[t]{3}{*}{.55} \\
\hline Medium & $46(26.0)$ & $54(29.8)$ & \\
\hline High & $71(40.1)$ & $63(34.8)$ & \\
\hline $\mathrm{BDI}$, mean (SD) & $17.7(8.0)$ & $17.1(7.2)$ & .47 \\
\hline PCS, mean (SD) & $34.2(9.1)$ & $34.4(9.5)$ & .81 \\
\hline MCS, mean (SD) & $36.9(9.9)$ & $37.8(8.2)$ & .38 \\
\hline \multirow{2}{*}{\multicolumn{4}{|c|}{$\begin{array}{l}\text { SD standard deviation, BDI Beck Depression Inventory, PCS Physical Component Score, MCS Mental } \\
\text { Component Score }\end{array}$}} \\
\hline & & & \\
\hline \multicolumn{4}{|c|}{ * data missing from 3 respondents } \\
\hline \multicolumn{4}{|c|}{$\begin{array}{l}\text { t Low refers to primary school only, medium refers to lower vocational training or lower general education, } \\
\text { high refers to higher vocational training, secondary school, higher professional education and university } \\
\text { training }\end{array}$} \\
\hline \multicolumn{4}{|c|}{$\begin{array}{l}\text { Range of the BDI is } 0-63 \text {, with } 0 \text { as the most favourable outcome; PCS and MCS are standardised scores with a } \\
\text { mean of } 50 \text { and a standard deviation of } 10 \text { in the US general population; higher scores are more favourable }\end{array}$} \\
\hline
\end{tabular}


Results from the mixed-model ANCOVA analyses (Table 3) show that the intervention group had lower average BDI scores than the control group, indicating fewer depressive symptoms, and this was consistently found at all three follow-up measurements. The difference between the intervention and control groups was significant at the second follow-up (mean BDI difference 1.61, $\mathrm{F}=3.860, \mathrm{df}=1,510, \mathrm{p}$ value $<0.05$ ) and the last follow-up (mean BDI difference 2.09, $\mathrm{F}=4.998, \mathrm{df}=1,270$, $\mathrm{p}$ value 0.03 ). The intervention group consistently had higher scores for PCS and MCS than the control group, indicating better quality of life, but these differences did not reach statistical significance. A marginal difference for PCS was found at the second follow-up $(\mathrm{F}=3.326, \mathrm{df}=1,450, \mathrm{p}$ value 0.07$)$.

Table 3. Outcomes on depression and quality of life at follow-up

\begin{tabular}{|c|c|c|c|c|c|c|}
\hline & $\begin{array}{l}\text { Usual Care } \\
\qquad \mathrm{N}=178\end{array}$ & & $\begin{array}{c}\mathrm{MPI} \\
\mathrm{N}=183\end{array}$ & & & $\begin{array}{l}\text { Mean difference } \\
\text { (Usual care-MPI) }\end{array}$ \\
\hline & Mean (SE)* & $\mathrm{Nt}$ & Mean (SE)* & $\mathrm{Nt}$ & Pvalue & Mean $(95 \% \mathrm{Cl})^{*}$ \\
\hline \multicolumn{7}{|l|}{ BDI } \\
\hline After 1 week & $17.17(0.53)$ & 135 & $16.18(0.55)$ & 127 & .19 & $0.99(-0.50$ to 2.49$)$ \\
\hline After 3 months & $17.49(0.56)$ & 125 & $15.88(0.60)$ & 111 & $<.05$ & $1.61(>0.00$ to 3.22$)$ \\
\hline After 9 months & $18.00(0.64)$ & 123 & $15.91(0.68)$ & 114 & .03 & $2.09(0.25$ to 3.93$)$ \\
\hline \multicolumn{7}{|l|}{ PCS } \\
\hline After 1 week & $33.60(0.57)$ & 109 & $34.26(0.58)$ & 110 & .42 & $-0.66(-2.25$ to 0.94$)$ \\
\hline After 3 months & $33.31(0.61)$ & 102 & $34.89(0.62)$ & 101 & .07 & $-1.58(-3.28$ to 0.12$)$ \\
\hline After 9 months & $33.35(0.70)$ & 98 & $34.15(0.70)$ & 103 & .43 & $-0.79(-2.74$ to 1.16$)$ \\
\hline \multicolumn{7}{|l|}{ MCS } \\
\hline After 1 week & $38.30(0.86)$ & 109 & $39.84(0.86)$ & 110 & .21 & $-1.54(-3.92$ to 0.84$)$ \\
\hline After 3 months & $38.15(0.88)$ & 102 & $39.06(0.89)$ & 101 & .47 & $-0.90(-3.36$ to 1.55$)$ \\
\hline After 9 months & $37.56(0.89)$ & 98 & $39.43(0.88)$ & 103 & .14 & $-1.87(-4.34$ to 0.59$)$ \\
\hline
\end{tabular}

SE standard error, $95 \% \mathrm{Cl}$ 95\% confidence interval, BDI Beck Depression Inventory, PCS Physical Component Score, MCS Mental Component Score

Range of the BDI is $0-63$, with 0 as the most favourable outcome; PCS and MCS are standardised scores with a mean of 50 and a standard deviation of 10 in the US general population; higher scores are more favourable *estimates from mixed-model regression analyses, corrected for age, sex, level of education, and baseline value of the outcome measure

t Data on education was missing for 2 persons

No significant two-way or three-way product terms of disease with group and time were found in the analyses with BDI and PCS (data not shown). For MCS, there was a significant product term with disease. The group*disease term was significant ( $p$ value 0.08 ), indicating a different effect of the intervention in DM patients than in COPD patients. Table 4 presents the results of the MCS analyses stratified by disease. The stratified analyses revealed that in DM patients, the intervention group had higher overall scores on the MCS than the control group, with a statistically significant difference at the last follow-up (mean MCS difference 3.85, $F=5.324, d f=1,268.62, p$ value 0.02). For COPD patients, no effect on MCS was found. 
Table 5 shows improvement rates in depressive symptoms $(\geq 50$ reduction relative to baseline BDI score) and ORs for both groups. The intervention group had a significantly higher improvement rate at the last follow-up than the control group, with a significant odds ratio (OR 3.22; $95 \% \mathrm{Cl} 1.31-7.89)$. No interaction between group and disease was found (data not shown).

Table 4. Outcomes of disease-stratified analyses of the Mental Component Scores

\begin{tabular}{|c|c|c|c|c|c|c|}
\hline & \multicolumn{2}{|l|}{ Usual Care } & \multicolumn{2}{|l|}{ MPI } & & \multirow{2}{*}{$\begin{array}{c}\begin{array}{c}\text { Mean difference } \\
\text { (Usual care }-\mathrm{MPI})\end{array} \\
\text { Mean }(95 \% \mathrm{Cl})\end{array}$} \\
\hline & Mean $(\mathrm{SE})^{*}$ & $\mathrm{~N}$ & Mean (SE)* & $\mathrm{N}$ & Pvalue & \\
\hline \multicolumn{7}{|l|}{$\mathrm{DM}$} \\
\hline After 1 week & $37.47(1.18)$ & 54 & 40.07 (1.19) & 54 & .12 & $-2.60(-5.90$ to 0.70$)$ \\
\hline After 3 months & $37.15(1.17)$ & 55 & $39.94(1.21)$ & 52 & .10 & $-2.80(-6.11$ to 0.51$)$ \\
\hline After 9 months & $35.87(1.17)$ & 55 & $39.72(1.19)$ & 54 & .02 & $-3.85(-7.14$ to -0.57$)$ \\
\hline \multicolumn{7}{|l|}{ COPD } \\
\hline After 1 week & $39.20(1.25)$ & 55 & $39.70(1.22)$ & 56 & .78 & -0.50 (-3.95 to 2.95$)$ \\
\hline After 3 months & $39.35(1.33)$ & 47 & $38.22(1.30)$ & 49 & .55 & $1.12(-2.55$ to 4.80$)$ \\
\hline After 9 months & $39.67(1.37)$ & 43 & $39.22(1.29)$ & 49 & .81 & $0.45(-3.27$ to 4.17$)$ \\
\hline \multicolumn{7}{|c|}{$\begin{array}{l}\text { SE standard error, } 95 \% \mathrm{Cl} 95 \% \text { confidence interval, DM type II diabetes mellitus, COPD chronic obstructive } \\
\text { pulmonary disease } \\
\text { MCS is a standardised score with a mean of } 50 \text { and a standard deviation of } 10 \text { in the US general population; } \\
\text { higher scores are more favourable. }\end{array}$} \\
\hline
\end{tabular}

Table 5. Percentages and odds ratios for improvement* on the depression outcome.

\begin{tabular}{lccc}
\hline & \multicolumn{2}{c}{ BDI improvement rate } & OR $(95 \% \mathrm{Cl})+$ \\
\cline { 2 - 3 } & $\mathrm{N}(\%)$ & $\mathrm{N}(\%)$ & \\
\hline After 1 week & $10(7.4)$ & $8(6.3)$ & $0.58(0.18-1.88)$ \\
After 3 months & $11(8.7)$ & $14(12.4)$ & $1.49(0.58-3.84)$ \\
After 9 months & $9(7.3)$ & $20(17.5) \neq$ & $3.22(1.31-7.89)$ \\
\hline
\end{tabular}

*defined as a reduction of baseline BDI score by at least $50 \%$

† from logistic regression corrected for age, sex, educational level, time, and baseline BDI value; control group is reference category

$\neq \mathrm{P}$ value .02

\section{DISCUSSION}

Our nurse-led intervention significantly reduced depressive symptoms in chronically ill elderly patients with minor or mild to moderate major depression at three and nine months after the intervention. BDI improvement rates were significantly higher in the intervention patients than in the controls at the last follow-up. Although we expected effects on quality of life in all patients, a significant effect was only found on the mental component score in DM patients at the last follow-up.

Several aspects should be taken into account when interpreting our results. First, as expected, we had an overall dropout rate of $33 \%$, with slightly more dropouts in the intervention group than in the control group, but this difference was not significant. In the analyses, however, we used a mixed model for repeated measures, which uses all available data for each patient. Although we can not completely rule out bias from 
attrition, the absence of differences in baseline BDI depression scores between dropouts and non-drop-outs and the fact that intervention and control group continued to be comparable over time, does not make attrition bias plausible. Second, blinding of patients obviously was not possible, as we compared the intervention with usual care, as is often done in pragmatic trials. ${ }^{32}$

The results of the depression outcome are in line with outcomes of previous studies evaluating psychological interventions in chronically ill elderly patients. Several smaller trials found that $\mathrm{CBT}^{9}{ }^{9}$ interpersonal counselling, ${ }^{8}$ and self-management, ${ }^{12}$ reduced depression in chronically ill elderly, but one study only evaluated short-term effects and included both depressed and non-depressed patients. ${ }^{9}$ The PEARLS study evaluated a program including Problem Solving Therapy in chronically ill elderly persons with minor depression or dysthymia and found an OR of 5.2 for a $50 \%$ improvement of the depression score. ${ }^{7}$ Neither of the abovementioned studies, however, were performed in primary care settings, nor did these studies assign primary care nurses for the administration of the intervention.

In our study, differences between groups in BDI score were relatively small, as were improvement rates. This illustrates how persistent depressive symptoms in elderly populations are. ${ }^{33}$ Nevertheless, BDI effect sizes were 0.26 at the second and 0.29 at the third follow-up (not tabulated), which can be regarded as small to medium-sized effects. ${ }^{34}$ Furthermore, the OR for BDI improvement at the last follow-up revealed a threefold higher probability of improvement in intervention patients than in controls. Also, in patient with diabetes, there were consistent positive intervention effects on quality of life, which reached statistical significance at the last follow-up, with a medium effect size of 0.45 (not tabulated).

According to some, much of the effect of psychological treatments can be attributed to the effects of patients receiving extra attention. ${ }^{4}$ However, if the effects of our intervention were solely attributable to the extra attention, we would have expected to see an effect immediately at the first follow-up. However, we only found effects in the longer term. Since our intervention is a short cognitive behavioral skill-based program, the most plausible explanation is that patients gained skills and continued to apply them in daily life during the follow-up period. As a result, their depression did not deteriorate during follow-up, and as depressive symptoms in the control group slightly deteriorated over time, this led to significant differences at later followup. It is not unlikely, that intervention patients will continue to improve over a longer time interval if patients continue to increase their skills and become more confident self managers. Two comparable studies also found that effects became more pronounced during longer follow-up. ${ }^{811} 12$

Trained nurses played a major role in our study, both in diagnosing depression and in administering the intervention at the patient's home. However, incorporating the intervention in the disease and care management programs of primary care facilities in the Dutch setting will probably mean that patients will not be visited at home. Since patients with chronic illnesses already come to primary care facilities for their regular check-ups, this should not represent a barrier to patients. Furthermore, having practice nurses deliver the intervention has several advantages: they see 
individual patients on a regular basis, they are aware of the patients' personal circumstances and health-related problems, they can be trained to assess depression using diagnostic interviews, ${ }^{35}$ and more importantly, they can monitor a possible relapse of depression and take action if necessary.

With the aging of the population in Western society, the number of elderly patients with a chronic illness is expected to increase. This will put further pressure on health care systems in general, and on primary care, in particular. It is important that patients do not fall victim to the negative consequences of a comorbid depression as well, as this may have a substantial adverse impact on the course of their somatic illness and hence on their quality of life. Therefore, early detection of depressive disorders in chronically ill elderly persons is important and screening methods should be incorporated in their regular care. Minimal interventions like our MPI, which (1) provide patients with the skills to cope with the consequences of their illness and their depressive symptoms, (2) can be incorporated in existing disease and care management programs, and (3) can be administered by nurses (e.g. practice nurses), can play a major role in preventing further deterioration of patients and may help alleviate the burden on the health care system. The modest, but positive results from the current effectiveness study, and the positive results from an extensive process evaluation, revealing high patient satisfaction, ${ }^{23}$ strengthen our belief that the DELTA intervention may be well suited for implementation within existing disease and care management programs for DM and COPD in primary care.

\section{Conclusion}

Our relatively short psychological intervention, administered by a nurse, reduced depressive symptoms in chronically ill elderly patients with minor depression and mild to moderate major depression and improved quality of life in elderly DM patients. The intervention thus appears to have a generic effect on depression, but the effect on quality of life might be disease-specific. Given the findings from the current effectiveness-study (medium effect sizes and a pattern of increasing effects over longer time) and the positive results from process evaluation, opportunities for implementing the intervention in existing disease management programs should be explored, while awaiting results from the economic evaluation. Furthermore, patient characteristics and traits that predict response to treatment should be identified and recognition of depression in chronically ill elderly people in primary care should be further improved. To conclude, our intervention appears an effective and acceptable treatment for minor depression and mild to moderate major depression and may be a valuable addition to existing disease management programs for older patients.

\section{Acknowledgements}

We thank Kitty Daemen, Henny Geelen, Francine Hendriks, and Mieke Witte, for administering the intervention with dedication and enthusiasm, Wendy Engering for her contribution to the patient recruitment and Dorien Mintjes for her contribution 
to the data entry, as well as MEMIC (Centre for Data and Information Management, Maastricht University) for providing us with a data management system. This study was funded by the Netherlands Organisation for Health Research and Development (ZonMw), Health Care Efficiency Research Program, grant number 945-03-047. 


\section{REFERENCES}

1. Djernes JK. Prevalence and predictors of depression in populations of elderly: a review. Acta Psychiatr Scand 2006;113(5):372-87.

2. Cuijpers P, van Straten A, Smit F. Psychological treatment of late-life depression: a meta-analysis of randomized controlled trials. Int. J. Geriatr. Psychiatry 2006;21(12):1139-49.

3. Pinquart M, Duberstein PR, Lyness JM. Treatments for later-life depressive conditions: a meta-analytic comparison of pharmacotherapy and psychotherapy. Am. J. Psychiatry 2006;163(9):1493-501.

4. McCusker J, Cole M, Keller E, Bellavance F, Berard A. Effectiveness of treatments of depression in older ambulatory patients. Arch. Intern. Med. 1998;158(7):705-12.

5. Bogner HR, Cary MS, Bruce ML, Reynolds CF, 3rd, Mulsant B, Ten Have T, et al. The role of medical comorbidity in outcome of major depression in primary care: the PROSPECT study. Am / Geriatr Psychiatry 2005;13(10):861-8.

6. Harpole LH, Williams JW, Jr., Olsen MK, Stechuchak KM, Oddone E, Callahan CM, et al. Improving depression outcomes in older adults with comorbid medical illness. Gen Hosp Psychiatry 2005;27(1):4-12.

7. Ciechanowski P, Wagner E, Schmaling K, Schwartz S, Williams B, Diehr P, et al. Community-integrated home-based depression treatment in older adults: a randomized controlled trial. JAMA 2004;291(13): 1569-77.

8. Mossey JM, Knott KA, Higgins M, Talerico K. Effectiveness of a psychosocial intervention, interpersonal counseling, for subdysthymic depression in medically ill elderly. J. Gerontol. A. Biol. Sci. Med. Sci. 1996;51(4):M172-8.

9. Kunik ME, Braun U, Stanley MA, Wristers K, Molinari V, Stoebner D, et al. One session cognitive behavioural therapy for elderly patients with chronic obstructive pulmonary disease. Psychol. Med. 2001;31(4):717-23.

10. Emery CF, Schein RL, Hauck ER, Maclntyre NR. Psychological and cognitive outcomes of a randomized trial of exercise among patients with chronic obstructive pulmonary disease. Health Psychol. 1998;17(3):232-40.

11. Brody BL, Roch-Levecq AC, Thomas RG, Kaplan RM, Brown SI. Self-management of age-related macular degeneration at the 6-month follow-up: a randomized controlled trial. Arch Ophthalmo/2005;123(1):46-53.

12. Brody BL, Roch-Levecq AC, Kaplan RM, Moutier CY, Brown SI. Age-related macular degeneration: selfmanagement and reduction of depressive symptoms in a randomized, controlled study. J Am Geriatr SoC 2006;54(10):1557-62.

13. Hunkeler EM, Meresman JF, Hargreaves WA, Fireman B, Berman WH, Kirsch AJ, et al. Efficacy of nurse telehealth care and peer support in augmenting treatment of depression in primary care. Arch Fam Med 2000;9(8):700-8.

14. Mynors-Wallis LM, Gath DH, Day A, Baker F. Randomised controlled trial of problem solving treatment, antidepressant medication, and combined treatment for major depression in primary care. BMJ 2000;320(7226):26-30.

15. Lamers F, Jonkers CC, Bosma H, Diederiks JP, van Eijk JT. Effectiveness and cost-effectiveness of a minimal psychological intervention to reduce non-severe depression in chronically ill elderly patients: the design of a randomised controlled trial [ISRCTN92331982]. BMC Public Health 2006;6(1):161.

16. Lorig KR, Sobel DS, Stewart AL, Brown BW, Jr., Bandura A, Ritter P, et al. Evidence suggesting that a chronic disease self-management program can improve health status while reducing hospitalization: a randomized trial. Med Care 1999;37(1):5-14.

17. Lorig KR, Holman H. Self-management education: history, definition, outcomes, and mechanisms. Ann Behav Med 2003;26(1):1-7.

18. Spitzer RL, Kroenke K, Williams JB. Validation and utility of a self-report version of PRIME-MD: the PHQ primary care study. Primary Care Evaluation of Mental Disorders. Patient Health Questionnaire. JAMA 1999;282(18):1737-44.

19. Sheehan DV, Lecrubier Y, Sheehan KH, Amorim P, Janavs J, Weiller E, et al. The Mini-International Neuropsychiatric Interview (M.I.N.I.): the development and validation of a structured diagnostic psychiatric interview for DSM-IV and ICD-10. J. Clin. Psychiatry 1998;59 Suppl 20:22-33.

20. Hamilton M. A rating scale for depression. J. Neurol. Neurosurg. Psychiatry 1960;23:56-62. 
21. Williams JW, Jr., Noel PH, Cordes JA, Ramirez G, Pignone M. Is this patient clinically depressed? JAMA 2002;287(9):1160-70.

22. Van Eijk JT, Diederiks JP, Kempen Gl, Honig A, van der Meer K, Brenninkmeijer WJ. Development and feasibility of a nurse administered strategy on depression in community-dwelling patients with a chronic physical disease. Patient Educ. Couns. 2004;54(1):87-94.

23. Jonkers CCM, Lamers F, Bosma H, Metsemakers JF, Kempen GIJM, van Eijk JTM. Process evaluation of a minimal psychological intervention to reduce depression in chronically ill elderly persons. Patient Educ. Couns. 2007;68(3):252-257.

24. Geijer RMM, van Schayk CP, van Weel C, Sachs APE, van der Zwan ACC, Bottema BJAM, et al. NHGStandaard COPD en Astma bij Volwassenen: Behandeling [NHG Practice Guideline COPD: Treatment]. Huisarts Wet 1997;40:430-442.

25. Geijer RMM, Thiadens HA, Smeele IJM, Sachs APE, Bottema BJAM, van Hensbergen W, et al. NHGStandaard COPD en Astma bij Volwassenen: Diagnostiek [NHG Practice Guideline COPD: Diagnosis]. Huisarts Wet 2001;44(3):107-117.

26. Rutten GEHM, De Grauw WJC, Nijpels G, Goudswaard AN, Uitewaal PJM, Van der Does FEE, et al. NHGStandaard Diabetes mellitus type 2 [NHG Practice Guideline Diabetes mellitus type 2]. Huisarts Wet 2006;49(3):137-152.

27. Beck AT, Steer RA, Garbin MG. Psychometric properties of the Beck Depression Inventory: Twenty-five years of evaluation. Clinical Psychology Rev. 1988;8(1):77-100.

28. Beck AT, Ward CH, Mendelson M, Mock J, Erbaugh J. An inventory for measuring depression. Arch. Gen. Psychiatry1961;4:561-571.

29. Depression Guideline Panel. Depression in Primary Care: volume 2. Treatment of Major Depression. Clinical Practice Guideline, number 5. Rockwille, M.D.: U.S. Department of Health and Human Services, Public Health Service, Agency for Health Care Policy and Research. AHCPR publication no. 93-0551, 1993.

30. Aaronson NK, Muller M, Cohen PD, Essink-Bot ML, Fekkes M, Sanderman R, et al. Translation, validation, and norming of the Dutch language version of the SF-36 Health Survey in community and chronic disease populations. J Clin Epidemio/1998;51(11):1055-68.

31. Pocock S. Clinical trials: A Practical Approach. Chichester: John Wiley and Sons, 1983.

32. Hotopf M. The pragmatic randomised controlled trial. Adv Psychiatr Treat 2002;8(5):326-333.

33. Beekman AT, Geerlings SW, Deeg DJ, Smit JH, Schoevers RS, de Beurs E, et al. The natural history of latelife depression: a 6-year prospective study in the community. Arch Gen Psychiatry 2002;59(7):605-11.

34. Cohen J. Statistical power analysis for the behavioral sciences. 2nd ed. Hillsdale, NJ: Lawrence Erlbaum Associates, 1988.

35. Hedlund M, Stalenheim G, Ekselius L, Carlsson M. Diagnostic agreement between a doctor and a nurse for psychiatric disorders: a pilot study. Nord J Psychiatry 2005;59(5):339-42. 



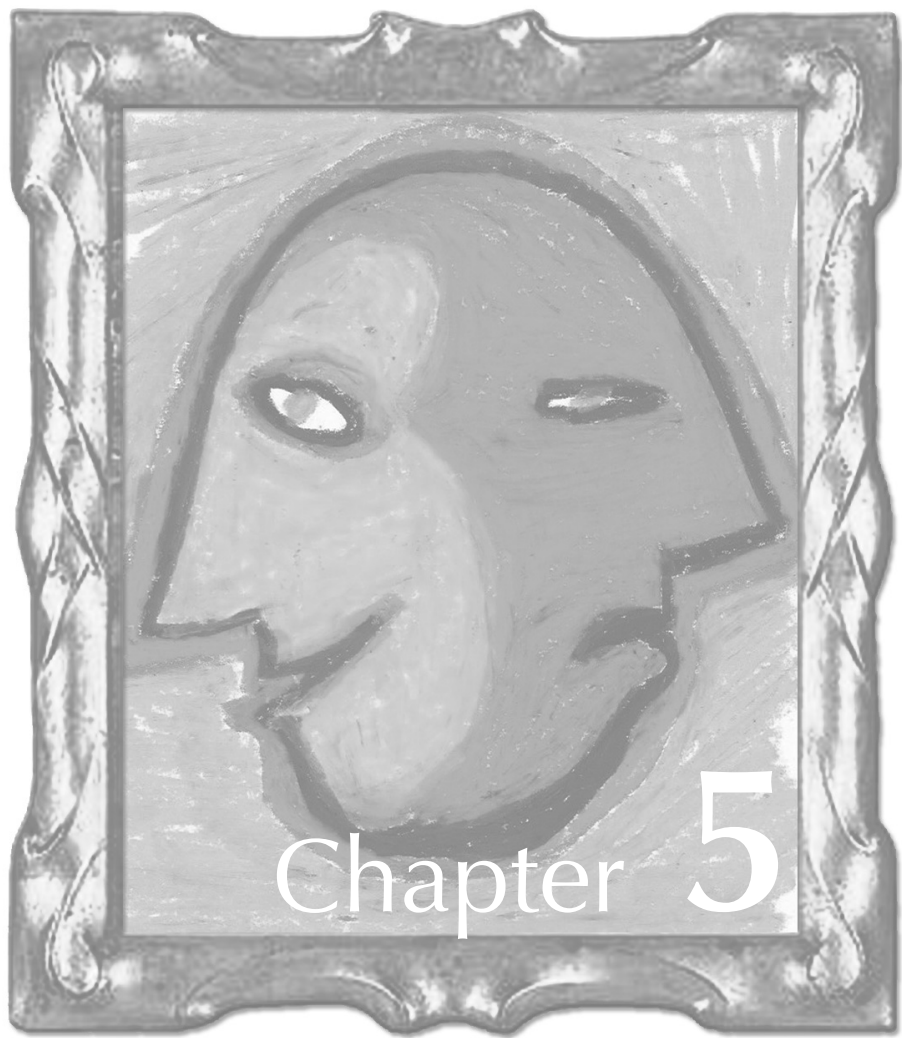

A minimal psychological intervention to treat depression in the chronically ill elderly: does it improve self-management beliefs and behaviors? 


\section{ABSTRACT}

Objective To examine the effects of a minimal psychological intervention (MPI) on self-efficacy, anxiety, daily functioning, and social participation in chronically ill elderly people with co-occurring depression.

Methods The DELTA study is a two-armed randomised controlled trial. Patients were recruited from 89 primary care practices in the Netherlands. Three hundred and sixtyone patients, aged 60 years and older, with diabetes or chronic obstructive pulmonary disease and co-occurring minor, mild or moderate depression were included in the study. One hundred and eighty-three patients were randomised to the intervention group and 178 to the control group. During a three-month period, patients allocated to the intervention group received a nurse-led minimal psychological intervention based on principles of cognitive behavioral therapy and self-management. Patients allocated to the control group received usual care. Self-efficacy, anxiety, daily functioning, and social participation were measured at baseline (before randomisation) and at one week, three months, and nine months after the intervention period.

Results At nine months after treatment, the MPI -compared with usual care- was associated with less anxiety $(p=.005)$ and better self-efficacy skills $(p=.02)$, daily functioning $(p=.003)$, and social participation $(p=.003)$. Differences between the two groups were primarily due to stabilization of outcomes in the intervention group and deterioration in the control group.

Conclusion The intervention proved to be effective and is a valuable tool to improve care for elderly patients with a chronic disease. We recommend implementation of our intervention within existing disease and care management programs for chronically ill patients in primary care. 


\section{INTRODUCTION}

Chronic diseases, such as type 2 diabetes mellitus (DM) and chronic obstructive pulmonary disease (COPD), are increasingly common and place a large burden on patients. Many patients face permanent limitations that cause a disruption of their normal life. The chronically ill patients are confronted with various threatening changes in life-style, physical functioning, and future perspectives. ${ }^{1}$ The physical problems, such as reduced mobility, pain, and shortness of breath, can limit patients in their daily functioning. Patients are thus forced to learn how to cope with their disease. Problems of coping with a chronic disease (or its consequences) are similar across patients with different chronic diseases, as they face similar changes in their lives. $^{23}$ The limitations they experience can easily provoke negative thoughts about their opportunities for social participation, which in turn negatively influence their daily functioning. Not surprisingly, many patients with chronic diseases develop symptoms of depression and become victims of a downward spiral, indicating a maladaptive reaction to their taxing circumstances. ${ }^{4-6}$ Such depressive feelings are especially common among elderly patients. ${ }^{7}$

A minimal psychological intervention (MPI) has been developed that aims to reduce symptoms of depression and anxiety, and related cognitions and behaviors, in chronically ill elderly persons by breaking through this negative spiral. ${ }^{8}$ In the Depression in Elderly with Long-Term Afflictions (DELTA) study, the MPI was tested in a primary care setting, using primary care nurses. The MPI is based on principles of self-management and cognitive behavioral therapy (CBT). The intervention involves exploring links between negative cognitions about the ability to function in daily life and the related behaviors, after which negative cognitions and behaviors are transformed into positive ones by applying reattribution techniques and action planning. Patients are stimulated to think about desirable behaviors and to describe their experiences when engaging in this desirable behavior. By applying these techniques the MPI aims at behavioral change and increased self-confidence through changing beliefs about self-efficacy. It intends to teach chronically ill patients to independently and autonomously explore solutions for their (health-related) problems in daily life and become an active self-manager.

Previously, we demonstrated that the MPI is effective in reducing depression in chronically ill elderly persons with co-morbid depression. ${ }^{9}$ Here, we report on the effectiveness of the MPI regarding improvement in self-management beliefs and behaviors. Improved self-confidence is expected to be reflected in increased selfefficacy. Furthermore, a self-confident self-manager will not be guided by feelings of anxiety. These factors are preconditions for the exploration of positive and desirable behaviors. Improvements in daily functioning and participation reflect the intended change in behavior. By improving daily functioning and social participation, the positive behavior is reinforced which falsifies negative cognitions. We hypothesized that the MPI would be more effective in improving self-efficacy, anxiety, daily func- 
$\mathbf{6 4} \mid$

tioning, and social participation than care as usual. Because patients with DM and COPD probably face similar coping problems, we expected our intervention to be generic across chronic diseases. To assess this, we also examined whether the type of chronic disease modified the effects of the MPI.

\section{METHODS}

\section{Design}

The DELTA study is a two-armed randomised controlled trial with measurements at baseline (before randomisation) and at one week, three months, and nine months after the intervention period (trial registration: ISRCTN92331982). Time between the baseline and first-follow-up measurement depended upon the time it took to complete the tailor-made intervention. In the control group, the first follow-up measurement was set at six weeks after baseline, which was estimated beforehand to be the mean duration of the intervention in the intervention group. A block randomisation scheme was used, with stratification for the type of chronic disease and the general practice where the patients had been recruited. The block size was two, because we expected to include a small number of patients per general practice and wanted to have them equally distributed over the groups. The researchers entered patients in a computer connected to an external agency, which performed the randomisation using a computerized random number generator. All data were collected through self-administered questionnaires. Data entry was performed by researchers blinded for the allocation. Approval for conducting the DELTA study was granted by the Medical Ethics Committee of the Maastricht University/University Hospital Maastricht. A detailed description of the design of the DELTA study has been published elsewhere. ${ }^{10}$

\section{Study population}

Participants were recruited in 89 primary care practices in the south of the Netherlands between October 2003 and May 2005. We selected all patients from those practices with an established diagnosis of DM or COPD, based on ICPC codes, who were 60 years or over. The DELTA research team sent the Patient Health Questionnaire (PHQ-9) ${ }^{11}$ to patients who were community-dwelling and did not meet exclusion criteria (treatment with antidepressants for depression, major psychiatric problems, current psychosocial/psychiatric treatment, serious cognitive problems, being on a waiting list for nursing home, being bedridden, loss of spouse within the last three months, and not being fluent in Dutch). Patients who reported having at least two symptoms of depression present for more than half of the days, one of them being loss of interest or depressed mood, were invited to take part in a structured diagnostic interview for DSM-IV axis I disorders, the Mini International Neuropsychiatric 
Interview (MINI). ${ }^{12}$ In addition, the Hamilton Depression Rating Scale (HDRS) was used to determine the severity of the depression. ${ }^{13}$

The MINI and HDRS were administered at the patients' home by trained research nurses. Patients with minor depression, mild to moderate major depression, or dysthymia were invited to participate in the trial. Patients with suicidal risk and patients with severe major depression (HDRS>18) were excluded and referred to their general practitioner. After signing an informed consent form and completing a baseline questionnaire, 361 patients (185 DM; 176 COPD) were randomly allocated to the MPI or usual care (Figure 1).

\section{Intervention}

Patients allocated to the intervention group received the MPI additionally to usual care. The intervention was delivered at the patients' home by research nurses who had been trained to administer the DELTA intervention. Patients were allocated to a different nurse than the one who had diagnosed the patient. The intervention is based on principles of CBT and self-management and consists of five phases, which have been described in more detail elsewhere. ${ }^{8}{ }^{10}$ Briefly, phase one involves the nurse exploring the patient's feelings, cognitions, and behaviors. During phase two, patients keep a diary, in which they record symptoms, complaints, thoughts, worries, and related feelings and behaviors. In phase three, patients are challenged to link their mood and cognitions to the consequent behavior, using information from the diary. The self-management approach is introduced in phase four, where patients explore possibilities to alter their behavior and where they draw up an action plan. Phase five consists of an evaluation of the degree to which goals from the action plan have been achieved. The intervention is tailor-made and a home visit could address one or more phases, depending on the progress. During the study, patients received two to ten visits over a maximum of three months. The mean number of visits was four, with a mean duration of 61 minutes. ${ }^{14}$ Patients assigned to usual care received regular treatment from their GP or practice nurse according to the practice guidelines for their chronic disease.

\section{Measures}

Information on demographic factors (age, gender, education) was collected during the PHQ-9 screening. Self-efficacy was defined as a person's belief in his or her ability to organize and execute certain behaviors that may lead to desired outcomes such as improved health. It was assessed using the 12 -item Self-Efficacy scale. ${ }^{15}{ }^{16}$ Scores range from 12 to 60 , and patients with higher scores have higher levels of self-efficacy. Anxiety was assessed using the anxiety subscale from the Symptom Checklist (SCL90). ${ }^{17}$ This subscale ranges from 10 to 50 , and patients with higher scores have more anxiety. Daily functioning was assessed with the Activities of Daily Living scale (ADL) from the Groningen Activity Restriction Scale (GARS). ${ }^{18}$ This scale ranges from 11 to 44 and higher scores reflect poorer daily functioning. Social participation was assessed 
using the questions from the Autonomy Outdoors domain of the Impact on Participation and Autonomy questionnaire (IPA). ${ }^{19} 20$ The Autonomy Outdoors domain includes five questions asking whether patients are able to attend social activities in a desired frequency and manner. Scores in this domain range from 5 to 25 , and higher scores reflect less social participation.

Missing items on the Self-Efficacy scale and GARS were imputed using the individual mean score of items that were not missing in patients for whom at least $50 \%$ of items were available. Missing items of the SCL-90 Anxiety scale and the Autonomy Outdoors scale were imputed according to their manuals requiring a $75 \%$ availability of items. The number of imputations across measurements (T0-T1-T2-T4) was 13-6-4-7 for the Self-Efficacy scale, 8-3-7-6 for the SCL-90 Anxiety scale, 5-6-5-4 for the GARS, and 30-13-13-7 for the Autonomy Outdoors scale. Missing follow-up measurements (selfefficacy 6-99-125-125, anxiety 14-103-126-125, daily functioning 2-98-121-123 and social participation 4-103-126-128) were not imputed because of the use of mixed-model statistics, which includes all available data of a patient (see statistical analysis).

\section{Statistical analysis}

The power calculation for the DELTA study was based on depression scores measured with the Beck Depression Inventory, which was the primary outcome, and has been described elsewhere. ${ }^{9}$ Analyses were based on the intention-to-treat principle. The comparability of groups was checked using t-tests and Chi-square tests for demographic and outcome variables. We used a mixed-model, repeated-measures ANCOVA to test for differences between groups at different points in time. In addition, these models were used to detect differences in trend over time between groups (group*time interaction). We included eight fixed effects in our model (age, sex, education level, chronic disease, baseline value of outcome, treatment group, time, and the interaction term between treatment group and time). Several random effects and covariance matrices were then tested, using -2 log likelihood tests to decide which model had the best fit. Finally, two-way and three-way interaction terms for group, time, and disease (DM or COPD) were used to test for effect modification by disease. In line with the literature, we set $\alpha$ at 0.10 to assess statistical significance for the interaction term. ${ }^{21}$ This allowed us to detect all possible differences between the chronic diseases and to address our hypothesis of a generic intervention. A check for outliers was conducted for all four outcomes, but no serious outlier influence was established. 


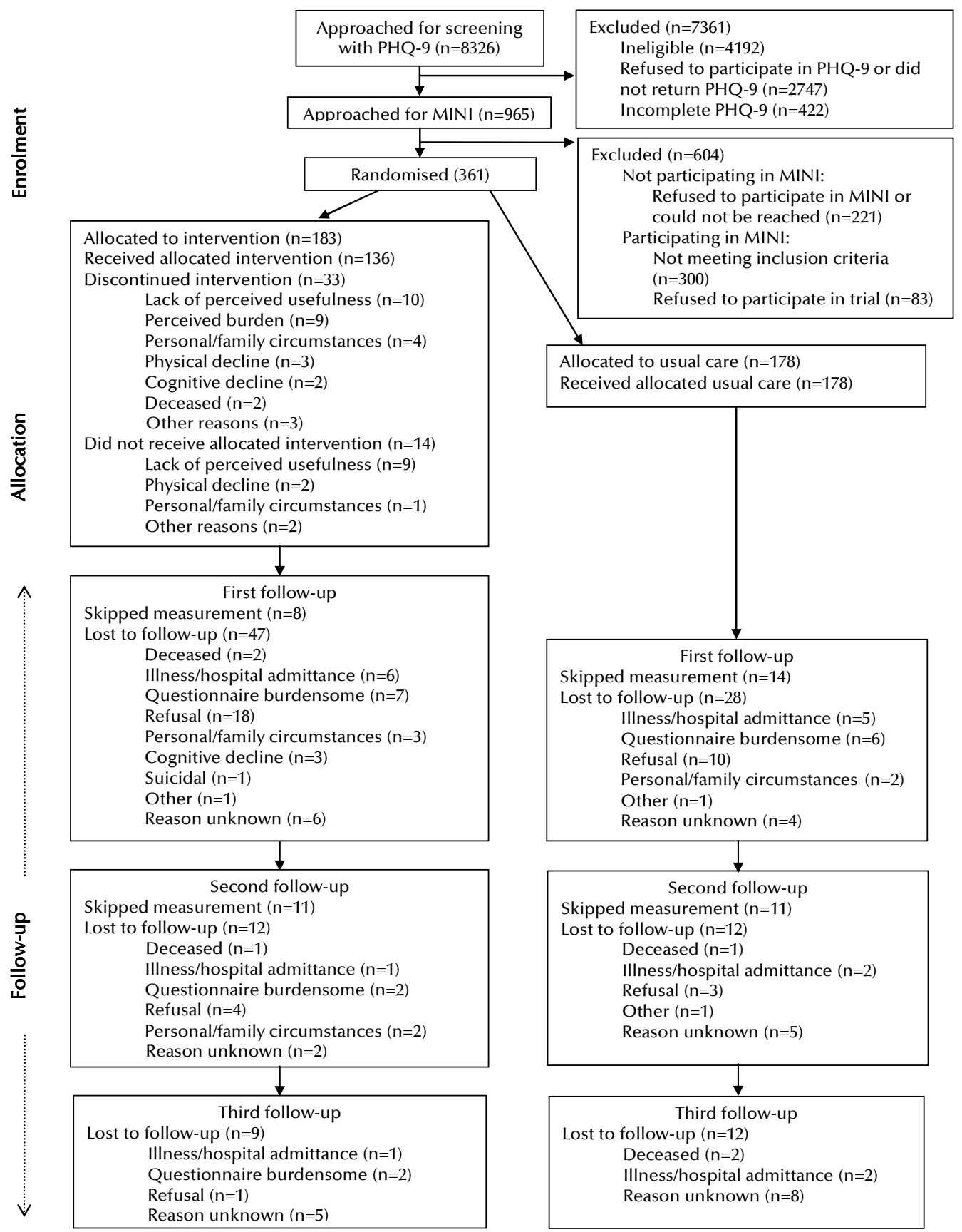

Figure 1. Patient Flow and Follow-Up in the DELTA Study

First follow-up at one week after the intervention, second follow-up at three months after the intervention and third follow-up at nine months after the intervention. 


\section{RESULTS}

Figure 1 describes the patient flow in the study. In total, 8326 patients with DM or COPD received the screening questionnaire, 965 of whom proved eligible for the diagnostic interview (17.3\%). Of these patients, 221 (23\%) refused to participate in the MINI, or could not be reached. A comparison of participants $(n=744)$ and nonparticipants $(n=221)$ revealed no differences between these groups regarding gender, age, educational level, or PHQ-9 sum score. The 83 patients who were eligible according to the MINI, but who refused to participate in the trial, were more likely to be female and older, and had a significantly lower educational level. In total, 361 patients were randomised; 183 to the intervention and 178 to usual care.

Table 1. Comparability of Intervention and Control Groups in Terms of Socio-Demographic Variables and Baseline Values of Outcomes

\begin{tabular}{|c|c|c|c|}
\hline & $\begin{array}{c}\text { Usual Care } \\
\mathrm{n}=178\end{array}$ & $\begin{array}{c}\text { MPI } \\
\mathrm{n}=183\end{array}$ & Pvalue \\
\hline Age, yrs (SD) & $70.6(6.8)$ & $70.8(6.5)$ & .73 \\
\hline \multicolumn{4}{|l|}{ Sex, No. (\%) } \\
\hline Male & $95(53.4)$ & 98 (53.6) & .97 \\
\hline Female & $83(46.6)$ & $85(46.4)$ & \\
\hline \multicolumn{4}{|l|}{ Chronic disease, No. (\%) } \\
\hline Diabetes type 2 & $94(52.8)$ & $91(49.7)$ & .56 \\
\hline COPD & $84(47.2)$ & $92(50.3)$ & \\
\hline \multicolumn{4}{|l|}{ Education level*十, No. (\%) } \\
\hline Low & $60(33.9)$ & $64(35.4)$ & .55 \\
\hline Medium & $46(26.0)$ & $54(29.8)$ & \\
\hline High & $71(40.1)$ & $63(34.8)$ & \\
\hline Self-efficacy, mean (SD)* $\ddagger$ & $48.9(7.9)$ & $49.0(8.3)$ & .91 \\
\hline Anxiety, mean $(\mathrm{SD}) * \neq$ & $20.3(7.1)$ & $20.5(6.7)$ & .83 \\
\hline Daily functioning, mean $(\mathrm{SD})^{*} \ddagger$ & $16.6(5.2)$ & $16.6(5.5)$ & .91 \\
\hline Participation, mean $(\mathrm{SD})^{*} \ddagger$ & $10.6(4.5)$ & $10.1(4.5)$ & .34 \\
\hline
\end{tabular}

SD standard deviation, MPI minimal psychological intervention

* Missing data: education $n=3$; self-efficacy $n=6$; anxiety $n=14$; daily functioning $n=2$; participation $n=4$

+ Low refers to primary school only, medium refers to lower vocational training or lower general education, high refers to higher vocational training, secondary school, higher professional education and university training

‡ Self-efficacy range 12-60, higher scores reflect more self-efficacy skills; Anxiety range 10-50, higher scores reflect more anxiety; Daily functioning range 11-44, higher scores reflect poorer daily functioning; Participation range 5-25, higher scores reflect less participation

The dropout rate throughout the follow-up was higher in the intervention group than in the control group, but the difference was not significant (38\% vs. $30 \%, p=0.11)$. Dropout was only associated with higher age $(p<.000)$, in that dropouts were on average 2.8 years older than patients who remained in the study. As shown in Table 1, the intervention and control groups were comparable in terms of baseline characteristics and the baseline values of the outcome measures.

Results from the mixed-model ANCOVA analyses (Table 2) showed that patients in the control group had poorer scores on all outcomes than patients in the intervention 
group. Significant differences were predominantly observed at the third follow-up. Differences in self-efficacy between the intervention and control groups were found at second $(\mathrm{p}=.04)$ and third $(\mathrm{p}=.02)$ follow-up, where the intervention group had more self-efficacy skills than their counterparts. As regards anxiety, the analysis revealed that the control group seemed to deteriorate, while the intervention group remained stable. The difference between the intervention and control groups reached significance at the last follow-up. Daily functioning was poorer for patients in the control group than those in the intervention group. This finding was consistent across all follow-up measurements and reached significance at the second $(p=.002)$ and third $(p=.003)$ follow-up assessments. As regards social participation, the control group perceived significantly less participation than the intervention group at the last follow-up $(p=.003)$. The trend over time for the intervention and control group, indicated by the interaction term between treatment group and time, proved to be significantly different for anxiety $(p=.03$; not tabulated) and daily functioning $(p=.05$; not tabulated). The group*time interaction terms were non-significant for self-efficacy and social participation.

Table 2. Outcomes on Self-Efficacy, Anxiety, Daily Functioning, and Participation at Follow-Up

\begin{tabular}{|c|c|c|c|c|}
\hline Outcome & $\begin{array}{c}\text { Usual Care } \\
\mathrm{N}=178 \\
\text { Mean }(95 \% \mathrm{Cl})^{*}\end{array}$ & $\begin{array}{c}\mathrm{MPI} \\
\mathrm{N}=183 \\
\text { Mean }(95 \% \mathrm{Cl})^{*}\end{array}$ & $\begin{array}{l}\text { Mean difference } \\
\text { Usual care - MPI } \\
\text { Mean }(95 \% \mathrm{Cl})^{*}\end{array}$ & Pvalue* \\
\hline \multicolumn{5}{|l|}{ Self-efficacy $\dagger$} \\
\hline After 1 week & 48.8 (47.8 to 49.7$)$ & $50.0(49.0$ to 51.0$)$ & $-1.2(-2.5$ to 0.2$)$ & .08 \\
\hline After 3 months & 48.1 (47.1 to 49.0$)$ & $49.6(48.5$ to 50.6$)$ & $-1.5(-3.0$ to -0.1$)$ & .04 \\
\hline After 9 months & 48.4 (47.3 to 49.5$)$ & $50.3(49.1$ to 51.4$)$ & $-1.8(-3.4$ to -0.2$)$ & .02 \\
\hline \multicolumn{5}{|l|}{ Anxietyt } \\
\hline After 1 week & 20.9 (20.0 to 21.9$)$ & 20.6 (19.6 to 21.6 ) & 0.3 (-1.1 to 1.7$)$ & .64 \\
\hline After 3 months & 21.8 (20.7 to 22.8 ) & 20.6 (19.5 to 21.7$)$ & $1.1(-0.4$ to 2.6$)$ & .14 \\
\hline After 9 months & 22.8 (21.7 to 24.0 ) & 20.4 (19.1 to 21.6$)$ & 2.5 (0.7 to 4.2 ) & .005 \\
\hline \multicolumn{5}{|l|}{ Daily functioningt } \\
\hline After 1 week & 16.7 (16.1 to 17.3$)$ & $16.4(15.7$ to 17.1$)$ & 0.3 (-0.6 to 1.2$)$ & .53 \\
\hline After 3 months & 17.8 (17.1 to 18.4$)$ & 16.3 (15.6 to 16.9$)$ & 1.5 (0.6 to 2.4$)$ & .002 \\
\hline After 9 months & 18.5 (17.8 to 19.3$)$ & 16.8 (16.1 to 17.6$)$ & 1.7 (0.6 to 2.7 ) & .003 \\
\hline \multicolumn{5}{|l|}{ Participationt } \\
\hline After 1 week & 10.5 (10.0 to 11.1$)$ & 9.9 (9.4 to 10.5$)$ & 0.6 (-0.1 to 1.4$)$ & .10 \\
\hline After 3 months & 10.9 (10.4 to 11.5$)$ & 10.2 (9.6 to 10.8 ) & 0.7 (-0.1 to 1.5$)$ & .08 \\
\hline After 9 months & 11.3 (10.7 to 11.9$)$ & 10.0 (9.3 to 10.6$)$ & 1.3 (0.4 to 2.2$)$ & .003 \\
\hline
\end{tabular}

$\mathrm{Cl}$ confidence interval, MPI minimal psychological intervention

* Adjusted for age, sex, level of education, chronic disease, and baseline value of the outcome measure

† Self-efficacy range 12-60, higher scores reflect more self-efficacy skills; Anxiety range 10-50, higher scores reflect more anxiety; Daily functioning range 11-44, higher scores reflect poorer daily functioning; Participation range 5-25, higher scores reflect less participation

No significant three-way product terms of disease with group and time were found, although we did find significant $(p<.10)$ two-way interaction terms between disease and group for daily functioning $(p=.07)$. Since this indicated a different effect of the intervention in DM patients than in COPD patients, stratified analyses by disease were performed for daily functioning (table 3). The stratified analyses revealed that for COPD patients, differences in daily functioning between the intervention and 
control groups were more profound than for DM patients. However, patterns were the same for both diseases and showed that differences between the intervention and control groups were mainly due to a deterioration of daily functioning in the control group.

Table 3. Outcomes on Daily Functioningt at Follow-Up, Stratified for Type of Chronic Disease

\begin{tabular}{|c|c|c|c|c|}
\hline Outcome & $\begin{array}{c}\begin{array}{c}\text { Usual Care } \\
\mathrm{N}=178\end{array} \\
\text { Mean }(95 \% \mathrm{Cl})^{*}\end{array}$ & $\begin{array}{c}\mathrm{MPI} \\
\mathrm{N}=183 \\
\text { Mean }(95 \% \mathrm{Cl})^{*}\end{array}$ & $\begin{array}{l}\text { Mean difference } \\
\text { Usual care - MPI } \\
\text { Mean }(95 \% \mathrm{CI})^{*}\end{array}$ & Pvalue* \\
\hline \multicolumn{5}{|l|}{ COPD } \\
\hline After 1 week & 16.8 (16.2 to 17.5$)$ & 15.9 (15.3 to 16.6$)$ & 0.9 (-0.3 to 1.8$)$ & .06 \\
\hline After 3 months & 18.1 (17.3 to 19.0$)$ & $16.2(15.3$ to 17.1$)$ & 1.9 (0.7 to 3.2$)$ & .003 \\
\hline After 9 months & 18.8 (17.7 to 19.9$)$ & 16.9 (15.8 to 18.1$)$ & $1.9(0.3$ to 3.5$)$ & .02 \\
\hline \multicolumn{5}{|l|}{ DM type 2} \\
\hline After 1 week & 16.5 (15.5 to 17.6$)$ & 16.9 (15.8 to 18.0$)$ & $-0.4(-1.9$ to 1.1$)$ & .58 \\
\hline After 3 months & $17.4(16.5$ to 18.3$)$ & 16.5 (15.5 to 17.5$)$ & 0.9 (-0.5 to 2.2$)$ & .20 \\
\hline After 9 months & $18.2(17.2$ to 19.2$)$ & 16.9 (15.8 to 18.0$)$ & 1.3 (-0.1 to 2.8$)$ & .08 \\
\hline
\end{tabular}

$\mathrm{Cl}$ confidence interval, MPI minimal psychological intervention

* Adjusted for age, sex, level of education, and baseline value of the outcome measure

t Daily functioning range 11-44, higher scores reflect poorer daily functioning

\section{DISCUSSION}

Our nurse-led intervention is associated with less anxiety and better self-efficacy skills, daily functioning, and social participation in chronically ill elderly patients with minor or mild to moderate major depression. Significant differences between the intervention and control groups were mainly observed at three and nine months after the intervention.

The consistency of the results underlines the robustness of our findings and confirms our belief that the MPI worked as intended. Since effects were not observed at first follow-up, we can refute the claim that the effect of psychological treatments might be attributable to patients receiving extra attention. ${ }^{22}$ Furthermore, effects at longer follow-up could signify an enduring effect. Others have found that psychological treatments might be preferable to antidepressants because of their enduring effect. ${ }^{23}$ ${ }^{24}$ They argue that patients receiving psychological treatments learn to make more accurate appraisals during future events. We should take into account that significant effects at longer follow-up were mainly due to deterioration in the control group and stabilization in the intervention group. In a group of chronically ill elderly people, prevention of further health status deterioration is often the most achievable goal.

The patients who received the MPI reported greater confidence in their ability to organize and engage in health-related behaviors (self-efficacy) than the control group. This is in line with long-term findings from a collaborative care treatment for depressed elderly people in primary care. ${ }^{25}$ Other trials have found that self-efficacy enhancing interventions reduce depressive symptoms, although none of these trials specifically included depressive patients. ${ }^{26-28}$ Self-efficacy has also been found to act both as a mediator and moderator in the relation between depression and chronic illness. $^{129}$ Both CBT and self-management approaches focus on the self-efficacy 
construct as the key mediating factor in improving health-related behaviors. ${ }^{1} 30$ Nevertheless, future studies are needed to shed light on the complex interplay between cognitive emotional factors, self-efficacy, and behaviors related to coping with a chronic disease.

In the DELTA study, we found positive effects for both depression ${ }^{9}$ and anxiety. The prevalence of co-morbidity of anxiety and depression among the elderly is high and the concepts are closely related. ${ }^{31}$ Therefore, interventions that aim to reduce depression are likely to reduce anxious feelings as well. Although our study used depression as selection criteria for inclusion, the intervention is likely to be applicable to all patients with emotional problems in relation to their chronic disease.

As regards daily functioning, we found larger effects for COPD patients than for DM patients, due to a more serious deterioration in the COPD control group. In general, DM can be seen as a gradual progressive illness, with the illness slowly becoming worse, whereas COPD can be regarded as a gradually relapsing condition, with more sudden deteriorations. ${ }^{32}$ It is therefore not surprising that COPD patients show a more severe worsening in daily functioning than DM patients. However, patterns were similar for both diseases, which supports our idea of a generic approach to address depressive feelings across chronic diseases.

Some limitations should be acknowledged. First, as expected, the overall dropout rate in our study was 33\% and dropouts were older than their participating counterparts. Our analyses, however, used a mixed model for repeated measures, which uses all available data for each patient. More importantly, the intervention and control groups did not differ in attrition and in baseline values of the outcome measures. Still, we can not completely rule out bias from attrition. Second, blinding of patients was not possible, as we compared the intervention with usual care. Finally, it could be argued that other factors, such as coping and mastery, should have been considered as outcomes as well. In our study, we choose to include these factors as patient traits (i.e. moderators). The results of these analyses have previously been reported. ${ }^{33}$ However, the inclusion of these factors as moderators instead of mediators remains arbitrary.

Since our intervention was effective in improving self-management beliefs and behaviors, we feel it is a valuable tool to improve primary care for elderly patients with a chronic disease. Our findings are supported by previous findings of the DELTA study on depressive symptoms, as well as by the favourable results of the costeffectiveness study, ${ }^{34}$ and the positive results of an extensive process evaluation, revealing high patient satisfaction. ${ }^{14}$ We therefore recommend that practice nurses be trained in the principles of the intervention and that our intervention be then implemented within existing disease and care management programs for chronically ill patients in primary care. 


\section{REFERENCES}

1. Marks R, Allegrante JP, Lorig K. A review and synthesis of research evidence for self-efficacy-enhancing interventions for reducing chronic disability: implications for health education practice (part I). Health Promot Pract 2005;6(1):37-43.

2. Lorig KR, Sobel DS, Stewart AL, Brown BW, Jr., Bandura A, Ritter P, et al. Evidence suggesting that a chronic disease self-management program can improve health status while reducing hospitalization: a randomized trial. Med Care 1999;37(1):5-14.

3. Lorig KR, Holman H. Self-management education: history, definition, outcomes, and mechanisms. Ann Behav Med 2003;26(1):1-7.

4. Ciechanowski PS, Katon WJ, Russo JE. Depression and diabetes: impact of depressive symptoms on adherence, function, and costs. Arch Intern Med 2000;160(21):3278-85.

5. DiMatteo MR, Lepper HS, Croghan TW. Depression is a risk factor for noncompliance with medical treatment: meta-analysis of the effects of anxiety and depression on patient adherence. Arch Intern Med 2000;160(14):2101-7.

6. Penninx BW, Guralnik JM, Ferrucci L, Simonsick EM, Deeg DJ, Wallace RB. Depressive symptoms and physical decline in community-dwelling older persons. JAMA 1998;279(21):1720-6.

7. Djernes JK. Prevalence and predictors of depression in populations of elderly: a review. Acta Psychiatr Scand 2006;113(5):372-87.

8. Van Eijk JT, Diederiks JP, Kempen GI, Honig A, van der Meer K, Brenninkmeijer WJ. Development and feasibility of a nurse administered strategy on depression in community-dwelling patients with a chronic physical disease. Patient Educ. Couns. 2004;54(1):87-94.

9. Lamers F, Jonkers CCM, Bosma H, Kempen GIJM, Meijer JAMJ, Penninx BWJH, et al. The effectiveness of a minimal psychological intervention in chronically ill elderly patients with depression: a randomised trial (the DELTA-study). submitted.

10. Lamers F, Jonkers CC, Bosma H, Diederiks JP, van Eijk JT. Effectiveness and cost-effectiveness of a minimal psychological intervention to reduce non-severe depression in chronically ill elderly patients: the design of a randomised controlled trial [ISRCTN92331982]. BMC Public Health 2006;6(1):161.

11. Spitzer RL, Kroenke K, Williams JB. Validation and utility of a self-report version of PRIME-MD: the PHQ primary care study. Primary Care Evaluation of Mental Disorders. Patient Health Questionnaire. JAMA 1999;282(18):1737-44.

12. Sheehan DV, Lecrubier $\mathrm{Y}$, Sheehan $\mathrm{KH}$, Amorim $\mathrm{P}$, Janavs J, Weiller E, et al. The Mini-International Neuropsychiatric Interview (M.I.N.I.): the development and validation of a structured diagnostic psychiatric interview for DSM-IV and ICD-10. J. Clin. Psychiatry 1998;59 Suppl 20:22-33.

13. Hamilton M. A rating scale for depression. J. Neurol. Neurosurg. Psychiatry 1960;23:56-62.

14. Jonkers CCM, Lamers F, Bosma H, Metsemakers JF, Kempen GIJM, van Eijk JTM. Process evaluation of a minimal psychological intervention to reduce depression in chronically ill elderly persons. Patient Educ. Couns. 2007;68(3):252-257.

15. Bosscher RJ, Smit JH. Confirmatory factor analysis of the General Self-Efficacy Scale. Behav Res Ther 1998;36(3):339-43.

16. Sherer M, Maddux JE, Mercandante B, Prentice-Dunn S, Jacobs B, Rogers RW. The Self-efficacy Scale: Construction and validation. Psychological Reports 1982;51(2):663-671.

17. Arrindel WA, Ettema JHM. SCL-90: Handleiding bij een multidimensionele psychopathalogie-indicator. Lisse: Swets en Zeitlinger B.V., 1986.

18. Kempen GI, Sullivan M, van Sonderen E, Ormel J. Performance-based and self-reported physical functioning in low-functioning older persons: congruence of change and the impact of depressive symptoms. J Gerontol B Psychol Sci Soc Sci1999;54(6):P380-6.

19. Cardol M, de Haan RJ, de Jong BA, van den Bos GA, de Groot IJ. Psychometric properties of the Impact on Participation and Autonomy Questionnaire. Arch Phys Med Rehabil2001;82(2):210-6.

20. Cardol M, de Haan RJ, van den Bos GA, de Jong BA, de Groot IJ. The development of a handicap assessment questionnaire: the Impact on Participation and Autonomy (IPA). Clin Rehabil1999;13(5):411-9.

21. Fleiss JL. Analysis of data from multiclinic trials. Contro/ Clin Trials 1986;7(4):267-75.

22. McCusker J, Cole M, Keller E, Bellavance F, Berard A. Effectiveness of treatments of depression in older ambulatory patients. Arch. Intern. Med. 1998;158(7):705-12. 
23. Biegler P. Autonomy, stress, and treatment of depression. Bmj 2008;336(7652):1046-8.

24. Hollon SD, DeRubeis RJ, Shelton RC, Amsterdam JD, Salomon RM, O'Reardon JP, et al. Prevention of relapse following cognitive therapy vs medications in moderate to severe depression. Arch Gen Psychiatry 2005;62(4):417-22.

25. Hunkeler EM, Katon WJ, Tang L, Williams JW, Jr., Kroenke K, Lin EH, et al. Long term outcomes from the IMPACT randomised trial for depressed elderly patients in primary care. BMJ 2006.

26. Brody BL, Roch-Levecq AC, Kaplan RM, Moutier CY, Brown SI. Age-related macular degeneration: selfmanagement and reduction of depressive symptoms in a randomized, controlled study. J Am Geriatr SoC 2006;54(10):1557-62.

27. Pariser D, $\mathrm{O}^{\prime}$ Hanlon A. Effects of telephone intervention on arthritis self-efficacy, depression, pain, and fatigue in older adults with arthritis. J Geriatr Phys Ther 2005;28(3):67-73.

28. Piette JD, Weinberger M, McPhee SJ. The effect of automated calls with telephone nurse follow-up on patient-centered outcomes of diabetes care: a randomized, controlled trial. Med Care 2000;38(2):218-30.

29. Jerant A, Kravitz R, Moore-Hill M, Franks P. Depressive Symptoms Moderated the Effect of Chronic Illness Self-Management Training on Self-Efficacy. Med Care 2008;46(5):523-531.

30. Brewin CR. Theoretical foundations of cognitive-behavior therapy for anxiety and depression. Annu Rev Psychol1996;47:33-57.

31. Beekman AT, de Beurs E, van Balkom AJ, Deeg DJ, van Dyck R, van Tilburg W. Anxiety and depression in later life: Co-occurrence and communality of risk factors. Am J Psychiatry 2000;157(1):89-95.

32. Rolland JS. Chronic illness and the life cycle: a conceptual framework. Fam Process 1987;26(2):203-21.

33. Jonkers CCM, Lamers F, Bosma H, Metsemakers JFM, Van Eijk JTM. Personality characteristics as predictors of differential treatment outcome of a minimal psychological intervention in chronically ill elderly patients with depression In preparation.

34. Jonkers CCM, Lamers F, Evers SMAA, Bosma H, Metsemakers JFM, van Eijk JTM. Economic evaluation of a minimal psychological intervention in chronically ill elderly patients with depression: a randomised trial (the DELTA-study) submitted. 



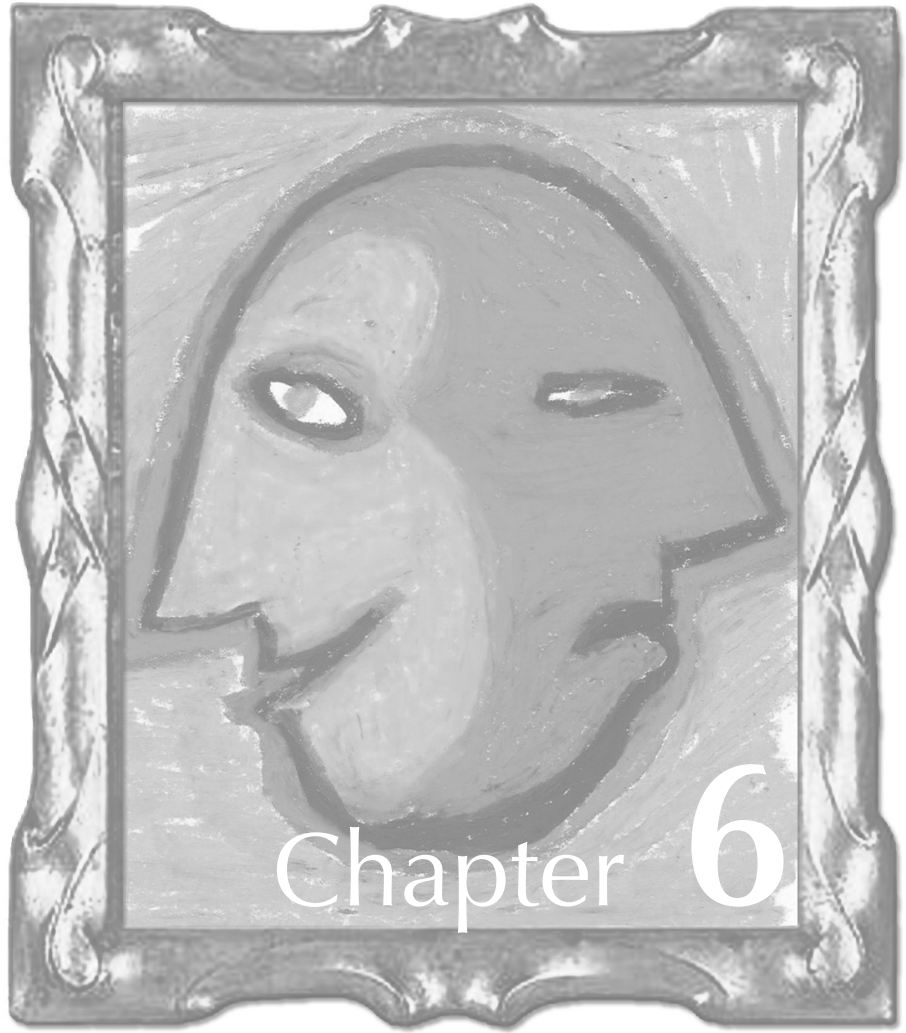

Personality characteristics as predictors of differential treatment outcome of a minimal psychological intervention in chronically ill elderly patients with depression 


\section{ABSTRACT}

Objective Not all depressed patients benefit equally from psychological treatment. This study examined whether patients who differ in personality characteristics also benefit differently from treatment. We expected that persons with adverse personality characteristics would benefit less from treatment with a minimal psychological intervention (MPI).

Methods Data $(n=237)$ were used from a trial that studied the effectiveness of the MPI in elderly patients with diabetes or chronic obstructive pulmonary disease and cooccurring minor or mild to moderate depression. The outcome measure was the difference between depression scores pre-treatment and at 12-months follow-up. The personality characteristics we included were neuroticism, extraversion, mastery, active coping style, passive coping style, and avoidant coping style. Analyses of variance were used to establish the differential treatment outcome (personality characteristic $x$ treatment). The differential effects were interpreted by separate models for groups with high and low scores for each personality characteristic.

Results Level of mastery predicted treatment outcome $(p=.03)$, in that patients with low mastery benefited more from treatment with the MPI than those with high mastery. Neuroticism, extraversion and coping style did not predict differential treatment outcome. Patterns were similar across chronic diseases.

Conclusion Contrary to our expectations, low mastery predicted better treatment outcome. Further research is needed to unravel the role of mastery in the treatment of depression and whether findings hold across other chronic diseases. 


\section{INTRODUCTION}

Depression is a common disorder, especially in older persons with chronic medical illnesses, such as type II diabetes mellitus (DM) and chronic obstructive pulmonary disease (COPD).$^{1-3}$ In these persons with chronic medical illnesses, even low levels of depression are associated with poor adherence to self-care regimens. ${ }^{45}$ Psychological treatment options, such as cognitive behavioral therapy (CBT), are available to treat depression and have proven to be effective in older adults. ${ }^{6-8}$ Psychological treatments have shown to reduce depressive symptoms, improve health status, and reduce health care utilization among patients with chronic medical illnesses. ${ }^{9-12}$ There is some evidence, however, that not all patients benefit equally from treatment with psychological interventions, which makes it important to study predictors of outcomes of depression treatment. ${ }^{14}{ }^{14}$ Identifying factors which predict beneficial treatment outcome might provide further guidance for evidence-based treatment choices.

Recent, studies have reviewed dimensional personality traits as predictors of treatment outcome and found inconclusive evidence. High neuroticism scores were found to be negatively associated with long-term treatment outcome, but there is less evidence for neuroticism as a predictor of short-term treatment outcome. ${ }^{15}$ Although higher extraversion scores have been reported to predict recovery from depression, ${ }^{16}$ other studies did not find an association between extraversion and treatment outcome. ${ }^{17-19}$ Other personality characteristics, such as mastery and coping style, have received less attention as predictors of differential treatment outcome, although they are reported to be associated with the onset and severity of depression in late life. Higher levels of mastery were found to have a buffering effect against the development of depressive symptoms in response to life stress. ${ }^{20}$ Furthermore, adverse coping styles, such as avoidant coping, are significant risk factors for non-remission of depression. $^{21}$

Hence, it remains unclear whether persons with adverse personality characteristics, such as high neuroticism and low mastery, respond differently to depression treatment than their better scoring counterparts. ${ }^{15} 22$ Such adverse characteristics might lead to poorer response to treatment, because these persons are likely to lack the skills to effectively mobilize personal resources, ${ }^{20}$ skills which could help them effectively manage the consequences of the depression. Psychological interventions usually appeal to these skills, as these are aimed at altering patients' cognitions and behaviors.

The DELTA study has previously reported that - in a group of elderly patients with cooccurring DM or COPD - a nurse-led minimal psychological intervention (MPI) aimed at reducing depression was effective, ${ }^{23}$ cost-effective ${ }^{24}$ and feasible and acceptable for patients and nurses. ${ }^{25}$ Here, we examined whether patients who differed in terms of personality characteristics (neuroticism, extraversion, mastery and coping style) also benefited differently from treatment. 


\section{METHODS}

The DELTA study, a randomised controlled trial, was designed to evaluate the effectiveness and cost-effectiveness of an MPI aimed at reducing depression and improving quality of life. A detailed description of the design of the DELTA study has been published elsewhere. ${ }^{26}$ The present study examined whether the overall effect on the depression outcome at 12-months follow-up is modified by personality characteristics. Approval for conducting the DELTA study was granted by the Medical Ethics Committee of the Maastricht University/University Hospital Maastricht.

\section{Study population}

Participants were recruited in 89 primary care practices in the south of the Netherlands between October 2003 and May 2005. The Patient Health Questionnaire (PHQ$9)^{27}$ was sent to patients with an established diagnosis of DM or COPD, aged 60 years and over, who were community-dwelling and did not meet exclusion criteria (treatment with antidepressants for depression, major psychiatric problems, current psychosocial/psychiatric treatment, serious cognitive problems, being on a waiting list for nursing home, being bedridden, loss of spouse within the last three months, and not being fluent in Dutch). Patients who reported having at least two symptoms of depression present for more than half of the days, one of them being loss of interest or depressed mood, were invited to take part in a structured diagnostic interview for DSM-IV axis I disorders, the Mini International Neuropsychiatric Interview (MINI). ${ }^{28}$ In addition, the Hamilton Depression Rating Scale (HDRS $)^{29}$ was used to determine the severity of the depression.

The MINI and HDRS were administered at the patients' home by trained nurses. Patients with minor depression, mild to moderate major depression or dysthymia were invited to participate in the trial. Patients with suicidal risk and patients with severe major depression (HDRS>18) were excluded and referred to their general practitioners. After signing an informed consent form and completing a baseline questionnaire, patients $(n=361)$ were randomly allocated to the MPI or usual care. All data were entered by the researchers, who were blinded for the allocation. Patients who completed the baseline questionnaire and the 12-months follow-up questionnaire were included in the present study. Due to attrition, our final study population consisted of 114 patients in the intervention group and 123 patients in the control group. T-tests and Chi-square tests revealed that our study population did not differ from the initial DELTA population, except as regards age. Although older patients were more likely to have dropped out than their younger counterparts $(p<.001)$, dropout was equally divided over the MPI and usual care groups. 


\section{Intervention}

Patients allocated to the intervention group received the MPI supplementary to usual care. The intervention was delivered at the patients' homes by nurses who had been trained to administer the DELTA intervention. The intervention is based on principles of CBT and self-management and consists of five phases, which have been described in more detail elsewhere. ${ }^{26}{ }^{30}$ Briefly, phase one involves the nurse exploring the patient's feelings, cognitions and behaviors. During phase two, patients keep a diary, in which they record symptoms, complaints, thoughts, worries and related feelings and behaviors. In phase three, patients are challenged to link their mood and cognitions to the consequent behavior, using information from the diary. The selfmanagement approach is introduced in phase four, where patients explore possibilities to alter their behavior and where they draw up an action plan. Phase five consists of an evaluation of the degree to which goals from the action plan have been achieved. The intervention is tailor-made and a home visit can address one or more phases, depending on the progress. During the study, patients received two to ten visits over a maximum of three months. The mean number of visits was four, with a mean duration of 61 minutes. ${ }^{25}$ Patients assigned to usual care received regular treatment according to the practice guidelines for their chronic somatic illness.

\section{Measures}

\section{Depressive symptoms}

The outcome measure was depression severity, measured at twelve months followup, which was approximately nine months after the intervention. Depression was measured with the Beck Depression Inventory (BDI). ${ }^{31}$ The BDI consists of 21 items measuring symptoms of depression and has proven to be a valid and reliable tool. ${ }^{32}$ Each item is rated on a 0 to 3 scale, with a total score ranging from 0 to 63 . Higher scores represent having more depressive symptoms.

\section{Personality characteristics}

The predictor variables were collected at baseline, except for neuroticism and extraversion which were measured at the first follow-up (immediately after the intervention). Neuroticism refers to a person's tendency to experience negative emotions (e.g. nervousness, sadness, and anger). Extraversion refers to a person's tendency to be venturesome, energetic, assertive and sociable and to experience positive emotions (e.g. joy). These two personality traits were measured by the Eysenck Personality Questionnaire (EPQ). ${ }^{33}$ Scores range from 0 to 12 , with patients with high scores experiencing higher levels of the trait. Mastery is defined as the extent to which a person beliefs to have control over his or her own life and the capacity to deal with life's difficulties. Mastery was measured using the Personal Mastery Scale developed by Pearlin and Schooler. ${ }^{34}$ Scores range from 7 to 35, with higher scores representing greater mastery. Information on coping style was obtained

using three subscales of the Utrecht Coping List (UCL). ${ }^{35}$ The UCL regards coping as a 
personal disposition, i.e. a trait. Coping refers to the way people deal with a certain situation. The three subscales we assessed included active coping, passive coping and avoidant coping. The active coping subscales ranges from 7 to 28 , the passive subscale also from 7 to 28, and the avoidance subscale from 8 to 32. A higher score for a coping style represents a higher level of use of this style.

\section{Covariates}

The covariates age (years), gender (male/female), education (eight ordinal categories) and pre-treatment depression severity (BDI) were measured at baseline.

\section{Analysis}

Baseline characteristics of the study population were analyzed by means of descriptive statistics. Missing items on the BDI and on the personality measurement scales were imputed using the individual mean score of items that were not missing in patients for whom at least $50 \%$ of items were available.

The differential treatment response was examined by analysis of variance. Models were used with age, gender, education and pre-treatment BDI score as covariates, the continuous predictor variable and type of treatment (MPI versus usual care) as independent variables, and an interaction term for predictor $\mathrm{x}$ type of treatment. The dependent variable was the difference in BDI scores from pre-treatment to posttreatment. For the purpose of interpreting differential effects, the sample was divided into groups with high and low scores based on the median scores of the predictor factors. Separate models were used for groups with high and low scores for each personality factor and the adjusted means and 95\% confidence interval are reported. The significance level for all analyses was set at 0.05 .

\section{RESULTS}

Table 1 shows the baseline characteristics of the intervention and control groups of our study population. All baseline characteristics were comparable between groups, although the MPI group tended to report slightly higher mastery skills than the usual care group $(p=.07)$. 
Table 1. Comparability of intervention and control groups in terms of socio-demographic variables, predictor factors and baseline depression outcome

\begin{tabular}{|c|c|c|c|}
\hline \multirow[t]{2}{*}{ Variable } & $\mathrm{MPI}$ & Usual care & \multirow[t]{2}{*}{ Pvalue } \\
\hline & $\mathrm{N}=114$ & $\mathrm{~N}=123$ & \\
\hline Age, yrs (SD) & $69.2(6.1)$ & $70.3(6.6)$ & .20 \\
\hline \multicolumn{4}{|l|}{ Sex, No. $(\%)$} \\
\hline Male & $64(56.1)$ & $62(50.4)$ & \multirow[t]{2}{*}{.44} \\
\hline Female & $50(43.9)$ & $61(49.6)$ & \\
\hline \multicolumn{4}{|l|}{ Chronic illness, No. (\%) } \\
\hline Diabetes & $59(51.8)$ & $68(55.3)$ & \multirow[t]{2}{*}{.60} \\
\hline COPD & $55(48.2)$ & $55(44.7)$ & \\
\hline \multicolumn{4}{|l|}{ Education level ${ }^{*}$, No. (\%) } \\
\hline Low & $36(31.6)$ & $47(38.2)$ & \multirow[t]{3}{*}{.29} \\
\hline Medium & $39(34.2)$ & $31(25.2)$ & \\
\hline High & $39(34.2)$ & 45 (36.6) & \\
\hline \multicolumn{4}{|l|}{ Personality factors $¥ \neq$, mean (SD) } \\
\hline Neuroticism (range $0-12$ ) & $6.9(3.5)$ & $6.8(3.1)$ & .78 \\
\hline Extraversion (range $0-12$ ) & $5.4(3.3)$ & $4.9(3.2)$ & .26 \\
\hline Mastery (range 7-35) & $20.4(5.3)$ & $19.1(5.0)$ & .07 \\
\hline Active coping style (range 7-28) & $16.6(3.5)$ & $16.6(3.7)$ & .96 \\
\hline Passive coping style (range 7-28) & $14.0(3.1)$ & $14.0(3.6)$ & .94 \\
\hline Avoidant coping style (range 8-32) & $17.4(3.7)$ & $17.6(4.0)$ & .80 \\
\hline BDI, mean (SD)§ (range 0-63) & $16.4(7.1)$ & $17.6(7.9)$ & .20 \\
\hline
\end{tabular}

* Low refers to primary school only, medium refers to lower vocational training or lower general education, high refers to higher vocational training, general secondary education, higher professional education and university training

+ All predictors were measured at baseline, except for neuroticism and extraversion which were measured at first follow-up, patients with high scores have higher levels of the trait

₹ Missing data: neuroticism $n=21$, extraversion $n=21$, mastery $n=11$, active coping $n=5$, passive coping $n=2$, and avoidant coping $n=2$, evenly divided over MPI and usual care groups

$\S$ Higher scores reflect having more depressive symptoms

A significant treatment effect was found for the MPI group compared to the usual care group at the 12-months follow-up (mean BDI difference $-2.28 ; 95 \% \mathrm{Cl}-4.18$ to $0.38, p=0.02$; not tabulated). Baseline depression scores did not significantly predict beneficial treatment response $(p=0.16$; not tabulated). The analyses of variance of the personality factors (Table 2) showed a differential treatment response for mastery (mastery $\mathrm{x}$ treatment; $\mathrm{p}=.03$ ), with those with high and low mastery scores differing in their response to the intervention. The separate analysis for low- and high-mastery groups revealed that only those with low mastery benefited from treatment with the MPI, while those with high mastery did not. The mean BDI difference in the low mastery group was $-4.32(95 \% \mathrm{Cl}-7.07$ to -1.58$)$, indicating that the MPI group improved significantly. The mean BDI difference for the high mastery group was also in favour of the MPI group $(-0.18 ; 95 \% \mathrm{Cl}-2.90$ to 2.54$)$, but this difference did not reach significance. Similar patterns were found for both diabetes and COPD patients, but the low numbers in the subgroups did not allow the interaction terms to be tested (data not shown). No significant treatment effects were found for the other personality factors. 
$\mathbf{8 2} \mid$

Table 2. Analyses of variance with difference in BDI scores from pre-treatment to one year follow-up as dependent variable for groups with high and low scores for the predictor factors, adjusted for age, gender, education and pre-treatment BDI score. Negative scores indicate improved depression.

\begin{tabular}{|c|c|c|c|c|c|c|}
\hline & \multicolumn{2}{|r|}{ MPI } & \multicolumn{2}{|r|}{ Usual care } & \multirow{2}{*}{$\begin{array}{c}\text { MPI-Usual care } \\
\text { Mean difference } \\
(95 \% \mathrm{CI})\end{array}$} & \multirow{2}{*}{$\begin{array}{c}\text { P value } \\
\text { Predictor } \\
x \\
\text { treatment }\end{array}$} \\
\hline & $\mathrm{N}$ & $\begin{array}{l}\text { Adjusted mean } \\
(95 \% \mathrm{Cl})\end{array}$ & $\mathrm{N}$ & $\begin{array}{l}\text { Adjusted mean } \\
\quad(95 \% \mathrm{Cl})\end{array}$ & & \\
\hline \multicolumn{7}{|l|}{ Neuroticism } \\
\hline High neuroticism (>7) & 51 & $-0.64(-2.72 ; 1.43)$ & 51 & $-0.30(-2.38 ; 1.78)$ & $-0.34(-3.32 ; 2.64)$ & \multirow{2}{*}{.33} \\
\hline Low neuroticism $(\leq 7)$ & 53 & $-2.06(-4.14 ;-0.02)$ & 61 & $1.45(-0.45 ; 3.34)$ & $-3.51(-6.34 ;-0.68)$ & \\
\hline \multicolumn{7}{|l|}{ Extraversion } \\
\hline Low extraversion $(\leq 5)$ & 50 & $-0.98(-3.22 ; 1.25)$ & 66 & $2.26(0.33 ; 4.19)$ & $-3.50(-6.50 ;-0.49)$ & \multirow{2}{*}{.37} \\
\hline High extraversion $(>5)$ & 53 & $-1.94(-3.65 ;-0.22)$ & 47 & $-1.40(-3.22 ; 0.42)$ & $-0.54(-3.04 ; 1.96)$ & \\
\hline \multicolumn{7}{|l|}{ Mastery } \\
\hline Low mastery $(\leq 19)$ & 48 & $-2.57(-4.67 ;-0.47)$ & 68 & $1.68(-0.07 ; 3.44)$ & $-4.25(-6.99 ;-1.52)$ & \multirow{2}{*}{.03} \\
\hline High mastery (>19) & 61 & $-0.80(-2.54 ; 0.95)$ & 49 & $-0.65(-2.60 ; 1.30)$ & $-0.15(-2.79 ; 2.50)$ & \\
\hline \multicolumn{7}{|l|}{ Active coping style } \\
\hline Low active coping style $(\leq 16)$ & 53 & $-2.29(-4.42 ;-0.16)$ & 67 & $0.75(-1.14 ; 2.64)$ & $-3.05(-5.91 ;-0.18)$ & \multirow{2}{*}{.33} \\
\hline High active coping style (>16) & 59 & $-0.49(-2.21 ; 1.22)$ & 53 & $0.52(-1.27 ; 2.32)$ & $-1.02(-3.51 ; 1.47)$ & \\
\hline \multicolumn{7}{|l|}{ Passive coping style } \\
\hline High passive coping style $(>14)$ & 50 & $-1.87(-3.86 ; 0.12)$ & 55 & $0.02(-1.87 ; 1.90)$ & $-1.89(-4.65 ; 0.87)$ & \multirow{2}{*}{.42} \\
\hline Low passive coping style $(\leq 14)$ & 64 & $-1.22(-3.08 ; 0.65)$ & 66 & $0.82(-1.01 ; 2.66)$ & $-2.04(-4.68 ; 0.60)$ & \\
\hline \multicolumn{7}{|l|}{ Avoidant coping style } \\
\hline High avoidant coping style (>17) & 52 & $-1.13(-3.23 ; 0.97)$ & 61 & $-0.04(-2.00 ; 1.92)$ & $-1.10(-3.98 ; 1.79)$ & \multirow{2}{*}{.64} \\
\hline Low avoidant coping style $(\leq 17)$ & 61 & $-2.08(-3.89 ;-0.28)$ & 59 & $1.09(-0.74 ; 2.92)$ & $-3.17(-5.73 ;-0.62)$ & \\
\hline
\end{tabular}

\section{DISCUSSION}

Our study examined whether patients with DM or COPD and co-occurring depression who differ in personality characteristics (neuroticism, extraversion, mastery and coping style) also benefit differently from treatment with an MPI. The analysis revealed that treatment response differed significantly according to baseline mastery scores, in that only patients with low mastery benefited from treatment with the MPI. The other personality factors did not predict differential treatment response.

The finding that low mastery skills predict treatment response is remarkable, because previous studies have shown that higher levels of mastery have a buffering effect against the development of depression in response to life-stress ${ }^{20}$ and predict recovery from depression. ${ }^{36} \mathrm{~A}$ possible explanation is that our intervention teaches patients with low mastery to improve their mastery beliefs and skills, since our intervention was aimed at teaching patients to take responsibility for the day-to-day management of their illness. Since persons with low mastery skills generally do not feel they are in control of their lives, these persons could gain more than those with high mastery skills. 
This explanation implies that the level of mastery might be amenable to change and that it serves as a mediator in the relation between the improvement in depression and the MPI, rather than as a moderator. The stability of mastery as a personality trait is still being debated. Some have argued that mastery can be considered a stable construct over time, while others suggested that mastery is responsive to life events or situations. ${ }^{20}$ If mastery is responsive, the MPI may have influenced the level of mastery, particularly in those with low mastery. Future analysis should unravel the relation between mastery and depression and the influence of treatment on the level of mastery. The same arguments hold for coping styles, although we found no differential treatment response in terms of our coping measures.

Neuroticism scores in our population were relatively high compared to a general elderly Dutch population. ${ }^{33}$ This might not be surprising, since the concept of neuroticism overlaps with depressive symptoms ${ }^{15}$ and our sample was restricted to depressed patients. The overlap could have hampered the value of neuroticism as a predictor of treatment response, because controlling for pre-treatment depression left no variance to be explained by neuroticism and its differential treatment effect. ${ }^{15}$ Some further limitations should be considered. First, analyses were performed on a substantially smaller sub-sample than the initial sample due to attrition. Although patients lost by attrition tended to be older, dropout was equally divided across categories of all personality characteristics and across the MPI and usual care groups. Hence, the influence of dropout on our analyses is likely to have been small. Second, extraversion and neuroticism were measured at the first follow-up instead of at baseline. This was done to decrease the burden of questionnaires for the participants in the study. We assumed that neuroticism and extraversion would be fairly stable traits. Any short-term effects on neuroticism and extraversion can thus not be excluded.

In conclusion, there is no evidence that adverse personality characteristics lead to a generally poorer response to treatment than more favourable personality characteristics. Only level of mastery predicted differential treatment response, in that patients with low mastery benefited more from treatment with the MPI than those with high mastery. Further research is needed to unravel the role of mastery in the treatment of depression with psychological interventions and to find out whether findings hold across other chronic diseases.

\section{Acknowledgements}

We thank Kitty Daemen, Henny Geelen, Francine Hendriks, and Mieke Witte, for administering the intervention with dedication and enthusiasm, Wendy Engering for her contribution to the patient recruitment, Dorien Mintjes for her contribution to the data entry, as well as MEMIC (Centre for Data and Information Management) for providing us with a data management system. 


\section{REFERENCES}

1. Penninx BW, Beekman AT, Ormel J, Kriegsman DM, Boeke AJ, van Eijk JT, et al. Psychological status among elderly people with chronic diseases: does type of disease play a part? J. Psychosom. Res. 1996;40(5):521-34.

2. Anderson RJ, Freedland KE, Clouse RE, Lustman PJ. The prevalence of comorbid depression in adults with diabetes: a meta-analysis. Diabetes Care 2001;24(6):1069-78.

3. Yohannes AM, Baldwin RC, Connolly MJ. Prevalence of sub-threshold depression in elderly patients with chronic obstructive pulmonary disease. Int. J. Geriatr. Psychiatry 2003;18(5):412-6.

4. DiMatteo MR, Lepper HS, Croghan TW. Depression is a risk factor for noncompliance with medical treatment: meta-analysis of the effects of anxiety and depression on patient adherence. Arch Intern Med 2000;160(14):2101-7.

5. Gonzalez JS, Safren SA, Cagliero E, Wexler DJ, Delahanty L, Wittenberg E, et al. Depression, self-care, and medication adherence in type 2 diabetes: relationships across the full range of symptom severity. Diabetes Care 2007;30(9):2222-7.

6. Cuijpers P, van Straten A, Smit F. Psychological treatment of late-life depression: a meta-analysis of randomized controlled trials. Int. J. Geriatr. Psychiatry 2006;21(12):1139-49.

7. Pinquart M, Duberstein PR, Lyness JM. Treatments for later-life depressive conditions: a meta-analytic comparison of pharmacotherapy and psychotherapy. Am. J. Psychiatry 2006;163(9):1493-501.

8. McCusker J, Cole M, Keller E, Bellavance F, Berard A. Effectiveness of treatments of depression in older ambulatory patients. Arch. Intern. Med. 1998;158(7):705-12.

9. Ciechanowski P, Wagner E, Schmaling K, Schwartz S, Williams B, Diehr P, et al. Community-integrated home-based depression treatment in older adults: a randomized controlled trial. JAMA 2004;291(13): 1569-77.

10. Mossey JM, Knott KA, Higgins M, Talerico K. Effectiveness of a psychosocial intervention, interpersonal counseling, for subdysthymic depression in medically ill elderly. J. Gerontol. A. Biol. Sci. Med. Sci. 1996;51(4):M172-8.

11. Kunik ME, Braun U, Stanley MA, Wristers K, Molinari V, Stoebner D, et al. One session cognitive behavioural therapy for elderly patients with chronic obstructive pulmonary disease. Psychol. Med. 2001;31(4):717-23.

12. Emery CF, Schein RL, Hauck ER, MacIntyre NR. Psychological and cognitive outcomes of a randomized trial of exercise among patients with chronic obstructive pulmonary disease. Health Psychol. 1998;17(3):232-40.

13. Bush T, Rutter C, Simon G, Von Korff M, Katon WJ, Walker EA, et al. Who benefits from more structured depression treatment? Int. J. Psychiatry Med. 2004;34(3):247-58.

14. Lustman PJ, Freedland KE, Griffith LS, Clouse RE. Predicting response to cognitive behavior therapy of depression in type 2 diabetes. Gen. Hosp. Psychiatry 1998;20(5):302-6.

15. Mulder RT. Personality pathology and treatment outcome in major depression: a review. Am. J. Psychiatry 2002;159(3):359-71.

16. Bagby RM, Joffe RT, Parker JDA, Kalemba V, Harkness KL. Major Depression and the Five-Factor Model of Personality. J. Pers. Disord. 1995;9(3):224-234.

17. Blom MB, Spinhoven P, Hoffman T, Jonker K, Hoencamp E, Haffmans PM, et al. Severity and duration of depression, not personality factors, predict short term outcome in the treatment of major depression. J. Affect. Disord. 2007;104(1-3):119-26.

18. Quilty LC, De Fruyt F, Rolland JP, Kennedy SH, Rouillon PF, Bagby RM. Dimensional personality traits and treatment outcome in patients with major depressive disorder. J. Affect. Disord. 2007;doi:10.1016/ j.jad.2007.10.022.

19. Spek V, Nyklicek I, Cuijpers P, Pop V. Predictors of outcome of group and internet-based cognitive behavior therapy. J. Affect. Disord. 2008;105(1-3):137-45.

20. Jang Y, Haley WE, Small BJ, Mortimer JA. The role of mastery and social resources in the associations between disability and depression in later life. Gerontologist 2002;42(6):807-13.

21. Beutler LE, Moos RH, Lane G. Coping, treatment planning, and treatment outcome: discussion. J. Clin. Psychol. 2003;59(10):1151-67.

22. Bagby RM, Ryder AG, Cristi C. Psychosocial and clinical predictors of response to pharmacotherapy for depression. J. Psychiatry Neurosci. 2002;27(4):250-7. 
23. Lamers F, Jonkers CCM, Bosma H, Kempen GIJM, Meijer JAMJ, Penninx BWJH, et al. The effectiveness of a minimal psychological intervention in chronically ill elderly patients with depression: a randomised trial (the DELTA-study). submitted.

24. Jonkers CCM, Lamers F, Evers SMAA, Bosma H, Metsemakers JFM, van Eijk JTM. Economic evaluation of a minimal psychological intervention in chronically ill elderly patients with depression: a randomised trial (the DELTA-study) submitted.

25. Jonkers CCM, Lamers F, Bosma H, Metsemakers JF, Kempen GIJM, van Eijk JTM. Process evaluation of a minimal psychological intervention to reduce depression in chronically ill elderly persons. Patient Educ. Couns. 2007;68(3):252-257.

26. Lamers F, Jonkers CC, Bosma H, Diederiks JP, van Eijk JT. Effectiveness and cost-effectiveness of a minimal psychological intervention to reduce non-severe depression in chronically ill elderly patients: the design of a randomised controlled trial [ISRCTN92331982]. BMC Public Health 2006;6(1):161.

27. Spitzer RL, Kroenke K, Williams JB. Validation and utility of a self-report version of PRIME-MD: the PHQ primary care study. Primary Care Evaluation of Mental Disorders. Patient Health Questionnaire. JAMA 1999;282(18):1737-44.

28. Sheehan DV, Lecrubier $\mathrm{Y}$, Sheehan $\mathrm{KH}$, Amorim P, Janavs J, Weiller E, et al. The Mini-International Neuropsychiatric Interview (M.I.N.I.): the development and validation of a structured diagnostic psychiatric interview for DSM-IV and ICD-10. J. Clin. Psychiatry1998;59 Suppl 20:22-33.

29. Hamilton M. A rating scale for depression. J. Neurol. Neurosurg. Psychiatry 1960;23:56-62.

30. Van Eijk JT, Diederiks JP, Kempen GI, Honig A, van der Meer K, Brenninkmeijer WJ. Development and feasibility of a nurse administered strategy on depression in community-dwelling patients with a chronic physical disease. Patient Educ. Couns. 2004;54(1):87-94.

31. Beck AT, Ward CH, Mendelson M, Mock J, Erbaugh J. An inventory for measuring depression. Arch. Gen. Psychiatry 1961;4:561-571.

32. Beck AT, Steer RA, Garbin MG. Psychometric properties of the Beck Depression Inventory: Twenty-five years of evaluation. Clinical Psychology Rev. 1988;8(1):77-100.

33. Sanderman R, Arrindell WA, Ranchor AV, Eysenck HJ, Eysenck SBG. Het meten van persoonlijkheidskenmerken met de Eysenck Personality Questionnaire (EPQ): een handleiding Groningen: Noordelijk centrum voor Gezondheidsvraagstukken, Rijksuniversiteit Groningen, 1995.

34. Pearlin LI, Schooler C. The structure of coping. J. Health Soc. Behav. 1978;19(1):2-21.

35. Schreurs PJG, Willige van de G, Brosschot JF, Tellegen B, Graus GMH. De Utrechtse Coping Lijst: UCL; Omgaan met problemen en gebeurtenissen. Lisse: Swets en Zeitlinger B.V., 1993.

36. Steunenberg B, Beekman AT, Deeg DJ, Bremmer MA, Kerkhof AJ. Mastery and neuroticism predict recovery of depression in later life. Am. J. Geriatr. Psychiatry 2007;15(3):234-42. 



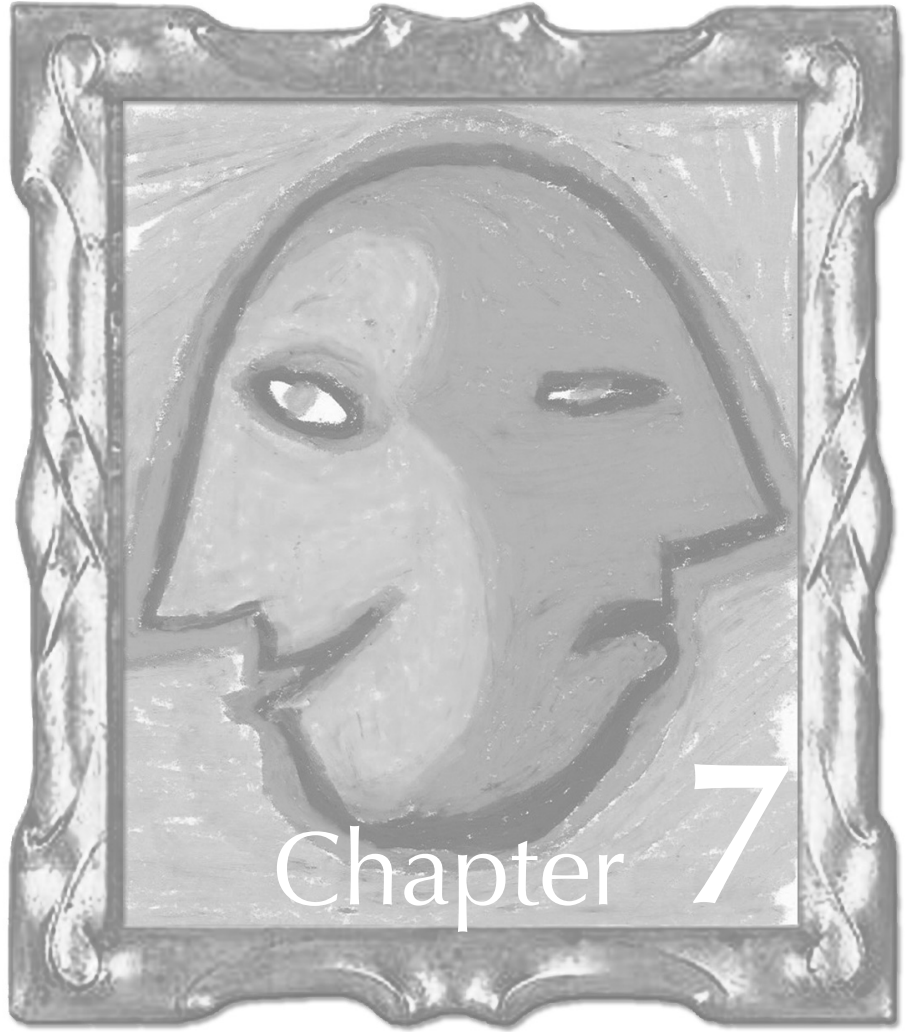

Economic evaluation of a minimal psychological intervention in chronically ill elderly patients with depression:

a randomised trial (the DELTA-study) 


\section{ABSTRACT}

Objective Depression is associated with high health care utilization and related costs. Effective treatments might reduce the economic burden. The objective of this study was to establish the cost-utility of a minimal psychological intervention (MPI) aimed at reducing depression and improving quality of life in elderly persons with diabetes or chronic obstructive pulmonary disease and co-occurring minor, mild or moderate depression.

Methods Trial-based cost-utility analysis comparing the MPI with usual care. Annual costs and quality-adjusted life years (QALYs) based on the Euroqol (EQ5D) and on depression-free days were calculated.

Results We found improvements, albeit not significant, in clinical outcomes and a decrease in mean annual costs in favour of the MPI group. Additional bootstrap analysis indicated a dominant intervention, with a probability of $63 \%$ that the MPI is less costly and more effective than usual care.

Conclusion This study tends to support further dissemination of the MPI in regular care. 


\section{INTRODUCTION}

Depression is a common disorder in older persons ${ }^{1}$ and is associated with a reduced quality of life, ${ }^{2}$ increased morbidity, ${ }^{3}$ and increased physical disability. ${ }^{4}$ This applies especially to older persons with chronic illnesses, such as type II diabetes mellitus (DM) and chronic obstructive pulmonary disease (COPD). ${ }^{56}$ Patients with depression run the risk of sliding into a downward spiral, since depression and disability are mutually reinforcing. ${ }^{4}$ Depression may impair one's ability to adhere to medical regimens (diet, exercise, quitting smoking, taking medication regularly), potentially worsening the course of the chronic illness, ${ }^{7}$ and may also lead to greater health care utilization and related costs. ${ }^{8}{ }^{9}$ It is therefore of great importance to develop treatments for chronically ill elderly persons that help reduce the burden of depression. This is especially true for the treatment of depression in primary care, since persons with depression often present initially to a general practitioner. ${ }^{8}$

Although attempts have been made to study the cost-effectiveness of collaborative care depression treatment, offering both pharmacological and psychological treatment options, ${ }^{8-11}$ the societal impact of psychological depression treatment among elderly persons with chronic somatic illnesses, incorporating health care costs as well as production losses, remains largely unclear. ${ }^{8}$ The Depression in Elderly with LongTerm Afflictions (DELTA) study has been designed to evaluate the effectiveness and cost-effectiveness of a minimal psychological intervention $(\mathrm{MPI})$ to reduce depression and improve quality of life in elderly persons with DM or COPD and co-occurring depression. The MPI was carried out by primary care nurses and is based on principles of self-management and cognitive behavioral therapy (CBT).

The aim of this article is to assess, from a societal perspective, the cost-effectiveness of the MPI compared to usual care. We expected our intervention to lead to an equal level of health care utilization as that with usual care, and therefore to equal healthrelated costs. In addition, we expected favorable outcomes in terms of quality of life and depression, implying a cost-effective intervention.

\section{METHODS}

\section{Design}

The economic evaluation was embedded in a two-armed randomised controlled trial (RCT). A detailed description of the design of the DELTA-study has been published elsewhere. $^{12}$ A block randomisation was used, with stratification for chronic illness and the general practice where the patient was registered. We used a block size of two, because we expected to include few patients per general practice and wanted equal distribution over the groups. The researchers entered each patient's identification number into a computer system connected to an external agency. Patients were then randomised by the agency, using a computerized random number generator. Data were entered by the researchers, who were blinded for the allocation. 
Costs and effects were assessed at baseline (prior to randomisation) and at three, six, nine (only costs), and twelve months after baseline. The first follow-up in the intervention group was one week after the final intervention contact, and depended upon the duration of the tailor-made intervention. The economic evaluation was performed from a societal perspective, which implies that all relevant costs and effects are taken into account. ${ }^{13}$ Approval for this study was granted by the Medical Ethics Committee of Maastricht University/University Hospital Maastricht.

\section{Participants}

Between October 2003 and May 2005, participants were recruited in 89 primary care practices in the south of the Netherlands. Patients with an established diagnosis of DM or COPD, aged 60 years and over, who were community-dwelling and did not meet exclusion criteria (treatment with antidepressants for depression, major psychiatric problems, current psychosocial/psychiatric treatment, serious cognitive problems, being on a waiting list for nursing home, being bedridden, loss of spouse within the last three months, and not being fluent in Dutch) were sent the Patient Health Questionnaire (PHQ-9). ${ }^{14}$ Patients who reported having at least two symptoms of depression present for more than half of the days, one of them being loss of interest or depressed mood, were invited to take part in a structured diagnostic interview for DSM-IV axis I disorders, the Mini International Neuropsychiatric Interview (MINI). ${ }^{15}$ In addition, the Hamilton Depression Rating Scale (HDRS) ${ }^{16}$ was used to determine the severity of the depression. The MINI and HDRS were administered at the patients' home by trained nurses. Patients with minor depression, mild to moderate major depression or dysthymia were invited to participate in the trial. Patients with suicidal risk and patients with severe major depression (HDRS $>18$ ) were excluded and referred to their GP. After signing an informed consent form and completing a baseline questionnaire, patients were randomly allocated to the MPI $(\mathrm{N}=183)$ or usual care $(\mathrm{N}=178)$.

\section{Intervention and usual care}

Patients allocated to the intervention group received the MPI supplementary to usual care. The intervention was delivered at the patient's home by nurses, who were trained in the DELTA intervention, based on principles of CBT and self-management, but had not received additional training for DM or COPD. The DELTA intervention consists of five phases, which have been described in more detail elsewhere. ${ }^{12} 17$ Briefly, in phase one, the nurse explores the patient's feelings, cognitions, and behaviors. During phase two, the patient keeps a diary, in which they record symptoms, complaints, thoughts, worries, and related feelings and behaviors. In phase three, the patient is challenged to link their mood to the consequent behavior, using information from the diary. The self-management approach is introduced in phase four, where the patient explores possibilities to alter their behavior and where they draw up an action plan. Phase five consists of an evaluation of the degree to which 
goals from the action plan have been achieved. The intervention is tailor-made and a home visit could comprise one or more phases. During the study, patients received two to ten visits over a period of at most three months, depending on the patient's progress. The mean number of visits was four, with a mean duration of 61 minutes. ${ }^{18}$ Patients assigned to usual care received regular treatment according to the practice guidelines of their chronic somatic illness. These practice guidelines, produced by the Dutch College of General Practitioners, encompass regular check-ups for medical symptoms, but do not involve detection and treatment of depressive symptoms. ${ }^{19-21}$ Care providers remained blinded for the results of the depression screening for the duration of the study. Due to blinding of the care providers and the randomisation, co-interventions are supposed to be comparable between intervention and control group.

\section{Measurements}

\section{Costs}

To establish the costs, relevant cost items were identified, after which these costs were measured and values were placed on the cost items.

We started by identifying program costs, health care costs, patient and family costs, and productivity losses. Program costs include the costs that can be attributed to the process of developing and administering the MPI, for example the costs of the home visits, MPI training for nurses, and nurses' travel expenses. Research-specific costs, such as costs of questionnaires, were excluded. Health care costs in our study were all costs related to patients' visits to a GP's surgery, hospital care (inpatient and outpatient), allied health professionals such as physiotherapists or dieticians, professional home care, medical devices and assistive devices, and prescribed and over-thecounter medication. Patient and family costs included costs of informal care (help from family and friends) and paid domestic help. Productivity losses consisted of sick leave from work and loss of activities in and around the home.

We then measured the cost categories identified above. The program costs were measured by means of a questionnaire in which nurses recorded time spent on home visits and travelling. The time spent developing the MPI and training nurses to use it was recorded by the researchers. Payroll information was used to calculate the hourly wages of nurses, developers, and trainers. Cost diaries ${ }^{22}$ were used to measure volumes of health care utilization, patient and family costs, and productivity losses. Patients kept a prospective diary for two weeks at baseline and for four weeks at all four follow-up measurements. After each measurement, a telephone operator, blinded for allocation, contacted patients to retrieve information from the diary. Data were immediately entered in a computer file to ensure efficiency and reliability.

Finally, the valuation was based on volumes obtained from the cost diary and questionnaires, multiplied by cost prices derived from the updated Dutch manual for costing. ${ }^{23}{ }^{24}$ Costs due to productivity losses were estimated using the friction cost approach, as described in this manual. Prices of informal care were based on shadow prices for unpaid work. Where no standard cost prizes were available, real costs or 
$92 \mid$ CHAPTER 7

tariffs were used to estimate costs. For example, costs of assistive devices were obtained from the market prices of these devices (volumes and cost price details are available upon request). Baseline costs were used to examine the comparability of the groups at baseline. The total annual costs were determined by extrapolating the costs from the available four months of follow-up measurements by three to obtain the total costs during twelve months of follow-up. The annual costs are presented in Euros and the baseline year was 2004. The discounting rate was $4 \%{ }^{23}{ }^{24}$

\section{Effects}

The generic effects on quality of life were assessed with the Euroqol (EQ5D). ${ }^{25}$ This widely used quality-of-life instrument includes five dimensions of health-related quality of life, namely mobility, self-care, daily activities, pain/discomfort and depression/anxiety. Each dimension was rated at three levels: no problems, some problems and major problems. The five dimensions were combined into a health state. Utility values were calculated for these health states, using preferences elicited from a general Dutch population. ${ }^{26}{ }^{27}$ The utility values were used to compute qualityadjusted life years (QALY-EQ5D) by means of the area under the curve method. ${ }^{28}$ In addition, depression-specific effects were assessed with the Beck Depression Inventory (BDI). ${ }^{29}$ We used the method developed by Lave et al. to calculate depression-free days (DFD) during follow-up. ${ }^{30}$ This method uses depression scores from the BDI over time to estimate days free of significant depressive symptoms. As suggested in previous research, we used a health utility improvement of 0.4 for depression-free days to estimate the QALY-DFD. ${ }^{30} 31$

The EQ5D and BDI were assessed by means of self-administered questionnaires, sent together with the cost diaries, at baseline and at the three, six, and twelve months' follow-up assessments.

\section{Analyses}

Analyses were based on the intention-to-treat principle. An analysis of baseline characteristics and baseline costs examined the comparability of the groups at baseline. Persons with effect scores on at least two of the three follow-up measurements and cost data on at least three of the four follow-up measurements were included in the analysis. Missing items on the BDI scale were replaced by the individual's own mean of non-missing items at that follow-up measurement, if at least half of the items for that follow-up were available. This method could not be applied to the EQ5D and cost data, since domains of the EQ5D and cost category levels (e.g. hospital-related costs or costs of informal care) consisted of one item. Therefore, missing data on the EQ5D and cost category levels were replaced by the individual's own mean of non-missing data at follow-up measurements. Using person specific mean imputation techniques is considered a valid method for imputation of longitudinal data. $^{32}$

Because cost data are typically highly skewed, we used bootstrap estimation with 1000 replications to obtain means and standard deviations of our cost and effect data. The 
differences between the intervention and control groups were estimated by means of linear regression, controlling for age, sex, education, chronic somatic illness, and baseline value of either the cost category or the effect measure.

\section{Cost-utility analysis}

To establish the cost-utility of our intervention, we bootstrapped the predicted annual total cost and the predicted effects (QALY-EQ5D and QALY-DFD) derived from the linear regression models. The incremental cost-utility ratio (ICUR) was calculated as:

$\operatorname{ICUR}=(\mathrm{Ci}-\mathrm{CC}) /(\mathrm{Ei}-\mathrm{Ec})$,

where $\mathrm{Ci}$ is the adjusted annual total cost of the intervention group, $\mathrm{Cc}$ is the adjusted annual total cost of the control group, Ei is the adjusted effect for the intervention group and Ec is the adjusted effect for the control group.

In addition to the primary (QALY-EQ5D) and secondary (QALY-DFD) analyses, we evaluated two models to examine the sensitivity of our cost-utility results. First, we conducted an analysis in which missing cost data were not imputed (complete case analysis). A second sensitivity analysis was performed to test whether a reduction of program cost from $€ 337$ to $€ 282$ would change the cost-utility ratio. The reduction of program costs was based on a scenario in which patients visit the nurse at the GP's surgery instead of the nurses paying home visits, as was done in our study. This scenario is considered to be a suitable alternative when implementing our intervention in routine practice.

\section{RESULTS}

Of the 361 eligible patients, 183 were assigned to the intervention group and 178 to the control group. After imputation, complete data were available for 228 persons (control $n=118$; intervention $n=110)$. These persons were significantly younger $(p<$ $.00)$ and had significantly higher utility scores at baseline $(p=.01)$ than persons for whom complete follow-up data was not available. No other significant differences in characteristics were found between these groups.

Table 1 shows the baseline characteristics of the intervention and control groups. The intervention group had slightly higher costs than the control group in the two weeks prior to the intervention, but differences were not significant. Other characteristics were comparable between groups. 
Table 1. Comparability of intervention and control groups in terms of socio-demographic variables and baseline values of outcomes

\begin{tabular}{|c|c|c|c|}
\hline Variable & $\begin{array}{c}\text { Usual Care } \\
n=118\end{array}$ & $\begin{array}{c}\text { MPI } \\
n=110\end{array}$ & Pvalue \\
\hline Age, yrs (SD) & $69.98(6.26)$ & $69.47(6.17)$ & .54 \\
\hline \multicolumn{4}{|l|}{ Sex, No. $(\%)$} \\
\hline Male & $63(53.4)$ & $59(53.6)$ & .97 \\
\hline Female & $55(46.6)$ & $51(46.4)$ & \\
\hline \multicolumn{4}{|l|}{ Chronic illness, No. (\%) } \\
\hline Diabetes & $64(54.2)$ & $57(51.8)$ & .72 \\
\hline COPD & $54(45.8)$ & $53(48.2)$ & \\
\hline \multicolumn{4}{|l|}{ Education level*, No. (\%) } \\
\hline Low & $41(34.7)$ & $34(30.9)$ & .25 \\
\hline Medium & $26(22.0)$ & $35(31.8)$ & \\
\hline High & $51(43.2)$ & $41(37.3)$ & \\
\hline Utilityt, mean (SD) & $0.63(0.20)$ & $0.61(0.22)$ & .35 \\
\hline BDIf, mean (SD) & $17.48(8.07)$ & $16.73(7.20)$ & .46 \\
\hline Costs prior 2wk mean Euro (SD) & $307(30)$ & $337(37)$ & .56 \\
\hline
\end{tabular}

* Low refers to primary school only, medium refers to lower vocational training or lower general education, high refers to higher vocational training, general secondary education, higher professional education and university training

† Based on the Dutch algorithm for the EQ5D scores; utility scores range from 0 (death) to 1 (full health)

₹ Range of the BDI is $0-63$, with 0 as the most favourable outcome

Table 2. Mean annual cost per patient*

\begin{tabular}{|c|c|c|c|}
\hline & Usual care & MPI & Pvaluef \\
\hline & mean euro $(\mathrm{sd}) \dagger$ & mean euro $(\mathrm{sd}) \dagger$ & \\
\hline Program costs & & $337(11)$ & \\
\hline Health care related costs & $8,082(833)$ & $7,243(885)$ & .50 \\
\hline GP & $471(31)$ & $550(53)$ & .10 \\
\hline Hospital & $3,371(630)$ & $2,885(701)$ & .69 \\
\hline Allied health professionals & $397(63)$ & $474(78)$ & .76 \\
\hline Professional home care & $1,616(286)$ & $936(205)$ & .25 \\
\hline Medical aids and assistive devices & 547 (139) & $710(191)$ & .60 \\
\hline Prescribed and OTC medication & $1,628(85)$ & $1,673(85)$ & .46 \\
\hline Patient and family costs & $472(74)$ & $497(98)$ & .62 \\
\hline Informal care & $281(66)$ & $410(91)$ & .61 \\
\hline Paid domestic help & $192(42)$ & $81(30)$ & .01 \\
\hline Productivity loss & $1,194(234)$ & $1,432(272)$ & .83 \\
\hline Paid work & 189 (119) & $0(0)$ & .14 \\
\hline Unpaid work & $1,014(208)$ & $1,442(283)$ & .42 \\
\hline Total costs & $9,770(890)$ & $9,549(1,059)$ & .53 \\
\hline
\end{tabular}

*Volumes and cost price details are available upon request

† Unadjusted bootstrapped mean and standard deviation

₹ Based on linear regression corrected for age, sex, chronic illness, education, and baseline cost 


\section{Annual costs and clinical effects}

The control group had slightly higher costs than the intervention group

(€ 9,770 vs. € 9,549; Table 2). Hence, a cost saving was achieved in the intervention group, despite the extra costs (on average €337) of the MPI in the intervention group. However, the overall cost difference was not significant, although a significant difference was found in costs of paid domestic help, in favour of the group that received the MPI (€192 vs. $€ 81 ; p=.01$ ).

Linear regression of the clinical effects revealed a significant difference between utilities derived from the EQ5D at the final follow-up measurement $(p=.02)$. However, no significant differences between utilities were found at the other follow-up measurements. In addition, no significant differences in mean QALY-EQ5D or mean QALYDFDs were found between patients from the intervention and control groups, although outcomes were all in favour of the intervention group (Table 3).

Table 3. Clinical effects

\begin{tabular}{|c|c|c|c|}
\hline & $\begin{array}{c}\text { Usual Care } \\
\mathrm{n}=118\end{array}$ & $\begin{array}{c}\mathrm{MPI} \\
\mathrm{n}=110 \\
\end{array}$ & Pvaluet \\
\hline & Mean (SD)* & Mean $(\mathrm{SD})^{*}$ & \\
\hline QALY - EQ5D $\ddagger$ & $0.59(0.02)$ & $0.62(0.02)$ & .06 \\
\hline Utility at three monthsł & $0.61(0.02)$ & $0.64(0.02)$ & .10 \\
\hline Utility at six months $¥$ & $0.59(0.02)$ & $0.61(0.02)$ & .33 \\
\hline Utility at twelve monthsł & $0.56(0.02)$ & $0.62(0.02)$ & .02 \\
\hline QALY - DFD§ & $0.78(0.01)$ & $0.80(0.01)$ & .31 \\
\hline DFD / year§ & $163(11)$ & $184(12)$ & .31 \\
\hline
\end{tabular}

\section{Cost-utility}

Because patients receiving the MPI had lower costs and experienced greater health effects, the MPI dominated usual care (Table 4). The ICUR of the primary analysis showed a saving of $€ 11,508$ per QALY-EQ5D (95\% CI -160,502 to 192,027). The ICUR of the secondary analysis showed a saving of $€ 12,534$ per QALY-DFD (95\% CI -190,366 to $101,049)$. The cost saving per depression-free day was $€ 14(95 \% \mathrm{CI}$

-157 to 106; data not shown).

Bootstrap replications of the ICUR were performed to address the uncertainty surrounding this ratio. The results of the primary analysis, using the QALY-EQ5D, are presented in a cost-effectiveness plane (Figure 1), with differences in cost on the vertical axis and differences in effects on the horizontal axis. Each dot $(n=1,000)$ represents a bootstrap replication. The distribution of our primary analysis shows that $63 \%$ of the dots are in the lower right-hand quadrant, indicating a probability of $63 \%$ that our MPI is the dominant treatment, because the MPI is less costly and more effective than care as usual (see also Table 4). In addition, $28 \%$ of the dots are located in the upper right-hand quadrant, indicating that a health gain is produced, but at 
additional costs. On the other hand, there is a probability of $5 \%$ that the MPI is inferior (upper left-hand quadrant) and $4 \%$ that the MPI is less costly but also less effective (lower left-hand quadrant). The percentage of dominance for the secondary analysis, based on DFDs, is slightly higher (67\%; Table 4) than that in our primary analysis.

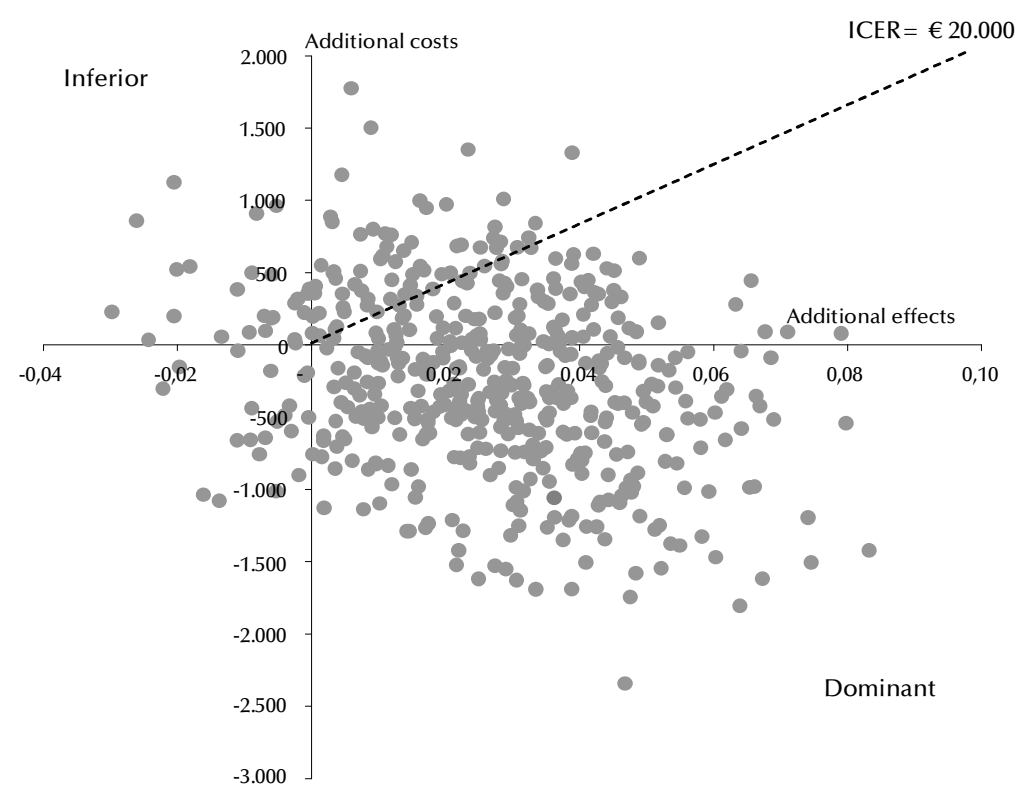

Figure 1. Cost-effectiveness plane: mean cost difference between the MPI and usual care groups (vertical axis) and mean effect difference (horizontal axis). 
Interpretation of these outcomes also depends on how much decision-makers are willing to pay for each quality-adjusted-life-year gained. For instance, if a decisionmaker is willing to pay $€ 20,000$ per QALY gained, the probability of the MPI being cost-effective is about $82 \%$ (see dotted line in Figure 1 and Figure 2). In Dutch health care, this ceiling ratio is often considered a reasonable critical level for QALY cost. ${ }^{33} \mathrm{~A}$ Dutch advisory committee to the Ministry of Health even proposed a ceiling ratio of $€$ 80,000 per QALY gained, ${ }^{34}$ which would result in an $89 \%$ probability of our intervention being superior to care as usual. This is further illustrated in the cost-effectiveness acceptability curve of our primary analysis (Figure 2). The probability of our intervention being superior to usual care ( $y$-axis) is shown for varying ratios for willingness to pay for each quality-adjusted-life-year gained. ${ }^{35} 36$

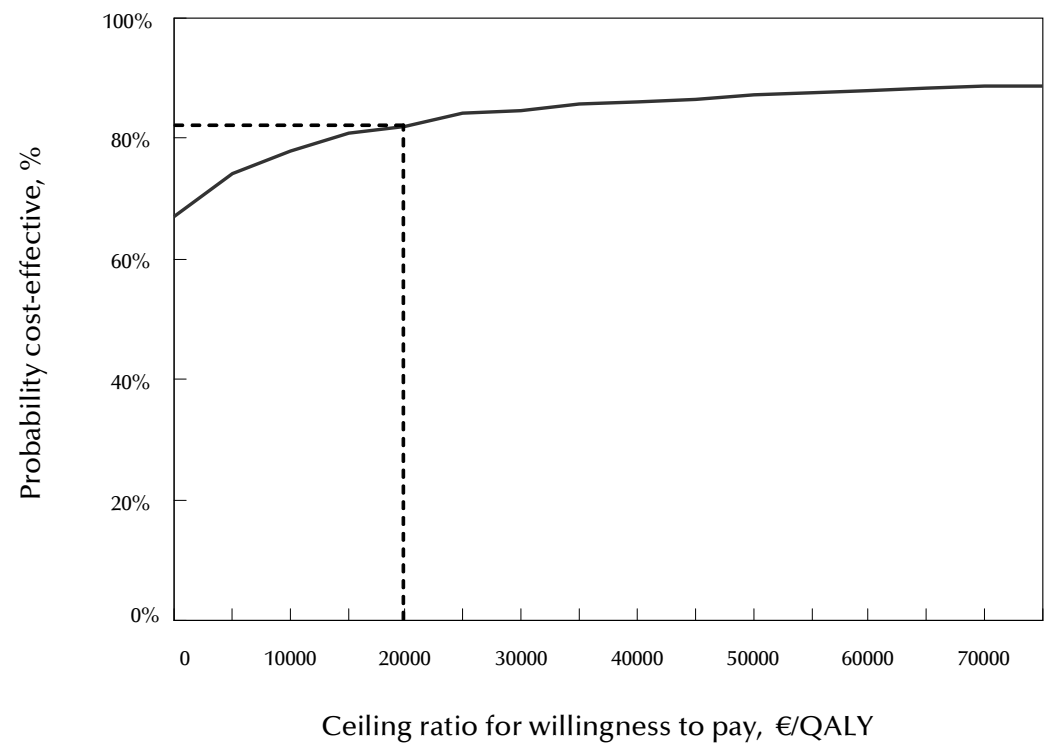

Figure 2. Cost-utility acceptability curve: probability that the MPI is cost-effective (vertical axis) given various ceiling ratios for willingness to pay (horizontal axis). 
Table 4. Incremental cost-utility ratio and percentage of dominance

\begin{tabular}{l} 
Type of analysis \\
\cline { 2 - 6 }
\end{tabular}

The sensitivity analyses, both the complete case analysis and the analysis with a reduction of program costs, indicated that results of our primary analysis were robust (Table 4). Both ICURs showed dominance, and the probabilities of the intervention being dominant were largely the same as in our primary analysis. In the complete case analysis, however, the probability of the MPI being less effective and less costly increased, while the probability of the MPI being more costly but also more effective decreased. As expected, a reduction of program costs led to an increase in dominance, since the costs in the intervention group were lower, while the effects remained the same.

\section{DISCUSSION}

In this group of elderly patients with DM or COPD and co-occurring minor, mild to moderate major depression or dysthymia, our minimal psychological intervention will probably lead to improvements in quality of life and depression-free days, and a decrease in mean annual costs. In our study, the MPI proved to be the dominant treatment, which is supported by the cost-effectiveness acceptability plane showing a $63 \%$ probability that the MPI is less costly and more effective than usual care. If decision-makers are willing to pay $€ 20,000$ per QALY gained, the probability increases to $82 \%$. Sensitivity analyses showed that our findings are robust; the probability of a cost-effective intervention remained largely the same. 
Limitations of this study include the attrition rate. This could have influenced our findings, especially because persons who dropped out of the analysis tended to be older and had poorer quality of life at baseline. However, attrition was not significantly different between the intervention and control groups. We used person specific mean imputation techniques to address issues of missing data. This method is considered valid, ${ }^{32}$ although more refined techniques might have provided better estimates. $^{37}$ A complete case analysis showed that our imputation techniques may have caused a higher probability of our intervention being cost-effective. A second limitation is the poor validity of the DFD method to establish cost-utility. ${ }^{31}$ Cost-utility analyses have been introduced to provide a generic outcome measure for the comparison of costs and effects across diseases. ${ }^{13}$ However, the cost-utility estimate of the DFD method is not based on generic outcomes but on depression severity, making it invalid for comparison with other diseases than depression. Nevertheless, we decided to include the DFD method as a secondary analysis, to be able to compare our results with those of studies using the DFD method. A third limitation concerns the generalizability of our findings across the two chronic somatic illnesses. We added chronic somatic illnesses to our regression models, but the individual costeffectiveness outcomes for diabetic and COPD patients remain unclear, as our study population was too small for disease-specific analyses. Fourth, we used a cost diary to assess the cost data. This method has some advantages over questionnaires, because it measures health care consumption prospectively and might be more accurate..$^{22} 38$ However, cost diaries often have relatively high levels of missing values. Finally, to reduce the burden for the patients, we measured discontinuous. Previous studies revealed that measuring in at least three months during a year provides good estimates of annual costs. ${ }^{22}{ }^{39}$ Nevertheless, high one-time expenses, such as inpatient hospital stays, might be missed or overestimated by measuring discontinuously. Also, the estimate of the QALY would have been more precise is we had used more measurement times.

While reviewing our results, one should take into account that differences in clinical effects, in terms of QALYs, were not significant between the intervention and control groups. However, the utility scores showed a significant difference at the final followup. An increase in differences over time has also been found for the depression parameter in our effectiveness study. ${ }^{40}$ Since our intervention is a short, cognitive behavioral skill based program, the most plausible explanation would be that patients gained skills to cope with depression and used them more and more in daily life. Therefore, the difference in effect may become more pronounced at longer followup. The lack of significant cost differences in our study had been anticipated: the goal of our intervention was not to reduce health care utilization, but to improve the quality of life for patients with a chronic somatic illness. In the long run, however, improvement of the health-related quality of life could lead to a reduction of health care utilization. Our cost analysis shows that the most considerable cost savings were in favour of the intervention group, and a longer follow-up might show a further reduction of health care utilization. 
Our study found a cost saving of $€ 14$ per depression-free day. According to a review by Wang et al., most other studies found an additional cost per depression-free day ranging from $€ 7$ to $€ 26$, instead of a cost saving. ${ }^{9}$ However, none of these studies focused on persons with chronic somatic illnesses. Recently, two additional studies were published that focused on depression treatment of persons with DM. ${ }^{41}{ }^{42}$ In line with our findings, these studies found beneficial cost-effectiveness outcomes, although both studies only reviewed health care related costs, not including production losses, and had a follow-up of twenty-four months instead of twelve months.

One of our sensitivity analyses was based on an implementation scenario in which patients visit a GP's surgery to receive the MPI instead of nurses visiting patients at home. In the Netherlands, primary care nurses are increasingly employed in general practice to treat persons with chronic somatic illnesses. Therefore, detection and monitoring of depressive symptoms and, if necessary, depression treatment could easily be integrated in regular care. This scenario seems to be a good alternative to home visits by nurses exclusively providing depression treatment, especially if health care insurers are willing to invest in an improved quality of life for persons with chronic somatic illnesses. Results of our process evaluation, ${ }^{18}$ effectiveness evaluation, ${ }^{40}$ and this cost-utility study support further dissemination of our MPI for elderly persons with a chronic illness.

Our findings suggests that treatment of depression with our minimal psychological intervention in persons with a chronic somatic illness probably leads to improvements in quality of life and depression-free days at no greater cost than care as usual, implying a cost-effective intervention. These results support further dissemination of the MPI, for example in disease management programs for persons with chronic somatic illnesses.

\section{Acknowledgements}

We thank Kitty Daemen, Henny Geelen, Francine Hendriks, and Mieke Witte, for administering the intervention with dedication and enthusiasm, Wendy Engering for her contribution to the patient recruitment, Dorien Mintjes for her contribution to the data entry, as well as MEMIC (Centre for Data and Information Management) for providing us with a data management system. This study was funded by the Netherlands Organisation for Health Research and Development (ZonMw), Health Care Efficiency Research Program, grant number 945-03-047. 


\section{REFERENCES}

1. Djernes JK. Prevalence and predictors of depression in populations of elderly: a review. Acta Psychiatr Scand 2006;113(5):372-87.

2. Spitzer RL, Kroenke K, Linzer M, Hahn SR, Williams JB, deGruy FV, 3rd, et al. Health-related quality of life in primary care patients with mental disorders. Results from the PRIME-MD 1000 Study. JAMA 1995;274(19):1511-7.

3. Penninx BW, Geerlings SW, Deeg DJ, van Eijk JT, van Tilburg W, Beekman AT. Minor and major depression and the risk of death in older persons. Arch Gen Psychiatry 1999;56(10):889-95.

4. Penninx BW, Guralnik JM, Ferrucci L, Simonsick EM, Deeg DJ, Wallace RB. Depressive symptoms and physical decline in community-dwelling older persons. JAMA 1998;279(21):1720-6.

5. Anderson RJ, Freedland KE, Clouse RE, Lustman PJ. The prevalence of comorbid depression in adults with diabetes: a meta-analysis. Diabetes Care 2001;24(6):1069-78.

6. Yohannes AM, Baldwin RC, Connolly MJ. Prevalence of sub-threshold depression in elderly patients with chronic obstructive pulmonary disease. Int. J. Geriatr. Psychiatry 2003;18(5):412-6.

7. DiMatteo MR, Lepper HS, Croghan TW. Depression is a risk factor for noncompliance with medical treatment: meta-analysis of the effects of anxiety and depression on patient adherence. Arch Intern Med 2000;160(14):2101-7.

8. Donohue JM, Pincus HA. Reducing the societal burden of depression: a review of economic costs, quality of care and effects of treatment. Pharmacoeconomics 2007;25(1):7-24.

9. Wang PS, Simon G, Kessler RC. The economic burden of depression and the cost-effectiveness of treatment. Int J Methods Psychiatr Res 2003;12(1):22-33.

10. Pirraglia PA, Rosen AB, Hermann RC, Olchanski NV, Neumann P. Cost-utility analysis studies of depression management: a systematic review. Am J Psychiatry 2004;161(12):2155-62.

11. Gilbody S, Bower P, Whitty P. Costs and consequences of enhanced primary care for depression: systematic review of randomised economic evaluations. Br J Psychiatry 2006;189:297-308.

12. Lamers F, Jonkers CC, Bosma H, Diederiks JP, van Eijk JT. Effectiveness and cost-effectiveness of a minimal psychological intervention to reduce non-severe depression in chronically ill elderly patients: the design of a randomised controlled trial [ISRCTN92331982]. BMC Public Health 2006;6(1):161.

13. Drummond MF. Methods for the economic evaluation of health care programmes. 2nd ed. Oxford: Oxford University Press, 1997.

14. Spitzer RL, Kroenke K, Williams JB. Validation and utility of a self-report version of PRIME-MD: the PHQ primary care study. Primary Care Evaluation of Mental Disorders. Patient Health Questionnaire. JAMA 1999;282(18):1737-44.

15. Sheehan DV, Lecrubier $\mathrm{Y}$, Sheehan $\mathrm{KH}$, Amorim P, Janavs J, Weiller E, et al. The Mini-International Neuropsychiatric Interview (M.I.N.I.): the development and validation of a structured diagnostic psychiatric interview for DSM-IV and ICD-10. J. Clin. Psychiatry 1998;59 Suppl 20:22-33.

16. Hamilton M. A rating scale for depression. J. Neurol. Neurosurg. Psychiatry 1960;23:56-62.

17. Van Eijk JT, Diederiks JP, Kempen GI, Honig A, van der Meer K, Brenninkmeijer WJ. Development and feasibility of a nurse administered strategy on depression in community-dwelling patients with a chronic physical disease. Patient Educ. Couns. 2004;54(1):87-94.

18. Jonkers CCM, Lamers F, Bosma H, Metsemakers JF, Kempen GIJM, van Eijk JTM. Process evaluation of a minimal psychological intervention to reduce depression in chronically ill elderly persons. Patient Educ. Couns. 2007;68(3):252-257.

19. Geijer RMM, van Schayk CP, van Weel C, Sachs APE, van der Zwan ACC, Bottema BJAM, et al. NHGStandaard COPD en Astma bij Volwassenen: Behandeling [NHG Practice Guideline COPD: Treatment]. Huisarts Wet 1997;40:430-442.

20. Geijer RMM, Thiadens HA, Smeele IJM, Sachs APE, Bottema BJAM, van Hensbergen W, et al. NHGStandaard COPD en Astma bij Volwassenen: Diagnostiek [NHG Practice Guideline COPD: Diagnosis]. Huisarts Wet 2001;44(3):107-117.

21. Rutten GEHM, De Grauw WJC, Nijpels G, Goudswaard AN, Uitewaal PJM, Van der Does FEE, et al. NHGStandaard Diabetes mellitus type 2 [NHG Practice Guideline Diabetes mellitus type 2]. Huisarts Wet 2006;49(3):137-152.

22. Goossens ME, Rutten-van Molken MP, Vlaeyen JW, van der Linden SM. The cost diary: a method to measure direct and indirect costs in cost-effectiveness research. J Clin Epidemio/2000;53(7):688-95. 
23. Oostenbrink JB, Bouwmans CAM, Koopmanschap MA, Rutten FFH. Handleiding voor kostenonderzoek: Methoden en standaard kostprijzen voor economische evaluaties in de gezondheidszorg [Manual for costing: Methods and Standard Costs for Economic Evaluations in Health Care]. Diemen: College voor zorgverzekeringen, 2004 updated version.

24. Oostenbrink JB, Koopmanschap MA, Rutten FF. Standardisation of costs: the Dutch Manual for Costing in economic evaluations. Pharmacoeconomics 2002;20(7):443-54.

25. EuroQol G. EuroQol--a new facility for the measurement of health-related quality of life. The EuroQol Group. Health Policy 1990;16(3):199-208.

26. Dolan P. Modeling valuations for EuroQol health states. Med Care 1997;35(11):1095-108.

27. Lamers LM, McDonnell J, Stalmeier PF, Krabbe PF, Busschbach JJ. The Dutch tariff: results and arguments for an effective design for national EQ-5D valuation studies. Health Econ 2006;15(10):1121-32.

28. Matthews JN, Altman DG, Campbell MJ, Royston P. Analysis of serial measurements in medical research. Bmj1990;300(6719):230-5.

29. Beck AT, Steer RA, Garbin MG. Psychometric properties of the Beck Depression Inventory: Twenty-five years of evaluation. Clinical Psychology Rev. 1988;8(1):77-100.

30. Lave JR, Frank RG, Schulberg HC, Kamlet MS. Cost-effectiveness of treatments for major depression in primary care practice. Arch Gen Psychiatry 1998;55(7):645-51.

31. Pyne JM, Tripathi S, Williams DK, Fortney J. Depression-free day to utility-weighted score: is it valid? Med Care 2007;45(4):357-62.

32. Engels JM, Diehr P. Imputation of missing longitudinal data: a comparison of methods. J Clin Epidemiol 2003;56(10):968-76.

33. Casparie AF, van Hout BA, Simoons ML. Richtlijnen en kosten [Guidelines and costs]. Ned Tijdschr Geneeskd1998;142(38):2075-7.

34. Council for Public Health and Health Care. Sensible and sustainable care; recommendations produced by the Council for Public Health and Health Care to the Minister of Health, Welfare and Sport. Zoetermeer: Council for Public Health and Health Care, 2006.

35. Van Hout BA, AI MJ, Gordon GS, Rutten FF. Costs, effects and C/E-ratios alongside a clinical trial. Health Econ 1994;3(5):309-19.

36. Fenwick E, O'Brien BJ, Briggs A. Cost-effectiveness acceptability curves--facts, fallacies and frequently asked questions. Health Econ 2004;13(5):405-15.

37. Briggs A, Clark T, Wolstenholme J, Clarke P. Missing. .. presumed at random: cost-analysis of incomplete data. Health Econ 2003;12(5):377-92.

38. Van den Brink M, van den Hout WB, Stiggelbout AM, Putter H, van de Velde CJ, Kievit J. Self-reports of health-care utilization: diary or questionnaire? Int J Technol Assess Health Care 2005;21(3):298-304.

39. Lamoureux EL, Chou SL, Larizza MF, Keeffe JE. The reliability of data collection periods of personal costs associated with vision impairment. Ophthalmic Epidemio/2006;13(2):121-6.

40. Lamers F, Jonkers CCM, Bosma H, Kempen GIJM, Meijer JAMJ, Penninx BWJH, et al. The effectiveness of a minimal psychological intervention in chronically ill elderly patients with depression: a randomised trial (the DELTA-study). submitted.

41. Simon GE, Katon WJ, Lin EH, Rutter C, Manning WG, Von Korff M, et al. Cost-effectiveness of systematic depression treatment among people with diabetes mellitus. Arch Gen Psychiatry 2007;64(1):65-72.

42. Katon W, Unutzer J, Fan MY, Williams JW, Jr., Schoenbaum M, Lin EH, et al. Cost-effectiveness and net benefit of enhanced treatment of depression for older adults with diabetes and depression. Diabetes Care 2006;29(2):265-70. 


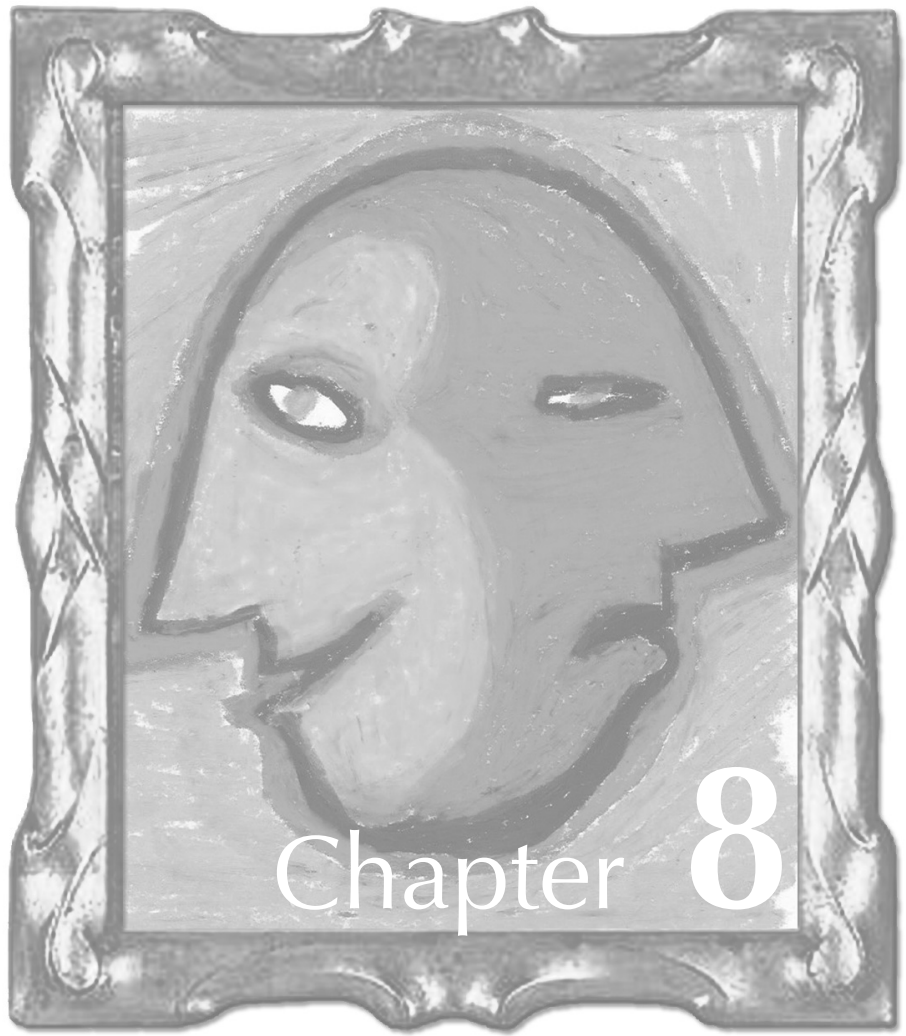

Cost-utility estimates in depression: does the valuation method matter? 


\section{ABSTRACT}

Objective Depression imposes a substantial burden on society. In view of the economic burden of depression, studies evaluating depression treatment increasingly incorporate a cost-utility analysis. Outcomes of these analyses are used by decision makers to prioritize health care. Although generic preference-based instruments have been recommended for measuring utility, depression research often uses a diseasespecific method, based on depression-free days (DFD), to measure utilities. The objective of this study was to compare utility measurement techniques in the context of a randomised controlled trial. In particular, we studied the agreement between QALYs measured with the EuroQol (EQ-5D), the Short Form 6D (SF-6D), and the DFD method, using the EQ-5D as the reference method. We also studied whether the use of different techniques leads to different conclusions for decision makers.

Methods Data were derived from the Depression in Elderly with Long-Term Afflictions (DELTA) study. This randomised controlled trial was designed to study the effectiveness and cost-effectiveness of a minimal psychological intervention for chronically ill patients with co-occurring minor or mild to moderate major depression. The EQ-5D, SF-6D and Beck Depression Inventory (to estimate DFDs) were assessed at baseline, and at three, six and twelve months after baseline.

Results Poor agreement was found between the EQ-5D and DFD (Kendall's Tau: 0.33; ICC: 0.21 (95\% Cl:-0.07-0.45)) and moderate agreement between the EQ-5D and SF-6D (Kendall's Tau: 0.60; ICC: 0.47 (95\% Cl: 0.36-0.57)). The incremental cost-utility ratio led to similar conclusions for decision makers across techniques. In conclusion, utilities from the disease-specific DFD method should not be compared directly with utilities derived from the EQ-5D.

Conclusion Although a disease-specific method might yield similar cost-utility ratios as generic instruments, generic instruments remain the preferred option for prioritizing health care. If the DFD method is a way forward, further research is required to validate utility weights assigned to the DFDs. 


\section{INTRODUCTION}

Depression is a highly prevalent disorder that imposes a substantial burden on society. ${ }^{1}$ The disorder is disabling, especially in elderly persons with chronic somatic illnesses, and is associated with increased physical disability, ${ }^{2}$ reduced quality of life, ${ }^{3}$ and increased mortality. ${ }^{4}$ Furthermore, depression results in increased health care utilization ${ }^{5}$ and medical costs. ${ }^{6}$ In view of the economic burden of depression, studies evaluating depression treatment have increasingly incorporated an economic evaluation. $^{7}$

Economic evaluations assess costs and benefits of a health care intervention and an alternative to provide a decision making framework. ${ }^{89}$ Cost-utility is a useful form of economic evaluation, as it provides a generic outcome, allowing comparisons between all interventions and diseases. This outcome is expressed in the cost per quality-adjusted life-years (QALY) gained. A QALY is calculated by adjusting the length of time that a patient spends in a specific health state by the quality of that health state, usually expressed in utilities. Health utilities are derived from people's preference for health states and can be assessed by various techniques. In general, it is assumed that utility values range from 0 to 1 , where 0 refers to death and 1 refers to full health. Values $<0$ indicate a health state worse than death. ${ }^{89}$

Generic quality of life instruments, such as the EuroQol (EQ-5D), are recommended by guidelines as the best method to measure utilities for cost-utility research, because they provide a valid and feasible estimate of the preference for a particular health condition. ${ }^{910}$ However, there is ongoing debate about the use of generic or diseasespecific instruments in health care decisions, as generic instruments might not be able to capture all relevant aspects of complex conditions such as depression. ${ }^{11}$ On the other hand, the aim of a cost-utility analysis is to help decision makers prioritize health care, and the use of disease-specific instruments might hamper comparisons across different diseases and interventions. ${ }^{12}$ One option to overcome these problems is to assign utility scores derived from generic instruments to a disease-specific instrument. This has been done in depression research, where utility scores are assigned to depression-free days (DFD), calculated with clinical instruments such as the Beck Depression Inventory (BDI). A recent study suggested that the diseasespecific DFD method leads to significantly higher QALYs than a generic instrument. ${ }^{13}$ However, generic and disease-specific methods have not yet been compared in the context of a randomised controlled trial. In the present study we tried to answer the following research questions:

What is the agreement between QALYs measured with different generic instruments (EQ-5D UK tariff, EQ-5D Dutch tariff and SF-6D), using the EQ-5D UK tariff as a reference method?

What is the agreement between QALYs measured with a generic instrument (EQ-5D UK tariff) and a disease-specific instrument (DFD method), using the EQ-5D UK tariff as a reference method? 
Does the use of the EQ-5D UK tariff, EQ-5D Dutch tariff, SF-6D and DFD method lead to differences in conclusions for decision makers regarding the cost-utility of an intervention?

This paper starts with an explanation of the different utility techniques. It then addresses each of the research questions and their evaluation in the context a randomised trial on depression.

\section{UTILITY MEASUREMENT TECHNIQUES AND THEIR THEORETICAL BASIS}

Utilities can be measured with generic direct preference elicitation techniques, generic indirect preference-based techniques, and disease-specific non-preferencebased techniques. These techniques, their theoretical basis, their advantages and disadvantages, and their use in depression research are described below.

\section{Direct preference elicitation techniques}

Direct preference elicitation techniques measure the direct preferences of participants for health states. The three most widely used techniques to measure participants' preferences directly are standard gamble (SG), time trade-off (TTO) and the visual analogue scale (VAS). The SG method gives participants a choice between a certain health state and an uncertain treatment that leads to either perfect health, with a probability of $p$, or death, with a probability of 1-p. The probability $p$ is varied until the participant is indifferent between the certain health state and the uncertain alternative. The resulting probability $\mathrm{p}$ is the utility for the certain health state. ${ }^{89}$ The TTO also presents a choice, but participants are asked to choose between two alternatives of certainty, rather than between a certain and an uncertain health state as is done in the SG. The first alternative involves living in a poor health state for a period $t$. The second alternative involves full health for a period $\mathrm{x}$, where $\mathrm{x}<\mathrm{t}$. The time is varied until the participant is indifferent between the two alternatives. The utility score for the health state is then $x / t$. The VAS requires participants to rate health states on a scale from 0 to $100 .^{89}$

The VAS is often regarded as inferior to the SG and TTO techniques, because the instrument does not provide a choice between health states and thus might not be able to measure actual preference. The SG technique has the most solid basis in theory, as it is choice-based and involves an uncertain risk, although empirical support for this theory is lacking. Both SG and TTO are less feasible than the VAS, as the techniques require development of relevant health state descriptions and are time consuming and difficult to administer. Furthermore, choosing between health states has proved to be difficult for participants and using generic health state descriptions could be inappropriate for some medical conditions. ${ }^{89}$ 
Table 1. Overview of studies measuring utility of depression with direct preference elicitation techniques

\begin{tabular}{|c|c|c|c|}
\hline Publication & Technique & Population & Description of health state \\
\hline $\begin{array}{l}\text { Bennett KJ, Torrance } \\
\text { GW, Boyle MH, } \\
\text { Guscott R, Moran LA., } \\
2000\end{array}$ & SG and VAS & $\begin{array}{l}105 \text { patients who had } \\
\text { experienced at least one } \\
\text { episode of major unipolar } \\
\text { depression in the past two } \\
\text { years, but were currently in } \\
\text { remission. }\end{array}$ & $\begin{array}{l}11 \text { health states: } 3 \text { pre-treatment } \\
\text { depression health states, } 6 \text { on- } \\
\text { treatment depression health } \\
\text { states, perfect health and death. } \\
\text { Two time frames: six-month } \\
\text { duration of depression and } \\
\text { lifetime duration. A selection of } \\
\text { health states was used in the SG } \\
\text { interview. }\end{array}$ \\
\hline $\begin{array}{l}\text { Donald Sherbourne } \\
\text { C, Unutzer J, }\end{array}$ & TTO and SG & $\begin{array}{l}1356 \text { depressed primary care } \\
\text { patients All patients had health }\end{array}$ & $\begin{array}{l}1 \text { health state: } 10 \text { years in current } \\
\text { health (depressed). }\end{array}$ \\
\hline
\end{tabular}

Schoenbaum M,

Duan N, Lenert LA,

Sturm R, et al., 2001

$\begin{array}{ll}\begin{array}{l}\text { Fryback DG, Dasbach } \\ \text { EJ, Klein R, Klein BE, }\end{array} & \begin{array}{l}60 \text { persons who reported being } \\ \text { depressed and } 1258 \text { persons }\end{array}\end{array}$

Dorn N, Peterson K,

et al., 1993

Hatziandreu EJ,

Brown RE, Revicki

DA, Turner R, insurance covering mental health.

Martindale J, Levine

S, et al., 1994

Revicki DA, Wood SG and VAS 70 primary care patients with M.,1998 unaffected by depression.

SG $\quad 5$ general practitioners and 5 psychiatrists.
1 health state: depression for remainder of life, based on life expectancy of interviewed person.

4 health states of major depression: varying in acute or remission and drug treatment.

\begin{tabular}{|c|c|c|c|}
\hline $\begin{array}{l}\text { Sackett DL, Torrance } \\
\text { GW., } 1978\end{array}$ & TTO & 243 general population. & $\begin{array}{l}1 \text { health state: depression for } \\
\text { three months. }\end{array}$ \\
\hline $\begin{array}{l}\text { Schaffer A, Levitt AJ, } \\
\text { Hershkop SK, Oh P, } \\
\text { MacDonald C, } \\
\text { Lanctot K., } 2002\end{array}$ & SG & $\begin{array}{l}40 \text { outpatients with major } \\
\text { depression and } 35 \text { healthy } \\
\text { controls. }\end{array}$ & $\begin{array}{l}13 \text { health states: } 10 \text { symptom } \\
\text { profiles reflecting individual } \\
\text { symptoms of major depression } \\
\text { and } 3 \text { profiles with a combination } \\
\text { of symptoms to portray mild, } \\
\text { moderate and severe depression. }\end{array}$ \\
\hline $\begin{array}{l}\text { Torrance GW, Boyle } \\
\text { MH, Horwood SP., } \\
1982\end{array}$ & TTO & 148 general population. & $\begin{array}{l}1 \text { health state: being anxious or } \\
\text { depressed some or a good bit of } \\
\text { the time and having very few } \\
\text { friends and little contact with } \\
\text { others. }\end{array}$ \\
\hline $\begin{array}{l}\text { Wells KB, Sher- } \\
\text { bourne CD., } 1999\end{array}$ & TTO and SG & $\begin{array}{l}750 \text { primary care patients with } \\
\text { probable depression and } 2146 \\
\text { primary care patients with } \\
\text { probable depression and a } \\
\text { medical condition. All patients } \\
\text { had health insurance covering } \\
\text { mental health. }\end{array}$ & $\begin{array}{l}1 \text { health state: } 10 \text { years in current } \\
\text { health (probable depression). }\end{array}$ \\
\hline
\end{tabular}


Table 1 provides an overview of all studies that used direct preference elicitation techniques to establish utilities associated with depression. Several studies value depression as a single health state, without making distinctions in terms of severity, symptoms, or treatment. One study measured utilities per symptom of depression. ${ }^{14}$ Direct preference elicitation techniques have, so far, only been used to estimate utility associated with depression, but not as part of cost-utility analysis for depression treatment, because of the burden to participants and researchers.

\section{Indirect preference-based techniques}

Indirect preference-based techniques have been developed that are easier to understand and administer. These preference-based techniques use the direct elicitation techniques as a basis. First, they define the participant's health state based on a self-reported questionnaire. These questionnaires include the EuroQol (EQ5D), ${ }^{15}$ the Health Utilities Index (HUI) ${ }^{16}$ the Quality of Wellbeing Scale (QWB), ${ }^{17}$ and the Short Form 6D (SF-6D; derived from the SF-36). ${ }^{18}$ The instruments all have attributes for pain, physical function, social or role function, and anxiety/depression. ${ }^{19}$ Second, a weight that has been previously established by direct preference elicitation in a general population is applied to each of these attributes, and an overall score is calculated..$^{20-22}$ This overall score is the utility score for the participant's current health state.

Generic indirect preference-based techniques are the most widely used techniques in economic evaluation. ${ }^{23}$ The questionnaires can be readily incorporated in clinical trials and are, in contrast to the direct preference elicitation, easy to use for participants and researchers. The techniques are assumed to be relevant to all patient groups, because of their generic character, allowing comparisons between patient groups. However, generic measures of health have proved to be inappropriate or insensitive for some conditions. ${ }^{811}$ In addition, the instruments differ considerably in terms of attributes, the underlying valuation method (e.g. SG or TTO), and the consequent utility values. Brazier et al. reviewed the main generic preference-based techniques based on practicality, reliability, and validity. ${ }^{8}$ They argued that the QWB should not be used, because it uses the non-choice based VAS as a valuation method. Furthermore, the EQ-5D is not very well able to discriminate between utility scores of relatively healthy persons, and the SF-6D is not very well able to discriminate between utility scores of relatively unhealthy persons. ${ }^{24} 25$ Therefore, some have argued that the choice of technique should depend on the research population, which, however, reduces the comparability of utility outcomes between patient groups.

Relatively few studies have used generic preference-based instruments to establish the cost-utility of depression treatments. ${ }^{26-29}$ Resistance against the use of these instruments might be due to the fear that they will not be able to detect changes in mental health. For example, one study found a smaller gain in QALY measured with a generic preference-based instrument than expected from depression-specific health outcomes. ${ }^{30}$ However, recent studies found that the EQ-5D and SF-6D are able to 
distinguish between depression severity levels ${ }^{31}{ }^{32}$ and that treatment of depression is associated with significant improvements in EQ-5D scores. ${ }^{33}$

\section{Disease-specific indirect non-preference-based techniques}

Many studies have used a disease-specific instrument to measure changes in quality of life in their population. These instruments are also being used in economic evaluations. For this purpose, techniques have been developed to convert diseasespecific quality of life into utilities. The mapping approach translates responses to disease-specific quality of life instruments into the classification of one of the generic preference-based questionnaires by means of regression modelling. The diseasespecific instrument must include the dimensions of the preference-based technique (e.g. physical function). ${ }^{8}$ Another approach is to revalue the disease-specific instrument with a direct preference-based technique, which has been applied by Bennett et al. for a depression-specific instrument. ${ }^{34}$

Instead of disease-specific quality of life measures, depression severity measures are increasingly used to establish cost-utility. In this approach, the reduction of depression severity resulting from the treatment of depression is translated into a gain in QALY. First, the depression severity is established with instruments such as the Hopkins Symptom Checklist 20 Depression Scale (HSCL-20), ${ }^{35}$ the Hamilton Depression Rating Scale (HDRS), ${ }^{36}$ or the Beck Depression Inventory (BDI) ${ }^{37}$ at various measuring times. Second, depression-free days (DFD) are calculated by assigning participants who score above the cut-off score of the severity instrument for being fully symptomatic a value of 0 , and assigning participant who score below the cut-off score for being free of depressive symptoms a value of 1 . Scores between the two cutoff points receive a value that is weighted proportionally. ${ }^{38}$ DFDs over the course of one year are calculated by multiplying the average value of a given interval by the number of days in that interval, and summing the resulting DFDs for each interval. Last, QALYs are calculated by assigning a utility weight, based on the literature, to the DFDs. Participants with a full depression-free day are assumed to have a utility score of 1 , while severely depressed persons receive a utility score of 0.6 . Thus, participants are assumed to gain 0.4 if they shift from fully depressed to depression-free. The QALY score over one year is estimated by dividing the utility gain of 0.4 by 365 days and multiplying it by the number of DFDs over the year. The result is added to $0.6{ }^{38}$ The appeal of depression-specific instruments is that they are already being used in clinical practice and in effectiveness studies, and do not require additional data gathering. Another advantage is the possibility to estimate the cost-utility from old studies, which did not use a direct preference or preference-based measure. Furthermore, DFDs are appealing because the concept of a day free of depression is easy to understand for clinicians, researchers and policy makers. However, the use of disease-specific instruments in cost-utility analysis might hamper comparisons with other studies and across diseases. Additional concerns have been raised about the use of DFDs. First, the technique assumes a linear relation between depression severity and time, which is often not the case, since depression is known to have a 
fluctuating course. ${ }^{39}$ Therefore, DFDs measured with this technique will probably not reflect actual days free of depression as experienced by the participants. Second, the validity of the utility weight of 0.6 that is used for severe depression is questionable. This utility weight is based on studies using direct preference elicitation techniques and indirect preference based techniques. ${ }^{40-42}$ However, these studies differed considerably in terms of methods and health state descriptions of depression. The third concern about using DFDs is that the technique does not take into account participants' co-morbidities or the side-effects of treatment. The change in QALY is only based on depression severity, while depression might have an influence on other attributes of generic quality of life as well.

Regardless of these concerns, several prominent depression studies have used the DFD method. Some studies reported results in cost per DFD to avoid problems with assigning utility weights to the DFDs. ${ }^{43-46}$ Other studies assigned utility values and reported the cost per QALY. ${ }^{4348}$ A recent study assessed the validity of the DFD utility weight but also reported several limitations to this approach. ${ }^{13}$ However, the question arises whether the DFD cost per QALY can be compared with the cost per QALY of generic methods in the context of a randomised controlled trial.

\section{METHODS}

Using data from the Depression in Elderly with Long-Term Afflictions (DELTA) study, we examined the agreement between utility outcomes measured with different techniques, and compared the incremental cost-utility outcomes for each technique. Although direct preference elicitation techniques would provide the most valid utility estimates, we have not been able to incorporate a direct preference-based technique. Since guidelines for cost-effectiveness research recommend the use of generic indirect preference-based instruments, ${ }^{9}{ }^{10}$ we included two generic indirect preference-based techniques, the EQ-5D and the SF-6D, and the disease-specific DFD method. We used the generic EQ-5D UK tariff as a reference method because this instrument is most generally accepted and feasible in cost-utility analyses. ${ }^{910}$

\section{The DELTA study}

The DELTA study, a randomised controlled trial, was designed to evaluate the effectiveness and cost-effectiveness of a minimal psychological intervention (MPI) aimed at reducing depression and improving quality of life. Participants $(n=361)$, recruited in primary care, were 60 years or older, with type II diabetes mellitus (DM) or chronic obstructive pulmonary disease (COPD), and with co-occurring minor depression or mild to moderate major depression. A detailed description of the study design, effectiveness and cost-effectiveness has been published elsewhere. ${ }^{28} 49-51$ Participants completed a self-administered baseline questionnaire and three self-administered follow-up questionnaires at three (on average one week after intervention period), six, and twelve months after baseline, to measure utilities. Costs were collected using 
cost diaries at baseline and at three, six, nine, and twelve months after baseline. Detailed information about the collection of cost data has been published elsewhere. ${ }^{28}$ Patients were included in the current analysis if cost and utility data were available at baseline and at all follow-up measurements $(n=210)$.

\section{Instruments}

The EQ-5D is a widely used quality of life instrument and includes five dimensions of health-related quality of life, namely mobility, self-care, daily activities, pain/discomfort, and depression/anxiety. ${ }^{15}$ Each dimension is rated at three levels: no problems, some problems, and major problems. The five dimensions are summed to obtain a health state, and preference-based weights are applied to calculate the health utility. In our study, we used preferences elicited from a general UK population, resulting in a theoretical utility range of -0.59 to 1.00 (EQ-5D UK tariff). ${ }^{21}$ In addition, we used preferences from a smaller Dutch sample, resulting in a theoretical utility range of -0.33 to 1.00 (EQ-5D Dutch tariff). ${ }^{52}$ The Dutch tariff assigns less weight to all dimensions of the EQ-5D than the UK tariff, except for the anxiety and depression dimension. ${ }^{52}$

The SF-6D was derived from the Short Form 36, which is a well established questionnaire measuring health status. ${ }^{53}$ The SF-6D measures six domains, namely physical functioning, role limitations, social functioning, pain, mental health, and vitality. The SF-6D utility was calculated by applying preference-based weights from a representative sample of the general UK population. The theoretical range of the utility scores was from 0.30 to $1.00 .^{20}$

The DFDs were derived from the Beck Depression Inventory (BDI). The BDI is a 21item questionnaire, which measures depressive symptoms with scores ranging from 0 to 63 . Higher scores represent more severe symptoms. ${ }^{54}$ The BDI is a reliable and valid measure and is widely used in clinical populations and research settings. ${ }^{37}$ Patients were considered to be depression-free if they had BDI scores of 8 or less and severely depressed if they had BDI scores of 22 or more. Scores between 8 and 22 were weighted proportionally. A utility weight of 0.6 was used for days with severe depression, and each depression-free day had a utility weight of 1 . This resulted in a theoretical range of utility scores from 0.6 to $1.00 .^{1338}$

\section{Analysis}

Characteristics of patients at baseline were examined with descriptive statistics. To asses the agreement in terms of QALY, we first graphically compared utility scores over time for the EQ-5D UK tariff, EQ-5D Dutch tariff, SF-6D and the DFD method, and computed descriptive statistics (mean, median). Differences in utility scores between measures were tested per measuring time by Wilcoxon signed-rank test. Then, QALYs were calculated using the area under the curve method ${ }^{55}$ and correlations between the QALY scores were calculated by Kendall's Tau. Further agreement was assessed using the intraclass correlation coefficient (ICC) with a 2-way mixed effect model, 
such that the subject effect was random and the instrument effect was fixed. ${ }^{56}$ An ICC below 0.4 implies poor agreement, while an ICC between 0.4 and 0.75 implies fair agreement, and an ICC above 0.75 implies good agreement. ${ }^{57}$ For our purpose, the ICC between the EQ-5D UK tariff and the other techniques had to be at least fair to justify a claim that similar QALYs are measured. Based on differences in theoretical ranges and measurement methods, we expect the highest correlation and ICC between QALYs measured with the EQ-5D UK tariff and the EQ-5D Dutch tariff, and the lowest correlation and ICC between QALYs measured with the EQ-5D UK tariff and the DFD method.

In addition, Bland-Altman plots were used, in which the difference between two instruments is plotted against the average of the two instruments and limits of agreement are calculated. ${ }^{58}$ This allows examination of the extent to which agreement between the QALY scores of two measures is equally common for low and high QALY scores. Since the utility measurement techniques mainly differed in terms of the value of the lower bound of the theoretical utility range, less agreement between instruments was expected for lower QALY scores.

For our third research question, we examined whether the use of the various methods led to similar conclusions for decision makers. The cost per QALY was calculated, yielding a ratio reflecting the difference in cost between the treatment and control groups, divided by the difference in QALY between the treatment and control groups. Differences in cost-utility were attributable to differences in the estimation of the QALY, since the incremental cost remains similar across utility measurement techniques. In Dutch health care, interventions are considered acceptable if the costs per QALY gained are less than $€ 20,000 .^{59}$ We hypothesized that the use of the DFD method would lead to a lower cost per QALY than that of the EQ-5D and the SF-6D. This was based on the proven effectiveness of our intervention ${ }^{49}$ and the assumption that a disease-specific measure is better able to capture specific health improvements than a generic instrument. ${ }^{1260}$

\section{RESULTS}

Table 2 shows the baseline characteristics of patients included in this study $(n=210)$. The average age was 69 years and the average BDI score was 17 . We had slightly more male patients in our study and slightly more DM than COPD patients. Differences between the MPI and control groups were not significant. 


\begin{tabular}{lcc} 
Table 2. Comparability of MPI and Usual Care groups at baseline & \\
\hline & $\begin{array}{c}\text { MPI } \\
(\mathrm{n}=103)\end{array}$ & $\begin{array}{c}\text { Usual Care } \\
(\mathrm{n}=107)\end{array}$ \\
\hline $\begin{array}{l}\text { Age, year (SD) } \\
\text { Sex }\end{array}$ & $69.2(5.9)$ & $69.5(6.2)$ \\
$\quad$ & $59(55 \%)$ \\
$\quad$ Male, No (\%) & $58(56 \%)$ & $48(45 \%)$ \\
Chronic somatic illness & $45(44 \%)$ & \\
$\quad$ & $58(54 \%)$ \\
DM, No (\%) & $52(51 \%)$ & $49(46 \%)$ \\
Utility EQ-5D UK tariff, mean (SD) & $51(49 \%)$ & $0.58(0.23)$ \\
Utility EQ-5D Dutch tariff, mean (SD) & $0.56(0.24)$ & $0.63(0.20)$ \\
Utility SF-6D, mean (SD) & $0.61(0.21)$ & $0.59(0.09)$ \\
BDI score, mean (SD) & $0.59(0.08)$ & $17.1(7.3)$
\end{tabular}

* Beck Depression Inventory (BDI) ranges from 0-63 with 0 as the most favourable outcome

The utility scores over time for the various measures are presented in Figure 1. The mean utilities were lowest for the EQ-5D UK tariff and highest for the DFDs. In addition, median utility scores were compared (data not shown) and also revealed consistently higher scores for the DFD method at all measuring times. Pairwise comparison with the Wilcoxon Signed-Rank test showed significant differences for all pairs at all measuring times, except for the EQ-5D UK tariff with the SF-6D. The lowest empirical utility value of the EQ-5D UK tariff was -0.32 , while that of the EQ-5D Dutch tariff was -0.13 , that of the SF-6D 0.30, and that of the DFD 0.6.

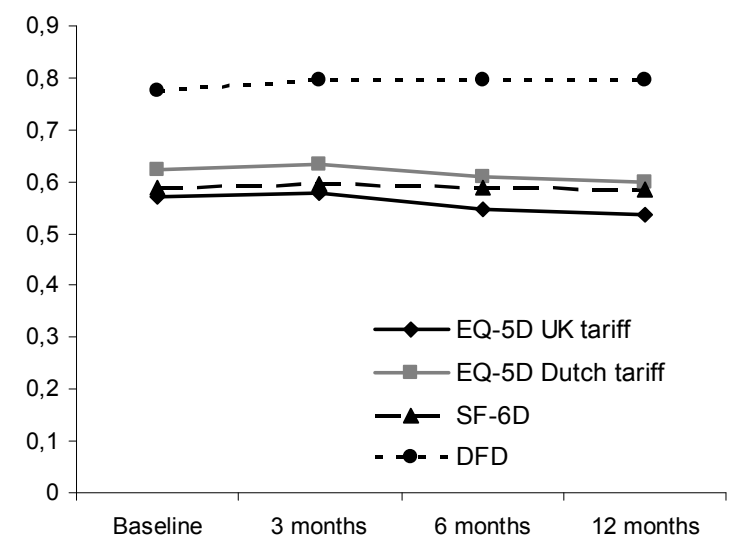

Figure 1. Mean utility scores over time in a population of chronically ill elderly people ( $n=210)$ 
$114 \mid$ CHAPTER 8

The QALY scores obtained with the UK tariff and Dutch tariff of the EQ-5D were found to be in good agreement, with a Kendall's Tau of 0.89 and an ICC of 0.95 (Table 3). Agreement between the EQ-5D UK tariff and the SF-6D was fair, with an ICC of 0.47. However, comparison of the EQ-5D UK tariff with QALY-DFD showed poor levels of agreement, with an ICC of 0.21 and a Kendall's Tau of 0.33 . Changing the cut-off score for severe depression from 22 to 30, as has been suggested by other researchers, ${ }^{13}$ led to less agreement between the QALY-DFD and the EQ-5D (data not shown). The Bland-Altman plots illustrate differences between QALYs using the EQ-5D UK tariff and the EQ-5D Dutch tariff (Figure 2a), the EQ-5D UK tariff and the SF-6D (Figure $2 b$ ), and the EQ-5D UK tariff and DFD (Figure 2c). The plot of the EQ-5D UK tariff and EQ-5D Dutch tariff confirms the close agreement between these valuation methods (Figure 2a). The plot of the EQ-5D UK tariff and SF-6D shows that there was more agreement for the higher than the lower QALY values (Figure 2b). For better health states (= higher means), the EQ-5D appears to yield higher scores than the SF-6D, whereas for lower health states (= lower means) the SF-6D tends to yield higher scores. Figure 2c shows that the DFD systematically yielded higher scores than the EQ5D UK tariff, since the mean difference is -0.24 (solid line). Furthermore, the width of the limits of agreement (i.e. mean difference +/- 1.96 SD) suggests a considerable difference between instruments in measuring the QALY.

Table 3. Agreement in QALY in a population of chronically ill elderly people ( $n=210)$

\begin{tabular}{|c|c|c|c|c|}
\hline & EQ-5D UK tariff & EQ-5D Dutch tariff & SF-6D & DFD \\
\hline EQ-5D UK tariff & - & $\begin{array}{c}\text { Kendall's Tau: } 0.89 \\
\text { ICC }(95 \% \mathrm{Cl}): \\
0.95(0.45-0.98)\end{array}$ & $\begin{array}{c}\text { Kendall's Tau: } 0.60 \\
\text { ICC }(95 \% \mathrm{CI}): \\
0.47(0.36-0.57)\end{array}$ & $\begin{array}{c}\text { Kendall's Tau: } 0.33 \\
\text { ICC }(95 \% \mathrm{CI}): \\
0.21(-0.07-0.45)\end{array}$ \\
\hline EQ-5D Dutch tariff & & - & $\begin{array}{c}\text { Kendall's Tau: } 0.61 \\
\text { ICC }(95 \% \mathrm{CI}): \\
0.53(0.43-0.62)\end{array}$ & $\begin{array}{c}\text { Kendall's Tau: } 0.38 \\
\text { ICC }(95 \% \mathrm{Cl}): \\
0.29(-0.04-0.53)\end{array}$ \\
\hline SF-6D & & & - & $\begin{array}{c}\text { Kendall's Tau: } 0.42 \\
\text { ICC }(95 \% \mathrm{Cl}): \\
0.19(-0.08-0.48)\end{array}$ \\
\hline
\end{tabular}

DFD 


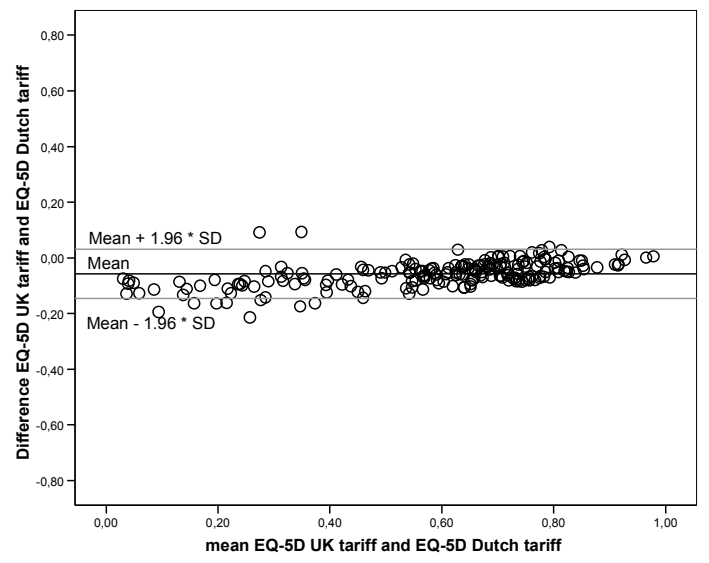

a. EQ-5D UK tariff and EQ-5D Dutch tar iff

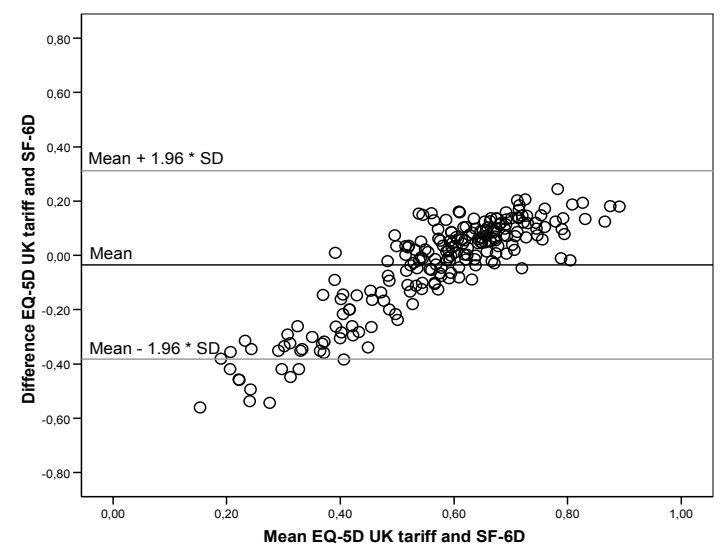

b. EQ-5D UK tariff and SF-6D

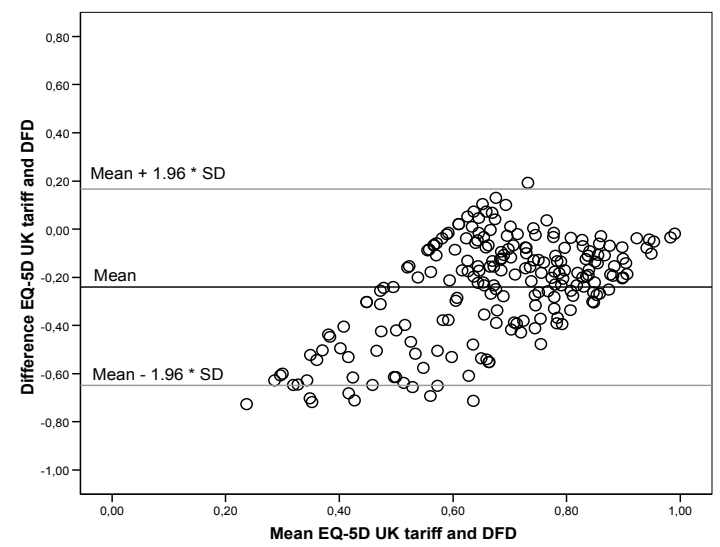

c. EQ-5D UK tariff and DFD

Figure 2. Bland-Altman plots illustrating differences between $Q A L Y$ scores and mean QALY scores 
Table 4 shows the incremental QALY difference, the incremental cost difference, and the cost per QALY for treatment and usual care obtained with the different measurement techniques. The cost per QALY ranged from $€ 3031$ to $€ 6185$. Although the DFD method showed systematically higher utility values over time (see Figure 1), all costutility ratios were below $€ 20,000$ per QALY gained and would lead to similar conclusions for decision makers. The incremental effect using the DFD method was smaller than that measured with the EQ-5D, but larger than the incremental effect found by the SF-6D.

Table 4. Mean incremental $Q A L Y$, mean incremental cost, and cost per $Q A L Y$

\begin{tabular}{lccc} 
& Mean incremental QALY & Mean incremental cost & Cost (in $€$ ) / QALY \\
\cline { 2 - 3 } & MPI - Usual care & MPI - Usual care & \\
\hline EQ-5D UK tariff & 0.0353 & $€ 107$ & $€ 3031$ \\
EQ-5D Dutch tariff & 0.0314 & $€ 107$ & $€ 3408$ \\
SF-6D & 0.0173 & $€ 107$ & $€ 6185$ \\
DFD & 0.0214 & $€ 107$ & $€ 5000$ \\
\hline
\end{tabular}

\section{DISCUSSION}

Depression severity instruments are increasingly being used to value utilities in costutility analysis, although several methodological considerations have been reported. Guidelines recommend generic preference-based techniques, because this allows comparison across interventions and diseases, and enables policy makers to prioritize health care. However, generic techniques and the disease-specific DFD technique have never been compared in the context of a randomised controlled trial. In our study, a trial on depression in chronically ill elderly persons, we found poor agreement between the EQ-5D UK tariff and DFD. Hence, using the EQ-5D UK tariff as a reference method, the DFD would be the worst alternative to value utility. The incremental cost-utility, however, was similar across techniques, indicating that the use of the disease-specific DFD method did not lead to different conclusions for decision makers than generic techniques.

The lack of agreement between the EQ-5D UK tariff and the DFD method might be due to differences in theoretical range between the two methods. The EQ-5D UK tariff results in utility scores ranging from -0.59 to 1.00 , while the DFD method leads to a theoretical range from 0.6 to1.00. These differences in range thus mainly relate to values of the lower bound. This is also reflected in the Bland-Altman plots, which showed greater differences for the lower mean utilities. The lack of agreement might also be caused by the composition of our study population, which consisted of patients with a chronic somatic illness and co-morbid depression. The DFD method only measures utility associated with the depression, while the utilities derived from the EQ-5D also incorporate other illnesses, potentially leading to a lower quality of life and, thus, lower utility. Higher utilities resulting from the DFD method than from another generic method were also found by an earlier study, which included patients with and without comorbid somatic illnesses. ${ }^{13}$ If the DFD method continues to be used as a measure of cost-utility, there seems to be a need for more valid utility 
weights. It would be preferable to use direct preference elicitations, such as SG and TTO, to gain better estimates of the actual utility values associated with different states of depression. These states should incorporate different severity levels of depression, differences in the duration of symptoms, and different levels of comorbidity.

More agreement, although only moderate, was found between the utility scores produced by the generic preference-based techniques EQ-5D and SF-6D. Again, the lack of strong agreement between the EQ-5D and SF-6D seems to be caused by differences in the theoretical range of utility values. Studies assessing the agreement between different generic preference-based techniques found evidence that the EQ$5 \mathrm{D}$ is not very well able to discriminate between relatively healthy persons, while the SF-6D is not very well able to discriminate between relatively unhealthy persons. ${ }^{24} 25$ In an unhealthy population like our study population, the EQ-5D should therefore be better able to detect changes in utility than the SF-6D. This is indeed reflected in our own results, since larger incremental effects were found with the EQ-5D than with the SF-6D.

Initially, we expected to measure greater health gains with the disease-specific DFD method than with the generic instruments. ${ }^{12}{ }^{60}$ However, the DFD technique did not lead to larger incremental effects in our study than the generic EQ-5D. Our findings could be explained by the fact that depression is related to physical disability ${ }^{2}$ and quality of life. ${ }^{3}$ Treatment of depression is thus likely to have an effect on other health-related domains besides depression. This would imply that generic instruments, which encompass more health-related domains, might even detect larger effects in terms of QALY. In addition, a study in a population of mental health patients, including those with depression, showed that both the EQ-5D and SF-6D were able to discriminate between severity subgroups of mental health patients, and captured improvements in health over time. ${ }^{31}$ Our study was not conclusive in this respect, because the health gains measured with the DFD method were smaller than those found with the generic EQ-5D, but larger than those found with the generic SF$6 \mathrm{D}$. However, this is in line with other findings, suggesting more favorable cost-utility outcomes for the EQ-5D than the SF-6D across different populations. ${ }^{19}$

Limitations of our study include the choice of the reference method. Direct preference elicitation techniques might have provided a more precise estimation of the utility value, but the EQ-5D is most feasible, is widely used, and has been validated in economic evaluations, which is why we chose it as the reference method. A second limitation concerns the non-normality of the EQ-5D and DFD data. Although correlations and differences between instruments were tested with non-parametric testing, Bland-Altman plots and ICC assume normality, which may have influenced our findings. Another limitation is that our study population included patients with minor depression. Although minor depression is known to have an impact on quality of life, the DFD method does not incorporate a cut-off score for minor depression, and patients with minor depression are considered to be depression-free. Therefore, the DFD method does not incorporate improvement in health in this population, while a generic quality of life instrument might show improvement, leading to larger incre- 
mental effects. Finally, the presence of chronic somatic illnesses in our research population may have led to smaller incremental effects with the DFD method than with the generic measures.

In conclusion, utilities derived from a disease-specific symptom severity measure, the DFD method, should not be compared directly with those derived from generic instruments such as the EQ-5D. Generic instruments are preferred for cost-utility analyses, especially when results are used to prioritize health care. If the DFD method is a way forward, further research is required to validate utility weights assigned to the DFDs.

\section{Acknowledgements}

The authors thank Prof. JFM Metsemakers for his comments on an earlier version of this work. The DELTA study was funded by the Netherlands Organisation for Health Research and Development, Health Care Efficiency Research program, grant number 945-03-047. 


\section{REFERENCES}

1. Donohue JM, Pincus HA. Reducing the societal burden of depression: a review of economic costs, quality of care and effects of treatment. Pharmacoeconomics 2007;25(1):7-24.

2. Penninx BW, Guralnik JM, Ferrucci L, Simonsick EM, Deeg DJ, Wallace RB. Depressive symptoms and physical decline in community-dwelling older persons. JAMA 1998;279(21):1720-6.

3. Spitzer RL, Kroenke K, Linzer M, Hahn SR, Williams JB, deGruy FV, 3rd, et al. Health-related quality of life in primary care patients with mental disorders. Results from the PRIME-MD 1000 Study. JAMA 1995;274(19):1511-7.

4. Penninx BW, Geerlings SW, Deeg DJ, van Eijk JT, van Tilburg W, Beekman AT. Minor and major depression and the risk of death in older persons. Arch Gen Psychiatry 1999;56(10):889-95.

5. Katz IR. On the inseparability of mental and physical health in aged persons: Lessons from depression and medical comorbidity. Am J Geriatr Psychiatry 1996;4(1):1-16.

6. Katon WJ, Lin E, Russo J, Unutzer J. Increased medical costs of a population-based sample of depressed elderly patients. Arch Gen Psychiatry 2003;60(9):897-903.

7. Wang PS, Simon G, Kessler RC. The economic burden of depression and the cost-effectiveness of treatment. Int J Methods Psychiatr Res 2003;12(1):22-33.

8. Brazier J, Ratcliffe J, Salomon JA, Tsuchiya A. Measuring and Valuing Health Benefits for Economic Evaluation. Oxford: Oxford University Press, 2007.

9. Drummond MF. Methods for the economic evaluation of health care programmes. 2nd ed. Oxford: Oxford University Press, 1997.

10. Gold MR, Siegel JE, Russell LB, Weinstein MC. Cost-Effectiveness in Health and Medicine. New York: Oxford University Press, 1996.

11. Chisholm D, Healey A, Knapp M. QALYs and mental health care. Soc Psychiatry Psychiatr Epidemiol 1997;32(2):68-75.

12. Guyatt GH, Feeny DH, Patrick DL. Measuring health-related quality of life. Ann Intern Med 1993;118(8):622-9.

13. Pyne JM, Tripathi S, Williams DK, Fortney J. Depression-free day to utility-weighted score: is it valid? Med Care 2007;45(4):357-62.

14. Schaffer A, Levitt AJ, Hershkop SK, Oh P, MacDonald C, Lanctot K. Utility scores of symptom profiles in major depression. Psychiatry Res 2002;110(2):189-97.

15. EuroQol G. EuroQol--a new facility for the measurement of health-related quality of life. The EuroQol Group. Health Policy 1990;16(3):199-208.

16. Torrance GW, Furlong W, Feeny D, Boyle M. Multi-attribute preference functions. Health Utilities Index. Pharmacoeconomics 1995;7(6):503-20.

17. Kaplan RM, Anderson JP. A general health policy model: update and applications. Health Serv Res 1988;23(2):203-35.

18. Brazier J, Usherwood T, Harper R, Thomas K. Deriving a preference-based single index from the UK SF-36 Health Survey. J Clin Epidemio/1998;51(11):1115-28.

19. McDonough CM, Tosteson AN. Measuring preferences for cost-utility analysis: how choice of method may influence decision-making. Pharmacoeconomics 2007;25(2):93-106.

20. Brazier J, Roberts J, Deverill M. The estimation of a preference-based measure of health from the SF-36. J Health Econ 2002;21(2):271-92.

21. Dolan P. Modeling valuations for EuroQol health states. Med Care 1997;35(11):1095-108.

22. Feeny D, Furlong W, Boyle M, Torrance GW. Multi-attribute health status classification systems. Health Utilities Index. Pharmacoeconomics 1995;7(6):490-502.

23. Richardson G, Manca A. Calculation of quality adjusted life years in the published literature: a review of methodology and transparency. Health Econ 2004;13(12):1203-10.

24. Brazier J, Roberts J, Tsuchiya A, Busschbach J. A comparison of the EQ-5D and SF-6D across seven patient groups. Health Econ 2004;13(9):873-84.

25. Kopec JA, Willison KD. A comparative review of four preference-weighted measures of health-related quality of life. J Clin Epidemio/2003;56(4):317-25.

26. Pyne JM, Rost KM, Zhang M, Williams DK, Smith J, Fortney J. Cost-effectiveness of a primary care depression intervention. J Gen Intern Med 2003;18(6):432-41. 
27. Van Roijen LH, van Straten A, AI M, Rutten F, Donker M. Cost-utility of brief psychological treatment for depression and anxiety. BrJPsychiatry 2006;188:323-9.

28. Jonkers CCM, Lamers F, Evers SMAA, Bosma H, Metsemakers JFM, van Eijk JTM. Economic evaluation of a minimal psychological intervention in chronically ill elderly patients with depression: a randomised trial (the DELTA-study) submitted.

29. Schoenbaum M, Unutzer J, Sherbourne C, Duan N, Rubenstein LV, Miranda J, et al. Cost-effectiveness of practice-initiated quality improvement for depression: results of a randomized controlled trial. JAMA 2001;286(11):1325-30.

30. Donald Sherbourne C, Unutzer J, Schoenbaum M, Duan N, Lenert LA, Sturm R, et al. Can utility-weighted health-related quality-of-life estimates capture health effects of quality improvement for depression? Med Care 2001;39(11):1246-59.

31. Lamers LM, Bouwmans CA, van Straten A, Donker MC, Hakkaart L. Comparison of EQ-5D and SF-6D utilities in mental health patients. Health Econ 2006;15(11):1229-36.

32. Sapin C, Fantino B, Nowicki ML, Kind P. Usefulness of EQ-5D in assessing health status in primary care patients with major depressive disorder. Health Qual Life Outcomes 2004;2:20.

33. Sobocki P, Ekman M, Agren H, Krakau I, Runeson B, Martensson B, et al. Health-related quality of life measured with EQ-5D in patients treated for depression in primary care. Value Health 2007;10(2):153-60.

34. Bennett KJ, Torrance GW, Boyle MH, Guscott R. Cost-utility analysis in depression: the McSad utility measure for depression health states. Psychiatr Serv 2000;51(9):1171-6.

35. Derogatis LR, Lipman RS, Rickels K, Uhlenhuth EH, Covi L. The Hopkins Symptom Checklist (HSCL). A measure of primary symptom dimensions. Mod Prob/ Pharmacopsychiatry 1974;7(0):79-110.

36. Hamilton M. A rating scale for depression. J. Neurol. Neurosurg. Psychiatry 1960;23:56-62.

37. Beck AT, Steer RA, Garbin MG. Psychometric properties of the Beck Depression Inventory: Twenty-five years of evaluation. Clinical Psychology Rev. 1988;8(1):77-100.

38. Lave JR, Frank RG, Schulberg HC, Kamlet MS. Cost-effectiveness of treatments for major depression in primary care practice. Arch Gen Psychiatry 1998;55(7):645-51.

39. Beekman AT, Geerlings SW, Deeg DJ, Smit JH, Schoevers RS, de Beurs E, et al. The natural history of latelife depression: a 6-year prospective study in the community. Arch Gen Psychiatry 2002;59(7):605-11.

40. Fryback DG, Dasbach EJ, Klein R, Klein BE, Dorn N, Peterson K, et al. The Beaver Dam Health Outcomes Study: initial catalog of health-state quality factors. Med Decis Making 1993;13(2):89-102.

41. Sackett DL, Torrance GW. The utility of different health states as perceived by the general public. J Chronic Dis 1978;31(11):697-704.

42. Kaplan RM. Health-Related Quality of Life in Mental Health Services Evaluation. New York: Oxford University Press, 1999.

43. Simon GE, Katon WJ, Lin EH, Rutter C, Manning WG, Von Korff M, et al. Cost-effectiveness of systematic depression treatment among people with diabetes mellitus. Arch Gen Psychiatry 2007;64(1):65-72.

44. Simon GE, Katon WJ, VonKorff M, Unutzer J, Lin EH, Walker EA, et al. Cost-effectiveness of a collaborative care program for primary care patients with persistent depression. Am J Psychiatry 2001;158(10):1638-44.

45. Simon GE, Manning WG, Katzelnick DJ, Pearson SD, Henk HJ, Helstad CS. Cost-effectiveness of systematic depression treatment for high utilizers of general medical care. Arch Gen Psychiatry 2001;58(2):181-7.

46. Simon GE, Von Korff M, Ludman EJ, Katon WJ, Rutter C, Unutzer J, et al. Cost-effectiveness of a program to prevent depression relapse in primary care. Med Care 2002;40(10):941-50.

47. Katon WJ, Schoenbaum M, Fan MY, Callahan CM, Williams J, Jr., Hunkeler E, et al. Cost-effectiveness of improving primary care treatment of late-life depression. Arch Gen Psychiatry 2005;62(12):1313-20.

48. Lynch FL, Hornbrook M, Clarke GN, Perrin N, Polen MR, O'Connor E, et al. Cost-effectiveness of an intervention to prevent depression in at-risk teens. Arch Gen Psychiatry 2005;62(11):1241-8.

49. Lamers F, Jonkers CCM, Bosma H, Kempen GIJM, Meijer JAMJ, Penninx BWJH, et al. The effectiveness of a minimal psychological intervention in chronically ill elderly patients with depression: a randomised trial (the DELTA-study). submitted.

50. Lamers F, Jonkers CC, Bosma H, Diederiks JP, van Eijk JT. Effectiveness and cost-effectiveness of a minimal psychological intervention to reduce non-severe depression in chronically ill elderly patients: the design of a randomised controlled trial [ISRCTN92331982]. BMC Public Health 2006;6(1):161.

51. Van Eijk JT, Diederiks JP, Kempen Gl, Honig A, van der Meer K, Brenninkmeijer WJ. Development and feasibility of a nurse administered strategy on depression in community-dwelling patients with a chronic physical disease. Patient Educ. Couns. 2004;54(1):87-94. 
52. Lamers LM, McDonnell J, Stalmeier PF, Krabbe PF, Busschbach JJ. The Dutch tariff: results and arguments for an effective design for national EQ-5D valuation studies. Health Econ 2006;15(10):1121-32.

53. Aaronson NK, Muller M, Cohen PD, Essink-Bot ML, Fekkes M, Sanderman R, et al. Translation, validation, and norming of the Dutch language version of the SF-36 Health Survey in community and chronic disease populations. J Clin Epidemio/1998;51(11):1055-68.

54. Beck AT, Ward CH, Mendelson M, Mock J, Erbaugh J. An inventory for measuring depression. Arch. Gen. Psychiatry 1961;4:561-571.

55. Matthews JN, Altman DG, Campbell MJ, Royston P. Analysis of serial measurements in medical research. Bmj 1990;300(6719):230-5.

56. McGraw KO, Wong SP. Forming inferences about some intraclass correlation coefficients. Psychol Methods 1996;1(1):30-46.

57. Fleiss JL. Statistical methods for rates and proportions. New York: Wiley, 1981.

58. Bland JM, Altman DG. Statistical methods for assessing agreement between two methods of clinical measurement. Lancet 1986;1(8476):307-10.

59. Casparie AF, van Hout BA, Simoons ML. Richtlijnen en kosten [Guidelines and costs]. Ned Tijdschr Geneeskd1998;142(38):2075-7.

60. Puhan MA, Guyatt GH, Goldstein R, Mador J, McKim D, Stahl E, et al. Relative responsiveness of the Chronic Respiratory Questionnaire, St. Georges Respiratory Questionnaire and four other health-related quality of life instruments for patients with chronic lung disease. Respir Med 2007;101(2):308-16.

61. Bennett KJ, Torrance GW, Boyle MH, Guscott R, Moran LA. Development and testing of a utility measure for major, unipolar depression (McSad). Qual Life Res 2000;9(1):109-20.

62. Hatziandreu EJ, Brown RE, Revicki DA, Turner R, Martindale J, Levine S, et al. Cost utility of maintenance treatment of recurrent depression with sertraline versus episodic treatment with dothiepin. Pharmacoeconomics 1994;5(3):249-68.

63. Revicki DA, Wood M. Patient-assigned health state utilities for depression-related outcomes: differences by depression severity and antidepressant medications. J Affect Disord1998;48(1):25-36.

64. Torrance GW, Boyle MH, Horwood SP. Application of multi-attribute utility theory to measure social preferences for health states. Oper Res 1982;30(6):1043-69.

65. Wells KB, Sherbourne CD. Functioning and utility for current health of patients with depression or chronic medical conditions in managed, primary care practices. Arch Gen Psychiatry 1999;56(10):897-904. 



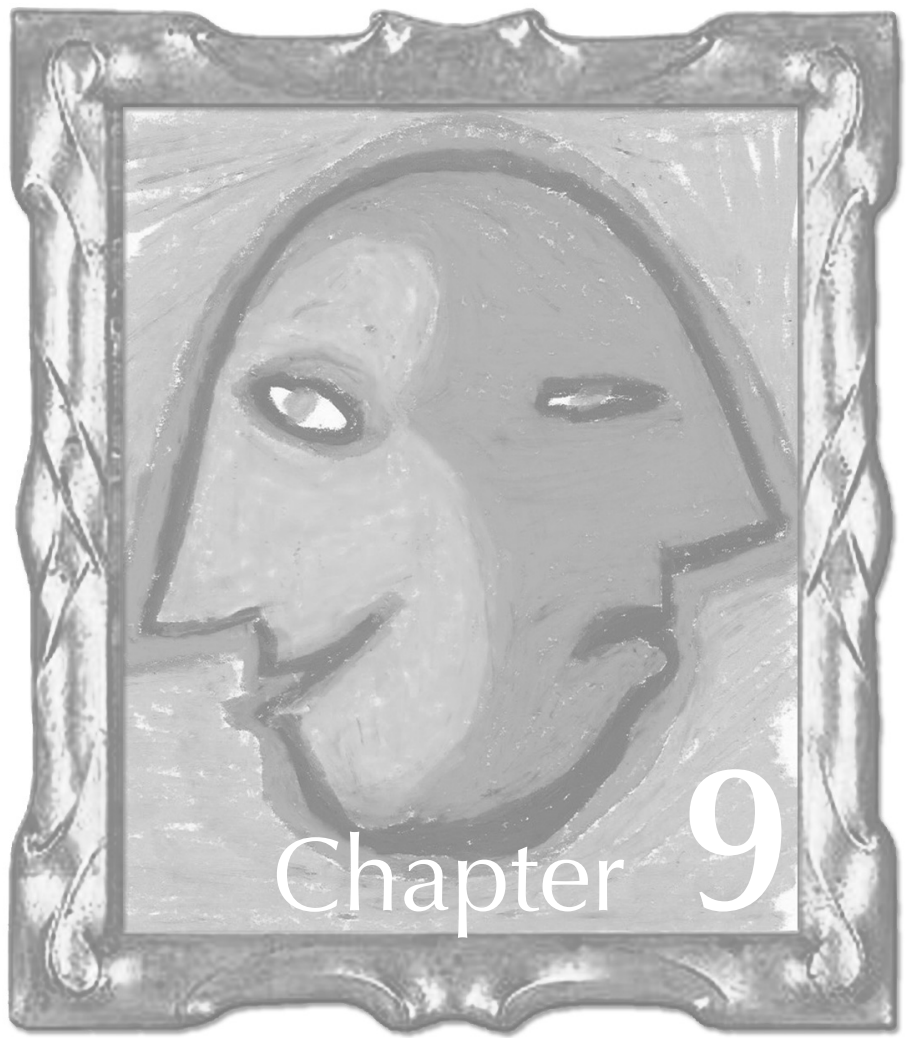

General discussion 
In recent years, the personal and societal burden of depression and related emotional problems is increasingly being recognized. For example, the World Health Organization has projected the disease to rank as the second most disabling disorder in $2020 .{ }^{1}$ Likewise, the Netherlands Organization for Health Research and Development (ZonMw) has increased their efforts to address the burden of depression. Recently, they signed an agreement with researchers and health care providers to harmonize research and practice in the field of psychological health, including anxiety and depression. $^{2}$ The attention for psychological wellbeing and the harmony between research and practice were also a focal point of the DELTA study. The study was aimed at the integration of support for emotional problems in the existing general practice care. The feasibility, effectiveness, and cost-effectiveness were subject of this study, providing a broad view and a solid basis for decisions on further implementation of such care. The aim of the research described in this thesis was to evaluate the impact of a nurse-led Minimal Psychological Intervention (MPI) on the emotional wellbeing of chronically ill elderly patients with co-occurring depression. To study this impact, the following research questions were addressed:

- What is the feasibility of the MPI for patients and nurses?

- What is the effectiveness of the MPI compared to usual care in reducing depression, increasing quality of life, and improving self-management beliefs and behaviors?

- Which patients benefit most from treatment with the MPI?

- What is the cost-effectiveness of the MPI compared to usual care from a societal perspective?

- What is the best valuation method to estimate cost-utility in depression research?

This chapter starts with an overview of the main findings of the study. Then, the results are discussed in light of previous findings, followed by some considerations regarding our study. Finally, implications for practice and future research are provided, as well as a general conclusion.

\section{MAIN FINDINGS}

The process evaluation (chapter 3) revealed that the MPI appeared to be feasible. The nurses delivered a complete intervention to two-third of the patients who started the intervention. Deviations from the protocol were mainly due to problems with the diary in which patients reported their feelings and behaviors. In general, patients adhered well to the commitments stemming from the action plans: $84 \%$ of the commitments were followed. Most patients were satisfied with the intervention and they would recommend the intervention to other chronically ill patients. However, not all patients found the intervention useful, which is also reflected in the number of dropouts during the intervention.

Results from the effect evaluation showed that patients receiving the MPI had fewer depressive symptoms than patients receiving care as usual (chapter 4). Furthermore, the improvement rate of depressive symptoms, indicated by a reduction of depres- 
sive symptoms of $50 \%$ or more, was significantly higher in intervention patients at the last follow-up. Also, a positive effect on generic quality of life was found at the last follow-up in diabetic patients. In addition to effectiveness regarding depression and quality of life, the MPI also showed effectiveness regarding anxiety, self-efficacy, daily functioning, and social participation (chapter 5). These factors reflect an improvement in self-management beliefs and behaviors. Significant differences between intervention and control group were mainly observed at three and nine months after the intervention period. No significant effects were observed directly after the intervention period.

An additional study was performed to gain insight into whether patients who differ in personality characteristics also benefit differently from treatment with the MPI (chapter 6). Neuroticism, extraversion, mastery, active coping style, passive coping style, and avoidant coping style were included as characteristics. The outcomes showed that patients with low mastery skills at the onset of the study benefitted more from treatment with the MPI than patients with high mastery skills. This finding was in contrast with our expectation that patients with adverse personality characteristics would benefit more from treatment.

The cost-effectiveness study revealed that the MPI, compared to usual care, probably leads to improvements in quality of life and depression-free days and a decrease in annual costs (chapter 7). This indicates that the MPI was dominant over care as usual in our study. However, over the whole year, differences in effects and differences in costs were not significant in statistical terms. The cost-effectiveness acceptability curve showed that the probability of a cost-effective treatment is $67 \%$. If decisionmakers are willing to invest $€ \mathbf{8 0 0 0 0}$ euro per QALY gained, which is considered a reasonable investment in Dutch health care, ${ }^{3}$ the probability of a cost-effective intervention will increase to $89 \%$. Furthermore, sensitivity analyses showed that the findings were robust; the probability of a cost-effective intervention remained largely the same across analyses.

In our cost-effectiveness study, we estimated the effects in terms of QALYs, which is a generic outcome measure, and in terms of depression-free days (DFD), which is a disease-specific outcome measure. Guidelines for cost-effectiveness analyses usually recommend generic instruments, because the generic outcome measure enables decision makers to prioritize health care, regardless the underlying disease. However, in depression research, the disease-specific DFDs are often used and transformed into generic QALYs. We reviewed whether findings from these two different techniques can be compared, using data from the DELTA study (chapter 8). The analysis showed that the agreement between outcomes was poor at each separate measurement time. However, the incremental difference over the year was similar, which leads to similar conclusions for decision makers across techniques. In any case, transformation of DFDs into generic QALYs lacks validity and further research is needed prior to its continued use. 


\section{COMPARISON WITH PREVIOUS STUDIES}

Not many treatments are exclusively aimed at chronically ill persons with cooccurring depression. Since the co morbidity of chronic disease and emotional problems is a crucial factor in our study, it is difficult to compare the DELTA study with other findings. Furthermore, the DELTA study is specifically aimed at elderly patients and most other psychological interventions include younger persons as well. However, keeping these differences in mind, we would like to discuss some of our findings in light of other studies aimed at depressive patients in primary care.

In Dutch primary care settings, mixed results have been found for treatment with a psychological intervention. Interpersonal psychotherapy and nurse-led problem solving therapy appeared to be more effective than care as usual, however only in more severe cases of major depression. ${ }^{4}$ Even less favourable results have been found for a psycho-educational prevention program and a training of GPs to improve recognition, diagnosis and treatment of depression. ${ }^{67}$ Three of these trials included cost-effectiveness analysis, but the lack of effectiveness caused unfavourable costeffectiveness outcomes. ${ }^{8-10}$ A study reviewing the effects of minimal contact psychotherapy in patients with sub-threshold depression, found the intervention to be both effective and cost-effective in primary care. ${ }^{11}{ }^{12}$ This study is in line with our own study, suggesting that a short intervention can be effective and cost-effective for treatment of depression in primary care patients.

In the United States, collaborative care has gained attention in the past few years as a way to improve depression treatment of primary care patients. Collaborative care uses several treatments to improve depression outcomes by making use of a stepped care approach. The overall treatment of a patient might extent up to twelve months. Treatments that are used include pharmacological as well as psychological treatment. Some of the treatments are similar to the elements used in the DELTA study, such as CBT and self-management. The collaborative care approach focuses on a collaboration between primary care and mental health care providers and is facilitated by care managers. ${ }^{13}$ It requires a systematic organizational change of primary care and mental health care. This is in contrast with the DELTA study that aims at an integration of attention for emotional problems within existing care. Furthermore, collaborative care is only aimed at major depression, while the DELTA study also includes minor depression. In general, collaborative care improves depression severity, quality of care for depression, patient satisfaction, and adherence. ${ }^{13-15}$ The effect sizes of collaborative care and the DELTA study are rather similar $(0.31$ and 0.29 , respectively at twelve months). ${ }^{15}$ In terms of cost-effectiveness, collaborative care proved to be costeffective with a cost per depression-free day ranging from $€ 7$ to $€ 26 .{ }^{16}$ In subgroups with co-morbid diabetes, somewhat more positive results were found..$^{17}$ One of these studies ${ }^{18}$ reported a cost-saving, as was the case in our study in which we found a cost-saving of $€ 14$ per depression-free day. While comparing our results with collaborative care, we should keep into mind that this approach originated in the United States and was nested within large private health care enterprises with a decentralized payment system. In the Netherlands, primary care is organized in small 
practices with a centralized payment system (i.e. public insurance). This has an influence on the comparability of both studies, for example because of differences in usual care. Furthermore, cost-effectiveness in collaborative care studies is reviewed from the perspective of these large health care enterprises, whereas the costeffectiveness of the DELTA study is viewed from a societal perspective. Currently, a Dutch cost-effectiveness study takes place in which the collaborative care approach is adapted to the Dutch primary care setting. ${ }^{19}$

\section{CONSIDERATIONS}

The DELTA study was designed as a pragmatic trial. Pragmatic trials measure the beneficial effect of an intervention in real practice as opposed to an ideal research situation. ${ }^{20}$ These trials provide evidence for health care providers and policy makers for policy decisions. In these trials the intervention is compared to usual care and selection criteria of patients are kept to a minimum to reflect variations between patients that occur in real practice. This was also the case in the DELTA trial where patients could have several co-morbidities, receive other treatments, and vary in their level of compliance. Presence of these external factors could hamper the internal validity of the trial and might have influenced findings. ${ }^{21}$ We tried to address this issue by random allocation of patients to control and intervention group. In that way, the interfering external factors are assumed to be equally distributed between the two groups. Analyses of baseline data, collected before randomisation, showed that characteristics of patients were indeed comparable between intervention group and control group.

In a group of chronically ill elderly, high attrition rates were to be expected as attrition has found to be associated with age and poorer health. ${ }^{22} 23$ In fact, attrition rates of $30 \%$ are not uncommon in research in an elderly population. ${ }^{22}$ In our study, we attempted to minimize data loss by telephonic reminders and encouraging patients to fill in questionnaires after dropping out of the intervention. Nevertheless, the dropout rate in the DELTA study amounted to $33 \%$. Dropouts were older than their participating counterparts but no other differences were found. In our analyses, we used models in which we corrected for baseline characteristics to reduce the chance of biases due to selective dropout. The mixed-effect approach, which was used in our effectiveness paper, further reduces the chance of selection bias due to dropout, since this method uses the observations of each patient, despite one or more observations being missing. Nevertheless, it is still possible that the attrition in our study may have hampered effectiveness results. In the cost-effectiveness analyses, the multilevel approach is not yet applicable. Instead we used linear regression techniques and used mean imputation of missing data. However, attrition is likely to have influenced our cost-effectiveness analyses more profoundly than our effectiveness analyses. A complete case analysis showed that both costs and effects might be somewhat overestimated due to the imputation of missing data. A further downside of linear regression analyses is that it assumes a normal distribution of data. Our cost 
data were highly skewed, as is often the case with this type of data. However, regression analysis proves fairly robust against violation of normality ${ }^{24}$ and it provides us with possibilities to correct for baseline values, whereas t-tests or Mann-Whitney $U$ test do not provide these possibilities. Therefore, regression analyses seemed to be the most appropriate technique to analyse the cost data.

Another consideration regarding the cost-effectiveness analyses is the manner of calculating QALYs. We used the area-under-the-curve methodology, which is considered the most appropriate method, meaning that the incremental difference in effect between intervention and control group over the year is calculated. In the DELTA study, the incremental effect became larger over time, leading to a significant difference in utility at the last follow-up. However, this trend is disregarded in the QALY calculation, because it looks at the difference over the year instead of the difference at one point in time. Given the increase in effect, a longer follow-up is likely to lead to a significant QALY difference. Modelling techniques could be used to estimate the cost-utility of our intervention using an extended follow-up period.

The generalizability of findings is generally good in pragmatic trials, since inclusion criteria are kept to a minimum. However, some limitations to the generalizability of findings in the DELTA trial should be noted. First, the persons who decided to participate in the DELTA study were higher educated and younger than the total sample of patients who were -based on the MINI interview- eligible for the DELTA study. Additional analyses showed that the effects of our intervention were lower in less educated participants. ${ }^{25}$ Therefore, in daily practice, where the population on average is lower educated than the population in the trial, the effectiveness of the MPI might be lower than the effectiveness in the DELTA trial. Second, for research purposes, the population was restricted to patients with DM and COPD. However, this might be too restrictive. Problems with coping with a chronic disease or its consequences are similar across patients with different chronic diseases, as they are faced with similar changes in life, such as reduced mobility and functionality. ${ }^{26} 27$ Furthermore, the intervention could be extended to other emotional problems, such as anxiety and frustration. In fact, the MPI provides tools to deal with all emotional problems related to the chronic disease that have an impact on daily functioning. Therefore, the intervention is likely to be effective in patients with other emotional problems as well as other chronic conditions.

Some additional issues regarding the participant selection should be considered. Previous to the study, we anticipated that 3600 chronically ill elderly should receive a screening questionnaire in order to include 360 patients in our trial. These numbers were based on results from a pilot study ${ }^{28}$ and concur with prevalence rates of depression in elderly persons in the Netherlands. ${ }^{29}$ However, in the DELTA study we needed to screen 8326 patients in order to include 361 patients. This could imply that we did not reach all persons of the target population, as depressed persons might have been less likely to return the screening questionnaire. Stigmatization could have played a role, especially since elderly tend to see depression as a personal weakness instead of a disease that can be treated. Furthermore, a lack of motivation is commonly reported in patients with depression and may have caused them not to return 
the screening questionnaire. To address issues regarding the usefulness and relevance of treating emotional problems, information for patients should be improved. In the DELTA study, concessions had to be made in the pragmatic design of the trial, making it less integrated in regular care than previously intended. The most important concession was that separate nurses were appointed to administer the intervention instead of nurses regularly working in general practice. The main reason was that nurses trained in our intervention only provided care to patients in the intervention group and not to those in the control group, reducing the chance of contamination. Randomisation per practice was not possible because nurses that regularly care for chronically ill patients in South Limburg provide that care in multiple practices. However, by using research nurses instead of regular nurses, we could not completely review whether an integration of our MPI with regular support for chronically ill patients is feasible. Although the intervention is a minimal intervention, requiring an average of 5 hours of support from a nurse, these additional tasks for practice nurses could strain their workload. Furthermore, the nurses visited the patient at home. An additional cost-effectiveness analysis showed that a change of location to the GP's office would be cost-effective. The target population of chronically ill community dwelling patients already visits the $\mathrm{GP}^{\prime}$ 's practice during their regular visit to the practice nurse. Therefore, this change from home visits to the GP's office is not expected to negatively affect the effectiveness of the MPI.

\section{IMPLICATIONS FOR PRACTICE}

Findings from the DELTA study support implementation of the MPI in regular care. However, several issues should be considered before the actual implementation takes place. These implications are partly based on the afore mentioned considerations and experiences in the DELTA study, but also on recent developments in the organization of care.

\section{Integrated care for chronically ill persons}

The Dutch primary care setting seems most suitable for the implementation of support for emotional problems, because most chronically ill patients and patients with depression are treated in primary care in the Netherlands. As stated before, other treatments are available in primary care for patients suffering from depression. Specialised mental health care nurses are also increasingly employed in this setting. However, the suggested approach in this study integrates the attention for emotional problems as part of the regular care for chronically ill patients. In that way, further fragmentation of care is prevented. So far, existing protocols and guidelines for chronically ill patients in primary care do not incorporate handling emotional problems, although the existence of emotional problems within these patients is widely recognized. Furthermore, attention for emotional problems could improve the chronic illness as well. ${ }^{30}$ 
The current developments in health care also support implementation in primary care. Nowadays, practice nurses play an important role in the routine management of chronic diseases in the Netherlands and in other countries with comparable health care systems. Evidence from our study warrant the provision of support for emotional self-management through nurses. Practice nurses are increasingly employed in and educated through so-called "care groups". In these care groups several primary care practices are organized. A care group negotiates with health insurers about the provision and quality of care for chronically ill patients. In addition, a care group enters into agreements with other health care providers, such as providers of home care and hospitals, making these care groups strong partners for further implementation of the MPI in regular care. When implementation in this setting proves feasible, expansion to other settings (e.g. nursing homes, home care and revalidation centers) could be considered.

An advantage of integrating the MPI in regular care is that patients can be monitored during their regular visits to the practice nurse. A monitoring system should be in place allowing the nurse to screen the emotional status of a patient. In the DELTA study, the PHQ-9 proved to be a reliable and valid tool for screening patients for depression. ${ }^{31}$ The screening of other emotional problems requires further identification of appropriate screening tools. A monitoring system also provides possibilities for watchful waiting. Watchful waiting has been recommended for patients with mild depression who do not feel they need emotional support or who, in the opinion of the practice nurse, may recover without support. ${ }^{32}$ Furthermore, the nurses can detect deterioration of emotional problems of patients who previously received support and, if necessary, provide booster sessions. A protocol is needed that includes rules for referral to specialized care, when severe mental disorders, such as alcohol abuse and suicidal ideation, are detected. In addition, adverse medication use could be monitored. For example, benzodiazepines are often prescribed in patients with emotional problems. However, these medications have a sedative function, undermining the need of these patients for pro-active and autonomous social participation in society. Therefore, registration of medication and, if necessary, consultation about medication use with the GP is considered a valuable addition to the MPI.

\section{Changing the patient versus changing the system}

In the DELTA study the MPI proved to be effective in improving self-management beliefs and behaviors in patients. Improvement of self-management skills, such as self-efficacy, has found to be beneficial for emotional wellbeing and has a positive effect on other aspects of quality of life as well. Self-efficacy works as a buffer to life stress and helps people to participate in healthy behaviors. It could be argued that self-management skills are an essential element of life and should be taught to everyone, regardless illness or age. However, self-management skills are not a magic pill and might not be suitable for everyone. Especially persons who need it most, such as persons with poor health and the lower educated, have difficulties requiring these 
self-management skills and benefit less from self-management interventions. ${ }^{25} 33$ Furthermore, it might not be the individual that needs to change to cope with the struggles of daily life more effectively. Instead, a change in the environment of a patient is important as well. For example, an adequate social support system is known to be of influence on health and emotional wellbeing. ${ }^{34}$ In lower educated patients, these social support networks are generally less well established. Additionally, the way a patient is supported by health care providers, such as nurses, is crucial in selfmanagement interventions. Providing self-management support often requires an attitude change in nurses. The nurses should encourage patients in finding solutions for problems themselves (i.e. act as a facilitator) instead of providing direct solutions and care (i.e. act as a caregiver). Not all nurses seem capable of this attitude change. Although the attitude change of the nurses in the DELTA study has not specifically been subject of evaluation, the importance of this change was often subject of discussion during booster sessions with the research nurses. The nurses in the DELTA study were specifically hired for the administration of the intervention and open to the principles of the intervention. However, regular practice nurses might have more resistance against the intervention, potentially negatively influencing the effectiveness of the MPI.

In summary, when implementing the intervention, the emphasis should be more towards a change in the system instead of a change in the patient. To achieve this change, the training needs to be professionalized and requirements need to be formulated before a nurse is considered capable of providing support for emotional problems. Embedding the training in the education of practice nurses through higher professional education seems feasible because of the availability of skilled educators, and necessary given the noticed gap of attention for emotional problems in the current curriculum. Furthermore, a time investment of nurses is needed to learn theory and application of the intervention. Implementation efforts should be closely monitored to ensure optimal care. One of the most important conditions for successful implementation is support from the field itself. Therefore, implementation efforts should take place in close collaboration with patients, practice nurses, GPs, health insurers, and institutions for higher professional education. A structural financial compensation should be in place to make provision of support for emotional problems in regular care possible.

\section{FUTURE RESEARCH}

If a pragmatic trial has proven effectiveness, the intervention is likely to be effective in real-life, since the circumstances approximate real-life settings. However, a broadening of the target population or a change in setting can affect outcomes. The question arises whether an additional pragmatic trial is needed to study effects in other settings and in other research populations. In other words, it should be reviewed whether we would be willing to invest in an additional trial in order to gain access to perfect information about the effectiveness of the MPI in those circumstances. ${ }^{35}$ If 
investment in a new trial with a different target population or within a different setting proves worthwhile, some additional research questions should be incorporated. First, more information is needed to provide an understanding of why specific patient characteristics predict treatment outcome. In the DELTA study we found evidence that patients with low mastery skills and the higher educated patients benefit more from treatment than their counterparts. However, at this moment, it does not seem appropriate to select participants or make adjustments to the intervention based on these characteristics as mechanisms remain unclear. Second, it would be valuable to register the content of the problems that were addressed by patients during the MPI. This might provide further guidance for improving the intervention and making it more beneficial for certain target populations, such as lower educated patients.

The information from the DELTA study already supports further implementation of support for emotional problems in the primary care for elderly patients with DM or COPD and co-occurring depression. Pre-specified implementation targets are needed to evaluate the implementation process and make adjustments if necessary. Especially the feasibility of integrating support for emotional problems within the regular tasks of practice nurses deserves extra attention. It should be taken into account that the effectiveness and cost-effectiveness of actual implementation of an intervention might be less than estimated within the pragmatic trial. For example the noncompliance of health care professionals, such as nurses, could easily cause a reduction of cost-effectiveness in regular care. This reduction of cost-effectiveness emerges when a service to patients that could have improved wellbeing is underused. ${ }^{36}$

\section{GENERAL CONCLUSION}

Despite the high prevalence of emotional problems in patients with chronic diseases, support for handling these emotional problems is not incorporated in Dutch regular care for chronically ill persons. In the DELTA study, a nurse-led MPI was tested that provides support for emotional problems to elderly patients with DM or COPD and co-occurring depression. The MPI proved feasible, effective, and cost-effective compared to usual care for chronically ill patients. Given these results, we recommend further implementation of this form of support for emotional problems in patients with chronic diseases. This implementation takes preferably place through practice nurses in primary care who already provide regular care to these patients. 


\section{REFERENCES}

1. Murray CJL, Lopez AD. Alternative visions of the future: projecting mortality and disability, 1990-2020. In: Murray CJL, Lopez AD, editors. The global burden of disease: a comprehensive assessment of mortality and disability from diseases, injuries, and risk factors in 1990 and projected to 2020. Cambridge, M.A.: Harvard University Press, 1996:325-395.

2. Zandvliet J, Van Megchelen P. Samen werken aan kwaliteitsverbetering Ggz. Mediator (ZonMw) 2007;18(3):16-17.

3. Council for Public Health and Health Care. Sensible and sustainable care; recommendations produced by the Council for Public Health and Health Care to the Minister of Health, Welfare and Sport. Zoetermeer: Council for Public Health and Health Care, 2006.

4. Van Schaik A, van Marwijk H, Ader H, van Dyck R, de Haan M, Penninx B, et al. Interpersonal psychotherapy for elderly patients in primary care. Am J Geriatr Psychiatry 2006;14(9):777-86.

5. Schreuders B, van Marwijk H, Smit J, Rijmen F, Stalman W, van Oppen P. Primary care patients with mental health problems: outcome of a randomised clinical trial. Br J Gen Pract 2007;57(544):886-91.

6. Bijl D, van Marwijk HWJ, Beekman ATF, De Haan M, van Tilburg W. A randomized controlled trial to improve the recognition, diagnosis and treatment of major depression in elderly people in general practice: design, first results and feasibility of the West Friesland Study. Primary Care Psychiatry 2003;8(4): 135-140.

7. Conradi HJ, de Jonge P, Kluiter H, Smit A, van der Meer K, Jenner JA, et al. Enhanced treatment for depression in primary care: long-term outcomes of a psycho-educational prevention program alone and enriched with psychiatric consultation or cognitive behavioral therapy. Psychol Med 2007;37(6):849-62.

8. Bosmans J, de Bruijne M, van Hout H, van Marwijk H, Beekman A, Bouter L, et al. Cost-effectiveness of a disease management program for major depression in elderly primary care patients. J Gen Intern Med 2006;21(10):1020-6.

9. Bosmans JE, van Schaik DJ, Heymans MW, van Marwijk HW, van Hout HP, de Bruijne MC. Costeffectiveness of interpersonal psychotherapy for elderly primary care patients with major depression. Int J Technol Assess Health Care 2007;23(4):480-7.

10. Stant AD, TenVergert EM, Kluiter H, Conradi HJ, Smit A, Ormel J. Cost-effectiveness of a recurrence prevention programme for depression in primary care. submitted;uit een proefschrift.

11. Smit F, Willemse G, Koopmanschap M, Onrust S, Cuijpers P, Beekman A. Cost-effectiveness of preventing depression in primary care patients: randomised trial. Br J Psychiatry 2006;188:330-6.

12. Willemse GR, Smit F, Cuijpers P, Tiemens BG. Minimal-contact psychotherapy for sub-threshold depression in primary care. Randomised trial. Br J Psychiatry 2004;185:416-21.

13. Kates N, Mach M. Chronic disease management for depression in primary care: a summary of the current literature and implications for practice. Can J Psychiatry 2007;52(2):77-85.

14. Williams JW, Jr., Gerrity M, Holsinger T, Dobscha S, Gaynes B, Dietrich A. Systematic review of multifaceted interventions to improve depression care. Gen Hosp Psychiatry 2007;29(2):91-116.

15. Gilbody S, Bower P, Fletcher J, Richards D, Sutton AJ. Collaborative care for depression: a cumulative meta-analysis and review of Ionger-term outcomes. Arch Intern Med 2006;166(21):2314-21.

16. Wang PS, Simon G, Kessler RC. The economic burden of depression and the cost-effectiveness of treatment. Int J Methods Psychiatr Res 2003;12(1):22-33.

17. Katon W, Unutzer J, Fan MY, Williams JW, Jr., Schoenbaum M, Lin EH, et al. Cost-effectiveness and net benefit of enhanced treatment of depression for older adults with diabetes and depression. Diabetes Care 2006;29(2):265-70.

18. Simon GE, Katon WJ, Lin EH, Rutter C, Manning WG, Von Korff M, et al. Cost-effectiveness of systematic depression treatment among people with diabetes mellitus. Arch Gen Psychiatry 2007;64(1):65-72.

19. IJff MA, Huijbregts KM, van Marwijk HW, Beekman AT, Hakkaart-van Roijen L, Rutten FF, et al. Costeffectiveness of collaborative care including PST and an antidepressant treatment algorithm for the treatment of major depressive disorder in primary care; a randomised clinical trial. BMC Health Serv Res 2007;7:34.

20. Roland M, Torgerson DJ. What are pragmatic trials? BMJ1998;316(7127):285. 
21. Godwin M, Ruhland L, Casson I, MacDonald S, Delva D, Birtwhistle R, et al. Pragmatic controlled clinical trials in primary care: the struggle between external and internal validity. BMC Med Res Methodol 2003;3:28.

22. Chatfield MD, Brayne CE, Matthews FE. A systematic literature review of attrition between waves in longitudinal studies in the elderly shows a consistent pattern of dropout between differing studies. J Clin Epidemio/ 2005;58(1):13-9.

23. Young AF, Powers JR, Bell SL. Attrition in longitudinal studies: who do you lose? Aust N ZJ Public Health 2006;30(4):353-61.

24. Thompson SG, Barber JA. How should cost data in pragmatic randomised trials be analysed? $B m j$ 2000;320(7243):1197-200.

25. Bosma H, Lamers F, Jonkers CCM, van Eijk JTM. Self-management: the holy grail for all or for some only? A randomised controlled trial.

26. Lorig KR, Holman H. Self-management education: history, definition, outcomes, and mechanisms. Ann Behav Med 2003;26(1):1-7.

27. Lorig KR, Sobel DS, Stewart AL, Brown BW, Jr., Bandura A, Ritter P, et al. Evidence suggesting that a chronic disease self-management program can improve health status while reducing hospitalization: a randomized trial. Med Care 1999;37(1):5-14.

28. Van Eijk JT, Diederiks JP, Kempen GI, Honig A, van der Meer K, Brenninkmeijer WJ. Development and feasibility of a nurse administered strategy on depression in community-dwelling patients with a chronic physical disease. Patient Educ. Couns. 2004;54(1):87-94.

29. Beekman AT, Copeland JR, Prince MJ. Review of community prevalence of depression in later life. $\mathrm{Br} J$ Psychiatry1999;174:307-11.

30. Penninx BW, Guralnik JM, Ferrucci L, Simonsick EM, Deeg DJ, Wallace RB. Depressive symptoms and physical decline in community-dwelling older persons. JAMA 1998;279(21):1720-6.

31. Lamers F, Jonkers CCM, Bosma H, Penninx BWJH, Knottnerus JA, Van Eijk JTM. Summed score of the Patient Health Questionnaire-9 was a reliable and valid method for depression screening in chronically ill elderly patients. Journal of Clinical Epidemiology 2008;61(7):679-87.

32. National Institute for Clinical Excellence. Depression. Management of depression in primary and secondary care. London: NHS, NICE, 2004.

33. Bayliss EA, Ellis JL, Steiner JF. Barriers to self-management and quality-of-life outcomes in seniors with multimorbidities. Ann Fam Med 2007;5(5):395-402.

34. Jang Y, Haley WE, Small BJ, Mortimer JA. The role of mastery and social resources in the associations between disability and depression in later life. Gerontologist 2002;42(6):807-13.

35. Hoomans T, Fenwick EA, Palmer S, Claxton K. Value of Information and Value of Implementation: Application of an Analytic Framework to Inform Resource Allocation Decisions in Metastatic HormoneRefractory Prostate Cancer. Value Health 2008.

36. Gandjour A, Lauterbach KW. When is it worth introducing a quality improvement program? A mathematical model. Med Decis Making 2003;23(6):518-25. 


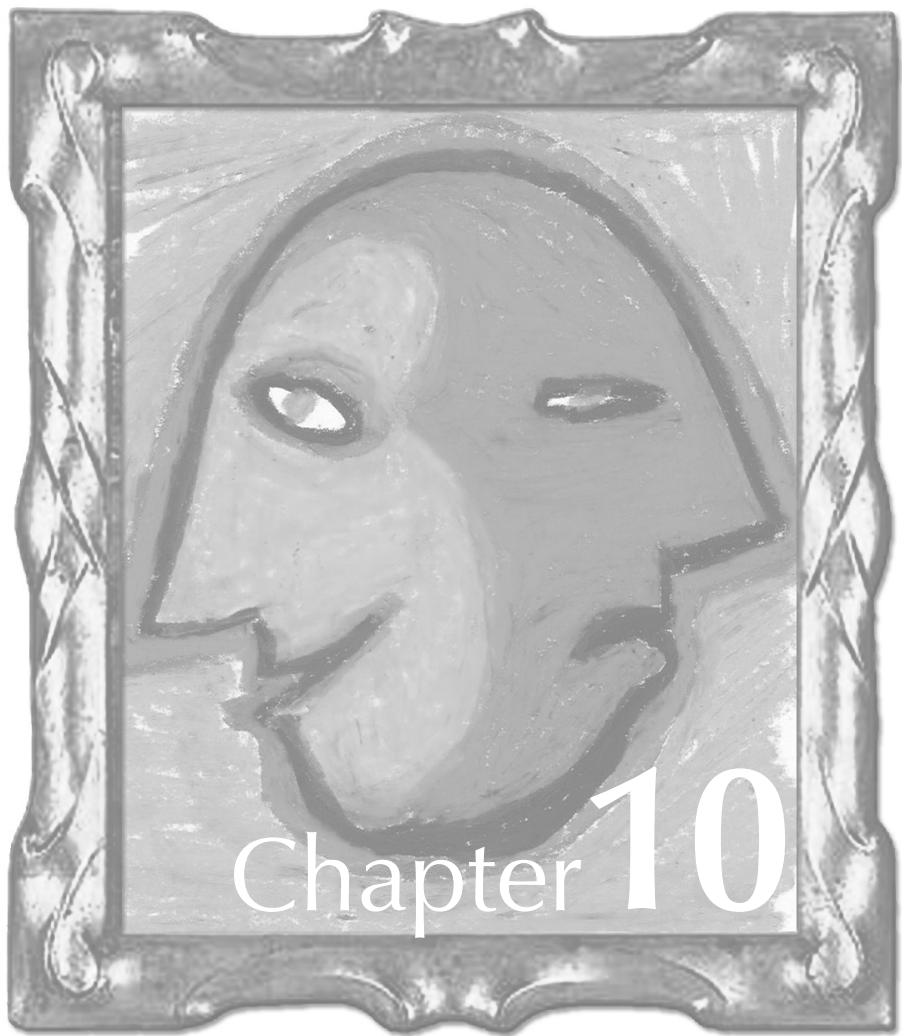

Summary

Samenvatting

Co-authors and affiliations

Dankwoord

About the author 



\section{SUMMARY}

A majority of the Dutch population with chronic diseases receive care in primary care practices. This care, provided by general practitioners (GPs) and primary care nurses, is protocolised in practice guidelines and disease management programs according to which many patients are treated. The guidelines and programs are primarily aimed at the medical management of the disease and less attention is being paid to the emotional consequences of having a chronic disease. These emotional consequences can be considerable, because experienced limitations in daily functioning can easily provoke negative thoughts. Not surprisingly, many chronically ill patients are faced with co-occurring mood problems, such as depression and anxiety. Especially in elderly patients, the co-occurrence of chronic disease and depression is high. The depression leads to lower quality of life, higher morbidity, higher physical disability, higher healthcare utilization, and higher costs. Psychological treatments, such as cognitive behavioural therapy (CBT) or self-management, are effective in elderly and have the advantage of providing patients with lasting skills to cope with the depressive feelings. Antidepressants are equally effective but do not have this enduring effect. Therefore, psychological treatments seem preferable in chronically ill elderly persons. The DELTA study (Depression in Elderly with Long-Term Afflictions) aimed to improve depressive feelings and quality of life in chronically ill elderly persons with co-occurring minor depression and mild to moderate major depression by providing a minimal psychological intervention (MPI). In a randomised controlled trial, the nurse-led MPI, based on CBT and self-management, was compared with care as usual in patients with type 2 diabetes (DM) and chronic obstructive pulmonary disease (COPD). The aims of the research described in this thesis were 1) to study the feasibility of the MPI for patients and nurses, 2) to evaluate the effectiveness of the MPI compared to usual care in reducing depression, increasing quality of life, and improving self-management beliefs and behaviours, 3) to assess which patients benefit most from treatment with the MPI, 4) to evaluate the cost-effectiveness of the MPI compared to usual care from a societal perspective, and 5) to determine the best valuation method to estimate cost-utility in depression research.

Chapter 2 of this thesis describes the design and rationale of the DELTA study. In 89 primary care practices in the south of the Netherlands, all patients of 60 years and over with DM or COPD were selected. These patients were screened for depression, using the Patient Health Questionnaire (PHQ-9). The Mini International Neuropsychiatric Interview (MINI) was used to confirm the diagnosis of depression. Eligible patients were then selected to participate in the trial and were randomised to the intervention or control group. Patients in the intervention group received a nurse-led minimal psychological intervention of maximal 10 home visits during a maximal period of three months. Patients assigned to usual care received regular treatment according to the practice guidelines of their chronic disease. Data on outcomes and costs were collected prior to randomisation and at one week, three, six (cost data only), and nine months after the intervention. 
Chapter 3 reports on the process evaluation of the DELTA study. The aim of this process evaluation was to assess whether the DELTA intervention was implemented and received as planned, which barriers were encountered and whether nurses and patients were satisfied with the intervention. Quantitative and qualitative data were gathered from all 183 patients who participated in the intervention and from four nurses who administered the intervention. Data were assessed by means of selfadministered questionnaires, checklists, and a group interview with the nurses. Results from this process evaluation indicated that, although several barriers were encountered, the intervention was well performed by nurses and well received by patients. However, a small proportion of the patients found the intervention not useful and thought they would not benefit.

In chapter 4, the effects of the intervention in terms of depressive symptoms and quality of life are presented. A total of 361 patients were included in the study; 183 in the intervention group and 178 in the control group. At baseline, groups were comparable in terms of demographics, depressive symptoms (measured with the Beck Depression Inventory), and quality of life (measured with the Short Form-36). The MPI had a positive effect on depressive symptoms, with increasing differences between intervention and control group over time and a significant difference at nine months after the treatment. The chance of a substantial reduction of depressive symptoms $(\geq 50 \%)$ was threefold as high in the intervention group than in the control group. For quality of life a positive effect was only found in diabetic patients.

Chapter 5 describes the effect of the MPI on self-efficacy, anxiety, daily functioning, and social participation. An improvement on these factors reflect an improvement in the ability of patients to become an active self-manager. The analysis were performed on the total study population of 361 patients. The results revealed that, at nine months after treatment, the MPI was effective in reducing anxiety, improving self-efficacy, improving daily functioning, and improving social participation. Differences between intervention and control group were primarily due to a stabilization of outcomes in the intervention group and deterioration in the control group.

In chapter 6, it is examined whether patients who differ in personality characteristics also benefit differently from treatment. The expectation was that persons with adverse personality characteristics benefited less from treatment with the MPI. The included personality characteristics were neuroticism, extraversion, mastery, active coping style, passive coping style, and avoidant coping style. Data were used of 237 patients with completed baseline and nine-month follow-up depression scores, and completed information on personality characteristics. The outcome was difference between pre-treatment and nine-month follow-up depression scores. The analysis showed that patients with low mastery benefited more from treatment with the MPI than patients with high mastery. Neuroticism, extraversion, and coping style did not predict differential treatment outcome. Patterns were similar across chronic diseases. 
In chapter 7, the economic evaluation is presented. The economic evaluation provides information on costs and effects of the MPI from a societal perspective, implying that all relevant costs and effects for society are taken into account. Cost data were collected by using cost diaries in which patients recorded their health care utilization; the total annual costs consisted of program costs, health care costs, patient and family costs, and productivity losses. The effects were measured in terms of quality-adjusted life years, based on the EuroQol-5D and on depression-free days. Analysis were performed on 228 patients with a complete set of cost and effect data. The results showed that the MPI, compared to usual care, shows improvements in quality of life and depression-free days at no greater cost than usual care. The costeffectiveness acceptability curve showed that the probability of a cost-effective treatment is $67 \%$. If decision-makers are willing to invest $€ 80000$ euro per QALY gained, the probability of a cost-effective intervention will increase to $89 \%$.

Chapter 8 describes whether the use of a generic or a disease-specific valuation technique to estimate utilities, leads to differences in outcomes in cost-utility analysis. Guidelines for cost-effectiveness analyses usually recommend generic instruments, because the generic outcome measure enables decision makers to prioritize health care, regardless the underlying disease. However, in depression research, the disease-specific depression-free days (DFDs) are often used and transformed into generic QALYs. In this study, two generic instruments, the EuroQol (EQ-5D) and the Short Form 6D (SF-6D), were used and compared with the DFDs. The agreement between QALYs was measured, using the EQ-5D as the reference method. The analysis showed that the agreement between outcomes was poor at each separate measurement time. However, the incremental difference over the year was similar, which leads to similar conclusions for decision makers across techniques. In any case, transformation of DFDs into generic QALYs lacks validity and further research is needed prior to its continued use.

In chapter 9, the main findings from the DELTA study are discussed and put into a broader perspective. The considerations are presented and implications for practice and future research are provided. The main conclusion of the research presented in this thesis is that the MPI proved feasible, effective, and cost-effective compared to usual care for chronically ill patients. Given these results, we recommend further implementation of this form of support for emotional problems in patients with chronic diseases. This implementation takes preferably place through practice nurses in primary care who already provide regular care to these patients. 



\section{SAMENVATTING}

De behandeling en follow up van de meeste Nederlanders met een chronische ziekte vindt plaats in de huisartspraktijk. De zorg die chronisch zieken ontvangen van de huisarts en/of praktijkverpleegkundige verloopt meestal volgens de richtlijnen van het NHG. Tot dusverre zijn deze richtlijnen voornamelijk gericht op het medische management van de ziekte. Minder aandacht bestaat voor de emotionele gevolgen van het leven met een chronische ziekte. Deze emotionele gevolgen kunnen aanzienlijk zijn, omdat chronisch zieken veelal tegen beperkingen in het dagelijkse functioneren aanlopen die de stemming negatief beinvloeden. Het is daarom niet vreemd dat veel chronisch zieken geconfronteerd worden met stemmingsproblemen zoals depressie, angst of onzekerheid. Dit speelt vooral ouderen parten. Een depressie leidt tot een lagere kwaliteit van leven, hogere morbiditeit, meer fysieke beperkingen, meer zorg gebruik en hogere kosten. Psychologische behandelingen, zoals cognitieve gedragstherapie (CBT), blijken effectief bij ouderen. Deze behandelingen hebben het voordeel dat patiënten vaardigheden aanleren die ze ook op langere termijn kunnen gebruiken om depressieve of andere negatieve gevoelens tegen te gaan. Behandeling met medicijnen zoals antidepressiva is ook mogelijk, maar deze middelen zijn meer gericht op symptoombestrijding en verliezen hun werking zodra de behandeling wordt gestopt. Psychologische behandelingen verdienen daarom de voorkeur bij chronisch zieke ouderen. De DELTA (Depression in Elderly with Long-Term Afflictions) studie is gericht op verbetering van depressieve symptomen en de kwaliteit van leven bij chronisch zieke ouderen met stemmingsproblemen middels een minimale psychologische interventie (MPI). In een gerandomiseerde studie is het effect onderzocht op depressieve symptomen van een door een verpleegkundige uitgevoerde interventie, die gebaseerd is op principes van CBT en zelf-management. Deze interventie is erop gericht om mensen vaardigheden aan te leren die hen in staat stelt actieve zelf-managers te worden en zelf oplossingen te vinden voor de emotionele gevolgen die zij ondervinden van hun chronische ziekte. Mensen die de interventie kregen aangeboden zijn vergeleken met de mensen die de gebruikelijke zorg in de huisartspraktijk kregen voor hun chronische ziekte. Het onderzoek richtte zich op patiënten met diabetes type II (DM) en/of COPD (chronic obstructive pulmonary disease). In dit proefschrift worden de volgende vragen van de DELTA studie beantwoord:

- Wat is de haalbaarheid en uitvoerbaarheid van de MPI volgens verpleegkundigen en patiënten?

- Wat is het effect van de MPI op depressieve symptomen, kwaliteit van leven en zelfmanagement gerelateerde gedachten en gedrag?

- Welke patiënten hebben het meeste baat de behandeling met de MPI?

- Wat is de kosten-effectiviteit van de interventie vergeleken met de gebruikelijke zorg vanuit maatschappelijk perspectief?

- Wat is de beste methode om de kosten-utiliteit te meten bij onderzoek naar behandeling van depressie? 
Hoofdstuk 2 van dit proefschrift omschrijft de opzet en de rationale van de DELTA studie. In 89 huisartspraktijken in Limburg zijn alle patiënten van 60 jaar en ouder met DM of COPD geselecteerd. Deze patiënten werden met behulp van de Patient Health Questionnaire (PHQ-9) gescreend op depressie waarna de diagnose werd geverifieerd door middel van de Mini International Neuropsychiatric Interview (MINI). Geselecteerde patiënten zijn uitgenodigd om deel te nemen aan de studie en na informed consent at random toegewezen aan de interventie of controlegroep. Patiënten uit de interventiegroep ontvingen de MPI van een verpleegkundige die maximaal tien huisbezoeken gedurende een periode van maximaal drie maanden aflegde. Patiënten uit de controle groep ontvingen de gebruikelijke zorg in de huisartspraktijk volgens de richtlijnen die gelden voor de chronische ziekte. Meting vonden plaats voor randomisatie en 1 week, drie, zes (alleen kosten data) en negen maanden na afloop van de interventie.

In hoofdstuk 3 staan de resultaten vermeld van de procesevaluatie van de DELTA studie. Het doel van de procesevaluatie was vast te stellen of de DELTA interventie was geïmplementeerd en ontvangen zoals gepland, welke barrières de verpleegkundigen zijn tegengekomen tijdens het uitvoeren en of verpleegkundigen en patiënten tevreden waren met de interventie. Kwalitatieve en kwantitatieve data zijn verzameld bij alle 183 patiënten die de MPI hebben ontvangen en van de vier verpleegkundigen die de interventie hebben uitgevoerd. Gegevens zijn verzameld door middel van vragenlijsten, checklijsten en een groepsinterview met de verpleegkundigen. Resultaten van de procesevaluatie laten zien dat, ondanks enkele barrières, de interventie goed was uitgevoerd door de verpleegkundigen en goed ontvangen door de patiënten. Ongeveer $10 \%$ van de patiënten vond de interventie echter niet nuttig en dacht dat ze niet zouden profiteren van de behandeling.

Hoofdstuk 4 omschrijft de effecten van de interventie op het gebied van depressie en kwaliteit van leven. In totaal werden 361 patiënten geïncludeerd in de studie; 183 in de interventiegroep en 178 in de controle groep. Op baseline waren beide groepen vergelijkbaar wat betreft demografische factoren, depressieve symptomen (gemeten met de Beck Depression Inventory) en kwaliteit van leven (gemeten met de ShortForm 36). De MPI had een positief effect op depressieve symptomen waarbij er een steeds groter verschil werd waargenomen tussen interventie en controle groep over de tijd. Dit verschil was significant op negen maanden na de interventie. De kans op een substantiële vermindering van depressieve symptomen (meer dan 50\%) was drie keer zo groot in de interventie groep vergeleken met de controle groep. Een effect voor kwaliteit van leven was alleen aanwezig bij mensen met diabetes.

In hoofdstuk 5 worden de effecten van de MPI op self-efficacy, angst, dagelijks functioneren en sociale participatie gerapporteerd. Een verbetering op deze factoren weerspiegelt een verbetering in de mogelijkheden van patiënten om actieve zelfmanagers te worden. De analyses zijn uitgevoerd op de totale populatie bestaande uit 361 patiënten. De resultaten laten zien dat de MPI negen maanden na 
de interventie, leidde tot minder angst, betere self-efficacy, beter functioneren en betere sociale participatie vergeleken met gebruikelijke zorg. Het effect werd vooral bepaald doordat de interventiegroep in tegenstelling tot in de controle groep, niet verslechterde.

In hoofdstuk 6 is bekeken of patiënten met verschillende persoonlijkheidskenmerken ook verschillen in de mate waarin zij baat hebben bij de interventie. De verwachting was dat patienten met persoonlijkheidskenmerken die verandering van gedrag bemoeilijken, minder zouden profiteren van behandeling met de MPI. De persoonlijkheidskenmerken neuroticisme, extraversie, mastery, actieve coping stijl, passieve coping stijl, en vermijdende coping stijl zijn meegenomen in de analyses. De data is gebruikt van 237 patiënten met complete baseline gegevens, de depressie score op de negen maanden nameting en complete informatie over de persoonlijkheidskenmerken. Als uitkomstmaat is het verschil tussen depressiescore op baseline en na negen maanden gebruikt. Uit de analyses blijkt dat patiënten met een lage mastery meer profiteren van de behandeling dan mensen met een hoge mastery. Neuroticisme, extraversie en coping stijl voorspellen het behandel effect niet. We vonden wat dit betreft geen verschillen tussen patiënten met diabetes en COPD. .

In hoofdstuk 7 wordt de economische evaluatie gepresenteerd. De economische evaluatie geeft informatie over de kosten en baten van de MPI vanuit een maatschappelijk perspectief. Dat houdt in dat alle relevante kosten en baten voor de maatschappij in de analyse worden betrokken. Gegevens over de kosten zijn verzameld door middel van kostendagboekjes waarin patiënten bijhielden hoe vaak ze gebruik hebben gemaakt van de gezondheidszorg. De totale jaarlijkse kosten bestonden uit de programmakosten, gezondheidszorgkosten, patiënten en familiekosten en productiviteitsverliezen. De effecten zijn uitgedrukt in qualityadjusted life years, gebaseerd op de EuroQol-5D en op depressie-vrije dagen. De analyses zijn uitgevoerd bij 228 patiënten met een -na imputatie- complete set van kosten en effect data. Resultaten laten zien dat de MPI, vergeleken met de gebruikelijke zorg, leidt tot een verbetering van kwaliteit van leven en een toename van depressie-vrije dagen tegen gelijkblijvende kosten. De cost-effectiveness acceptability curve laat zien dat er een waarschijnlijkheid van $67 \%$ is dat de interventie kosteneffectief is. Als beleidsmakers bereid zijn om € $\$ 0.000$ euro per gewonnen levensjaar te investeren, dan vergroot de waarschijnlijkheid op een kosteneffectieve interventie tot $89 \%$.

In hoofdstuk 8 wordt nagegaan of het gebruik van generieke en ziektespecifieke valideringstechnieken voor het schatten van de utiliteiten leidt tot verschillende uitkomsten bij kostenutiliteitsanalyses. Richtlijnen voor kosteneffectiviteitsanalyses schrijven het gebruik van generieke instrumenten voor, zodat verschillende ziektes onderling vergeleken kunnen worden. Op deze wijze kunnen de uitkomsten beleidsmakers helpen om zorginterventies voor verschillende ziektes op basis van de 
kosteneffectiviteit te prioriteren. In depressie onderzoek wordt echter vaak gebruik gemaakt van een ziekte-specifieke maat, namelijk depressie-vrije dagen (DFD), die vervolgens worden omgevormd tot generieke QALYs. In deze studie worden twee generieke instrumenten gebruikt voor de berekening van QALYs namelijk de EuroQol (EQ-5D) en de Short-Form 6D (SF-6D). Deze worden vergeleken met de DFDs methode. Er is gekeken naar de overeenstemming tussen de QALYs, met de EQ-5D als referentie is gebruikt. De analyse laat zien dat er een slechte overeenstemming bestaat tussen de instrumenten op elk afzonderlijk meetmoment. Echter, het incrementele verschil over het gehele jaar is wel gelijk waardoor het gebruik van de verschillende instrumenten leidt tot vergelijkbare conclusies voor beleidsmakers. Op theoretische gronden is de transformatie van DFDs in generieke QALYs niet genoeg valide en behoeft deze transformatie meer onderzoek voordat deze verder toegepast zou kunnen worden.

In hoofdstuk 9 worden de belangrijkste bevindingen van de DELTA studie bediscussieerd en in een breder perspectief geplaatst. Verschillende overwegingen worden besproken en aanbevelingen worden gegeven voor de praktijk en voor verder onderzoek. De belangrijkste conclusie van het onderzoek in dit proefschrift is dat de MPI toepasbaar, effectief en kosteneffectief bleek te zijn vergeleken met de gebruikelijke zorg bij chronisch zieke patiënten. Deze resultaten pleiten voor verdere implementatie van deze vorm van zorg voor chronisch zieken met emotionele problemen. Hier ligt ons inziens met name een taak voor praktijkverpleegkundigen die nu ook al betrokken zijn bij de zorg voor chronisch zieken. 


\section{CO-AUTHORS AND AFFILIATIONS}

The co-authors of the studies described in this thesis and their current affiliations are:

$\mathrm{H}$ (Hans) Bosma, PhD

Maastricht University, Faculty of Health, Medicine and Life Sciences, School for Public Health and Primary Care (Caphri), Department of Social Medicine, Maastricht, The Netherlands

J PM (Jos) Diederiks, PhD

Maastricht University, Faculty of Health, Medicine and Life Sciences, School for Public Health and Primary Care (Caphri), Maastricht, The Netherlands

JThM (Jacques) van Eijk, PhD

Maastricht University, Faculty of Health, Medicine and Life Sciences, School for Public Health and Primary Care (Caphri), Department of Social Medicine, Maastricht, The Netherlands

SMAA (Silvia) Evers, PhD

Maastricht University, Faculty of Health, Medicine and Life Sciences, School for Public Health and Primary Care (Caphri), Department of Health Organisation, Policy and Economics, Maastricht, The Netherlands

GIJM (Ruud) Kempen, PhD

Maastricht University, Faculty of Health, Medicine and Life Sciences, School for Public Health and Primary Care (Caphri), Department of Health Care and Nursing Sciences, Maastricht, The Netherlands

JA (André) Knottnerus, PhD

Maastricht University, Faculty of Health, Medicine and Life Sciences, School for Public Health and Primary Care (Caphri), Department of General Practice, Maastricht, The Netherlands

F (Femke) Lamers

VU University Medical Center, EMGO Institute, Department of Psychiatry, Amsterdam, the Netherlands

JAMJ (Jaap) Meijer, MD

Virenze Group Practice for Psychotherapy and Occupational Counselling, Rijckholt, the Netherlands 
JFM (Job) Metsemakers, MD PhD

Maastricht University, Faculty of Health, Medicine and Life Sciences, School for Public Health and Primary Care (Caphri), Department of General Practice, Maastricht, The Netherlands

BWJH (Brenda) Penninx, PhD

VU University Medical Center, EMGO Institute, Department of Psychiatry, Amsterdam, the Netherlands 


\section{DANKWOORD}

Dit proefschrift is het eindresultaat mijn onderzoek, waar ik de afgelopen jaren met veel plezier aan heb gewerkt. Het plezier dat ik in mijn werk had, kwam vooral ook door de mensen met wie ik heb samengewerkt en die mij door de jaren heen hebben gesteund. Deze mensen wil ik graag op deze plek bedanken.

Allereerst wil ik mijn promotores bedanken: Jacques van Eijk, Job Metsemakers, Hans Bosma en Silvia Evers. Door de diversiteit van dit promotieteam had ik altijd voldoende deskundigheid om me heen. Jacques, je inschatting dat interventieonderzoek meer bij mij zou passen dan cohort-onderzoek was juist. Ik ben blij dat je me hebt laten wachten op dit project, het was het wachten meer dan waard! Ik heb bewondering voor je gedrevenheid en waardeer de ruimte die je me hebt gegeven om mijn eigen weg te gaan. Job, als tweede promotor raakte je pas later bij het onderzoek betrokken. Misschien dat ik daardoor je commentaren op mijn artikelen altijd zeer verfrissend vond. Bovendien vond ik het fijn dat je als huisarts de aansluiting met de praktijk nooit uit het oog verloor. Hans, als dagelijks begeleider heb ik veel steun aan je gehad. Hoewel mijn onderzoek niet geheel jouw "ding" was, was je altijd bereid met me mee te denken en kon ik altijd bij je binnenlopen. Dank daarvoor! Silvia, mijn medestander op MTA gebied. Je gaf me echt het gevoel dat ik die enorme MTA-klus niet alleen hoefde te klaren maar dat we er samen wel uit zouden komen. En dat is gelukt! Ik heb je enthousiasme, deskundigheid en gezelligheid enorm gewaardeerd.

De leden van de beoordelingscommissie wil ik bedanken voor hun bereidheid zitting te nemen in de commissie, het concept proefschrift te lezen en van commentaar te voorzien. Dank ook aan de leden van de begeleidingscommissie en co-auteurs van de artikelen: Niels Chavannes, Jos Diederiks, Ruud Kempen, André Knottnerus, Jaap Meijer, Brenda Penninx en Bert Vrijhoef. Jullie hielden ons DELTA team scherp en hebben de artikelen van waardevol commentaar voorzien. Verder dank aan Carmen Dirksen en Daniëlle Brunenberg voor hun bijdrage aan de opzet van het economische deel van de studie.

De uitvoering van het onderzoek was natuurlijk niet mogelijk geweest zonder de patiënten en de huisartspraktijken die deelname hebben verleend. Deze mensen wil ik hartelijk danken voor hun medewerking. Dank ook aan alle studenten, assistenten en secretaresses die hebben geholpen bij het verzamelen en verwerken van de data. In het bijzonder dank ik Wendy Engering, Dorien Mintjes en Bernadette Zinzen voor de hulp bij het recruteren van patiënten en het invoeren en opschonen van gegevens. Daarnaast wil ik het Memic bedanken voor het ontwerp van het datamanagement systeem en het uitvoeren van de telefonische interviews. Anita, Alfons, Marlène en alle enquêtrices: zonder jullie was ons project vast een (logistieke) puinhoop geworden! 
De trainers van de interventie, Wiljo Brenninkmeijer, Adriaan Honig, Carsten Leue en Klaas van der Meer wil ik danken voor de inhoudelijke bijdrage aan de training van de verpleegkundigen.

Natuurlijk zijn "onze" verpleegkundigen, Kitty Daemen, Henny Geelen, Francine Hendriks en Mieke Witte onmisbaar geweest bij de uitvoering van het onderzoek. Door jullie zijn patiëntnummers tot leven gekomen! Jullie rotsvast geloof in de interventie en het DELTA-team vond ik bewonderenswaardig. Het was een voorrecht om met jullie samen te mogen werken en ik mis nog steeds dat jullie niet meer elke keer op mijn werkplek binnen komen vallen.

Het grootste deel van mijn AIO-schap heb ik doorgebracht bij de sectie Medische Sociologie. Ik heb me bij Medsoc altijd heel goed thuis gevoeld en heb warme herinneringen aan de gezellige drukte op de gang en de discussies (en onbenullige verhalen) tijdens de theepauze. Ik dank ook vooral alle junioren voor de befaamde soepen en alle andere activiteiten die we hebben ondernomen. Ze zullen ons wel missen bij de IKEA! Speciale dank aan Rixt, Gonnie en Marike voor de gezelligheid en collegialiteit maar vooral ook omdat jullie altijd voor me klaar staan met adviezen en tips of gewoon een luisterend oor en een beker koffie.

De collega's van Sociale Geneeskunde wil ik graag bedanken voor hun oprechte interesse in mijn onderzoek. Ik vond het erg leuk om via deze nieuwe vakgroep weer een link te hebben met mijn Arbeid en Gezondheid roots. Ook dank ik mijn MTA collega's voor de nuttige refereer- en leesclub bijeenkomsten. Ik heb er veel van geleerd! Mijn nieuwe collega's van ZonMw, en dan vooral mijn directe collega's van het Nationaal Programma Ouderenzorg, bedank ik voor het warme onthaal in Den Haag. Ik kijk ernaar uit om samen met jullie de zorg voor kwetsbare ouderen naar een hoger niveau te tillen!

Femke, woorden schieten tekort.... Helaas wordt mijn boekje wel erg dik als ik nu een aantal lege pagina's invoeg, dus ik probeer het toch maar in woorden te vatten. We voelden elkaar aan, vulden elkaar aan en vormden als DELTA ladies een hecht front, soms tot wanhoop van onze begeleiders. De term 'werkoverleg' heeft bij ons een hele nieuwe dimmensie gekregen! Jouw professionaliteit maar ook je humor en vooral je vriendschap hebben ervoor gezorgd dat werken een feestje werd. Ik ben blij dat je tijdens mijn promotie als paranimf achter me staat om samen onze DELTAperiode af te sluiten. Ook mijn andere nimfje, Carin, wil ik natuurlijk graag bedanken. Met jou kan ik altijd mijn plannen en idealen delen. Heerlijk is dat! Ik wist al heel lang dat ik jou graag als paranimf aan mijn zijde wilde hebben en ben vereerd dat je er een halve wereldreis voor over hebt om erbij te zijn. 
Mijn vrienden, en in het bijzonder Marjolijn, Marianne, Ellen en Gudrun, wil ik graag bedanken voor de onvoorwaardelijke steun en vriendschap door de jaren heen. Jeroen en Marian, bedankt dat jullie altijd voor me klaarstaan. En Jeroen, misschien had ik inderdaad beter een écht vak kunnen leren... () Jonas, een lachje van jou en mijn dag is goed! Lieve pap en mam, bedankt voor het vertrouwen dat jullie altijd in mij en mijn kunnen gesteld hebben. Door de solide basis die jullie me hebben meegegeven en jullie onvoorwaardelijke steun is dit boekje er gekomen. En ookal geloven jullie het niet: ik had dit niet zonder jullie gekund! 



\section{ABOUT THE AUTHOR}

Karianne Jonkers was born on March 8th, 1977 in Deurne, the Netherlands. She completed her secondary education (VWO) at the Peelland College in Deurne. After her graduation in 1996, she started to study Health Sciences at the Maastricht University. She chose to specialise in Work and Health for which she spent three month at the University of Manchester, United Kingdom, to study Human Resource Management. This was followed by a research internship at the National Institute of Disability Management and Research in Canada, where she studied the effectiveness and costeffectiveness of a disability management programme for employers and employees.

After her graduation in 2001, Karianne started working as a health policy researcher at Ipso Facto in Houten, the Netherlands. Here, she evaluated several disease management programs and conducted research concerning lifestyle wishes of inpatients with intellectual disabilities.

In 2003 she returned to the Maastricht University for her PhD project at the Faculty of Health, Medicine and Life Sciences and School for Public Health and Primary Care (Caphri). This project, which is described in this thesis, covered a longitudinal randomised controlled trial evaluating the feasibility, effectiveness and costeffectiveness of a minimal psychological intervention aimed at improving depressive feelings and quality of life in chronically ill elderly persons. In addition, she worked as a PhD representative for Caphri from 2004 to 2006.

Since July 2008, she is working as a programme officer at the Netherlands Organisation for Health Research and Development (ZonMw) at the National Care for the Elderly Programme at which she can combine her experience in health policy and research. 